\title{
An alternative miRISC targeting a coding mutation site in FOXL2 links to granulosa cell tumor
}

Eunkyoung Shin ${ }^{\dagger 1}$, Hanyong Jin ${ }^{\dagger 2}$, Dae-Shik Suh ${ }^{\dagger 3}$, Yongyang Luo ${ }^{1}$, Hye-Jeong $\mathrm{Ha}^{1}$, Tae Heon $\mathrm{Kim}^{4}$, Yoonsoo Hahn ${ }^{2}$, Seogang Hyun ${ }^{* 2}$, Kangseok Lee ${ }^{* 2}$, and Jeehyeon Bae ${ }^{* 1}$

${ }^{1}$ School of Pharmacy, Chung-Ang University, Seoul 06974, Korea; ${ }^{2}$ Department of Life Science, Chung-Ang University, Seoul 06974, Korea; ${ }^{3}$ Department of Obstetrics and Gynecology, Asan Medical Center, University of Ulsan College of Medicine, Seoul 05505, Korea; ${ }^{4}$ Department of Pathology, Bundang CHA Hospital, CHA University, Seongnam 13496, Korea

*Correspondence: sghyun@cau.ac.kr (S.H), kangseok@cau.ac.kr (K.L.) and jeehyeon@cau.ac.kr (J.B)

$\uparrow$ These authors contributed equally to this work. 


\begin{abstract}
Recent evidence suggests that animal microRNAs (miRNAs) can target coding sequences (CDSs); however, the pathophysiological importance of such targeting remains unknown. Here, we show that a somatic heterozygous missense mutation (c.402C $>$ G; p.C134W) in FOXL2, a feature shared by virtually all adult-type granulosa cell tumors (AGCTs), introduces a target site for miR-1236, which induces haploinsufficiency of the tumor-suppressor FOXL2. This miR-1236-mediated selective degradation of the variant FOXL2 mRNA is preferentially conducted by a distinct miRNA-loaded RNA-induced silencing complex (miRISC) directed by the Argonaute3 (AGO3) and DHX9 proteins. In both patients and mouse model of AGCT, the inversely regulated variant FOXL2 abundance with the miR-1236 levels was highly correlated with malignant features of AGCT. Our study provides a molecular basis for understanding the conserved FOXL2 CDS mutation-mediated etiology of AGCT, revealing the existence of a previously unidentified mechanism of miRNA-targeting disease-associated mutations in the CDS by forming a noncanonical miRISC.
\end{abstract}




\section{INTRODUCTION}

MicroRNAs (miRNAs) are endogenous, noncoding RNAs of $\sim 22$ nucleotides (nt) in length that suppress the stability or translational efficiency of mRNAs. Conventionally, miRNAs are known to target sequences in the 3'-untranslated regions (UTRs) of mRNAs. However, recent multiple high-throughput sequencing and proteomic analyses suggest that miRNAs can also bind sites within mRNA coding sequences (CDSs) (Broughton, Lovci et al., 2016, Chi, Zang et al., 2009, Hafner, Landthaler et al., 2010, Hausser, Syed et al., 2013, Schnall-Levin, Zhao et al., 2010, Xue, Ouyang et al., 2013), and the intracellular effects of miRNAs targeting CDS sites have been proposed (Elcheva, Goswami et al., 2009, Forman, Legesse-Miller et al., 2008, Schnall-Levin, Rissland et al., 2011, Tay, Zhang et al., 2008, Zhang, Zhang et al., 2018). However, the physiological relevance and the pathological consequences of miRNA binding to CDSs remain unclear.

Argonaute (AGO) clade proteins are essential components of miRNA-loaded RNA-induced silencing complexes (miRISCs) that select target mRNAs by directly interacting with mature miRNAs (Czech \& Hannon, 2011, Hock \& Meister, 2008). In mammals, four AGO paralogs (AGO1-4) are involved in miRNA pathways (Czech \& Hannon, 2011, Hock \& Meister, 2008), and they share $\sim 80 \%$ amino acid-sequence identity (Sasaki, Shiohama et al., 2003). AGO2 has been described as a specialized AGO that possesses slicer activity, enabling cleavage of target mRNAs by miRNAs and small-interfering RNAs (siRNAs) (Liu, Carmell et al., 2004, Meister, Landthaler et al., 2004). However, previous data suggested that all mammalian AGOs may serve overlapping and distinct functions in miRNA-mediated regulation ( $\mathrm{Su}$, Trombly et al., 2009). High-throughput pyrosequencing data showed that the profiles of miRNAs associated with AGO2 and AGO3 largely overlap, but preferential associations with AGO2 or AGO3 also occur for a 
small set of miRNAs (Azuma-Mukai, Oguri et al., 2008). AGO3 is also associated with slicer activity (Park, Phan et al., 2017). However, the functional significances of mammalian AGO1, AGO3, and AGO4 in miRNA activity are poorly understood.

Conclusive evidence demonstrating clear pathophysiological consequences elicited by miRNA-binding to the CDSs of disease-associated gene loci is lacking. Here, we investigated whether miRNA binding to the CDS of FOXL2 contributes to adult-type granulosa cell tumor (AGCT) development. GCTs are malignant ovarian cancers comprised of AGCTs and juvenile GCTs (JGCTs) (Schumer \& Cannistra, 2003). FOXL2 is evolutionarily conserved and encodes a forkhead-domain transcription factor essential for the ovary development and function (Schmidt, Ovitt et al., 2004, Uhlenhaut, Jakob et al., 2009). A highly prevalent heterozygous somatic missense mutation (c.402C $>$ G; p.C134W) in FOXL2 is exclusively found in $>97 \%$ of patients with ACGT and is considered the main cause of AGCT (Shah, Kobel et al., 2009). However, the etiological nature of the $402 \mathrm{C}>\mathrm{G}$ mutation remains largely unknown. Previously, we showed that the FOXL2 protein acted as a tumor suppressor in granulosa cells, whereas C134W FOXL2 did not, due to serine 33 hyperphosphorylation by GSK3 $\beta$, leading to accelerated MDM2-mediated ubiquitination and proteasomal degradation (Kim, Kim et al., 2014, Kim, Yoon et al., 2011). However, a relatively moderate change in FOXL2 protein stability by the C134W mutation does not appear to wholly account for haploinsufficiency of FOXL2 (Kim et al., 2014, Kim et al., 2011).

Here, we identified allelic imbalance in FOXL2 mRNAs in patients with AGCT arising from recognition of the $402 \mathrm{C}>\mathrm{G}$ locus as a target site of miR-1236 that drives degradation of this variant FOXL2 mRNA, which explains the etiology of this conserved mutation in AGCTs. 


\section{RESULTS}

\section{Allelic imbalance of FOXL2 transcripts in AGCT samples}

To study allelic imbalance of heterozygous FOXL2 mRNAs, we analyzed the relative levels of wild-type (WT) and variant FOXL2 (402C $>$ G) mRNAs from complementary DNA (cDNA) samples from the individual AGCT tissues by high-throughput ultra-deep RNA sequencing. Ultradeep RNA sequencing analysis of AGCT tissues showed that decreased proportion of variant FOXL2 mRNA level compared to WT FOXL2 mRNA in 14 AGCT patients (WT:402C $>\mathrm{G}=73: 27$ ) and the opposite trend in 6 patients (WT:402C $>\mathrm{G}=36: 64$ ) (Fig 1A). A previous study, which identified this conserved mutation, reported relative abundance of WT versus variant FOXL2 mRNA levels in four AGCT patients, where no uniformed trend was observed (Shah et al., 2009). For these reasons, we recruited additional AGCT patients from two independent hospitals and performed high-throughput pyrosequencing analysis $(n=46)$ that enables amplification and detection of both alleles from the same pyrosequencing reaction using common primers designed to bind FOXL2 cDNA. As shown in Fig 1B and Appendix Fig S1A, the relative abundance of FOXL2 mRNA analyzed by pyrosequencing were $70: 30$ for WT:402C $>\mathrm{G}$ in 46 AGCTs including 20 corresponding AGCTs analyzed for RNA sequencing presented in Fig 1A. In addition, allelespecific real-time and semi-quantitative RT-PCR analyses of 46 AGCTs were performed using primers presented in Appendix Fig S1B, and we observed consistent lower steady-state levels of FOXL2 variant mRNA compared to WT FOXL2 mRNA (Appendix Fig S1C and S1D). For these analyses, we used paired genomic DNA (gDNA) levels of both alleles for the normalization of data, where the gDNA levels of both alleles were similar in all AGCTs (Appendix Fig S1E). These results indicate that contamination of non-cancerous stromal cells in preparation of total RNA from AGCT tissues for these analyses was minimal. We also performed primer extension assays on 
cDNA samples, as shown in Appendix Fig S1F, the mutated allele was not readily detectable in AGCTs.

We obtained analogous results using AGCT-derived KGN cells by pyrosequencing, allelespecific semi-quantitative RT-PCR, allele-specific real-time RT-PCR, and primer extension assays, which are heterozygous for the 402C $>$ G mutation (Fig 1C, Appendix Fig S1G, and S1H). The relative abundance of variant FOXL2 mRNA was $22 \%$ of WT FOXL2 mRNA levels, while the gDNA levels of both alleles were similar in KGN cells (Fig 1C). When COV434, a cell line derived from JGCTs lacking the 402C $>$ G mutation (Jamieson, Butzow et al., 2010), was tested as a control using the mutant-allele specific primer, no amplicons containing the $402 \mathrm{C}>\mathrm{G}$ mutation were detected (Fig 1C and Appendix Fig S1G). We also observed a comparable allelic imbalance by allele-specific real-time RT-PCR on full-length FOXL2 mRNA generated by the cap analysis of gene expression (CAGE) method from KGN cells (Appendix Fig S1I).

Next, we tested whether the decreased steady-state levels of the variant FOXL2 mRNA resulted from alterations in mRNA stability. WT and variant FOXL2 mRNA abundances were measured in KGN cells at several time points using allele-specific real-time RT-PCR after adding actinomycin $\mathrm{D}(\mathrm{ActD})$, which blocks transcription. The level of variant FOXL2 mRNA decreased more rapidly than that of WT mRNA $\left(\mathrm{t}_{1 / 2}=3.68 \mathrm{~h}\right.$ for variant $F O X L 2$ versus $\mathrm{t}_{1 / 2}=15.43 \mathrm{~h}$ for WT), indicating that the lower steady-state level of the variant FOXL2 mRNA resulted from decreased mRNA stability (Fig 1D). Variant FOXL2 mRNA instability was unlikely due to its altered secondary structure, as the $402 \mathrm{C}>\mathrm{G}$ mutation was not predicted to affect the mRNA structure, based on M-fold analysis (http://mfold.rna.albany.edu/?q=mfold/RNA-Folding-Form) (Zuker, 2003) (Appendix Fig S2A and S2B). 


\section{Selective degradation of the variant FOXL2 mRNA by miR-1236}

Next, we determined whether selective degradation of the variant FOXL2 mRNA was due to miRNAs targeting the mutation site in the CDS. By analyzing the variant FOXL2 mRNA sequence with an miRNA-prediction tool (genie.weizmann.ac.il/pubs/mir07/mir07_prediction.html) (Kertesz, Iovino et al., 2007), we identified miRNAs predicted to bind the sequence surrounding the mutation (Appendix Table 1). We selected five miRNAs predicted to preferentially bind the mutant allele over the WT allele for further analysis. Using DNA oligonucleotides complementary to these miRNAs (anti-miRNAs), which effectively inhibited the respective miRNAs based on upregulation of their known target mRNAs (Appendix Fig S3A), we found that anti-miR-1236 specifically increased the variant FOXL2 mRNA-expression level without affecting that of WT FOXL2 in KGN cells (Fig 2A). The remaining four anti-miRNAs did not affect the mRNA levels of WT FOXL2 or the variant (Fig 2A). Consistent with this effect at the mRNA level, anti-miR1236 also increased FOXL2 protein expression (Fig 2B). Conversely, transfection of an miR-1236 RNA mimic decreased FOXL2 protein expression (Fig 2C). In contrast to our observations with KGN cells, transfecting miR-1236 into COV434 cells (which lack the $402 \mathrm{C}>\mathrm{G}$ mutation) did not affect FOXL2 protein expression (Fig 2C). To further validate the specificity of miR-1236 on the FOXL2 variant, we cotransfected a WT- or variant FOXL2-expression plasmid together with miR1236 RNA into 293 T cells expressing minimal WT FOXL2 (but not the variant), and changes in FOXL2 expression were monitored by western blotting. The miR-1236 mimic specifically decreased the variant FOXL2 level without affecting that of WT FOXL2 (Appendix Fig S3B). The effective depletion or overexpression of miR-1236 in cells transfected with anti-miRNAs or mimic oligonucleotides, respectively, was confirmed with a TaqMan ${ }^{\circledR}$ microRNA assay for miR-1236 (Appendix Fig S3C). 
Moreover, we generated miR-1236-knockout (KO) KGN and COV434 cell lines using a clustered regularly interspaced short palindromic repeat (CRISPR)/CRISPR-associated protein 9 (Cas9)-nickase-based system (Appendix Fig S4A-4H) that is known to exert minimal off-target effects (Ran, Hsu et al., 2013). Using extracted total RNA from the KO cells, we performed TaqMan ${ }^{\circledR}$ microRNA analyses and confirmed miR-1236 depletion (Appendix Fig S4B and S4F). Northern blotting showed that miR-1236 was detectable in control KGN cells, but not in miR$1236^{-/-}$cells (Appendix Fig S4I). Then, we evaluated WT and variant FOXL2 mRNA levels in the KO cells. Variant FOXL2 mRNA expression reverted to the level of WT mRNA when both alleles $\left(\mathrm{miR}-1236^{-/}\right)$were excised and was partially restored when a single allele (miR-1236 $\left.{ }^{-/+}\right)$of miR1236 was disrupted, without affecting WT FOXL2 mRNA expression (Fig 2D). Re-introducing miR-1236 mimic via transfection in miR-1236-KO cells downregulated variant FOXL2 mRNA expression without altering WT FOXL2 expression (Fig 2D), demonstrating that restoration of variant FOXL2 mRNA level resulted from miR-1236 KO. The observation that known miR-1236 target genes, $A F P$ and ZEB1(Gao, Cai et al., 2015, Wang, Yan et al., 2014), were upregulated in these KO cells also suggested that efficient and effective excision of miR-1236 occurred (Appendix Fig S4J and S4K). Consistently, elevated FOXL2 protein expression was confirmed in miR-1236-KO KGN cells, whereas no change in FOXL2 expression occurred in miR-1236-KO COV434 cells (Fig 2E). These in vivo genome-editing results further corroborated miR-1236 as an endogenous functional miRNA that selectively acted on variant FOXL2 mRNA.

\section{Allele-specific downregulation of the FOXL2 mRNA variant with miR-1236 via targeting the 402C $>$ G mutation site}

Reporter constructs were developed to confirm that miR-1236 targets the $402 \mathrm{C}>\mathrm{G}$ locus in the 
variant FOXL2 mRNA CDS. A 231-bp DNA fragment containing the 402C $>$ G locus of the FOXL2 variant or the corresponding fragment of WT FOXL2 was inserted, in-frame, into the CDS of the luciferase gene (Fig 3A). miR-1236 transfection decreased the activity of the luciferase reporter harboring the $402 \mathrm{C}>\mathrm{G} F O X L 2$ variant sequence by $70 \%$, without affecting the activity of the luciferase reporter containing the WT FOXL2 sequence (Fig 3B). Similarly, we observed allelespecific repression when the 231-bp FOXL2 fragments were inserted in the $3^{\prime}$-UTR of the luciferase reporter gene (Fig 3C and 3D). The specificity of the interaction between miR-1236 and the variant locus in FOXL2 mRNA was further tested using two miR-1236 mutants. The miR1236-G mutant shifted the 7-mer seed match from the 402C $>$ G FOXL2 mRNA to the WT FOXL2 mRNA (Fig 3E), whereas the seed sequence of the miR-1236-U mutant did not match either 402C $>$ G or WT FOXL2 mRNA (Fig 3F). Notably, the selectivity of the miR-1236-G mutant was reversed, as it repressed the WT reporter without affecting the $402 \mathrm{C}>\mathrm{G}$ mutant reporter (Fig $3 \mathrm{E}$ ). In contrast, the miR-1236-U mutant did not suppress the $402 \mathrm{C}>\mathrm{G}$ mutant or WT FOXL2 reporter (Fig 3F).

In addition, the preferential binding of miR-1236 to $402 \mathrm{C}>\mathrm{G}$ over the WT FOXL2 transcript was confirmed by performing in vitro-binding assays. Synthetic 230-nt transcripts of WT or 402C $>$ G FOXL2 mRNA were incubated with radiolabeled miR-1236, and RNA-duplex formation was monitored. miR-1236 preferentially duplexed with the $402 \mathrm{C}>\mathrm{G} F O X L 2$ transcript, with predicted dissociation constants $\left(\mathrm{K}_{\mathrm{d}}\right)$ of 1,589 and $194 \mathrm{nM}$ for the WT and $402 \mathrm{C}>\mathrm{G}$ FOXL2 transcripts, respectively (Fig 3G). Thus, these data indicate that the $402 \mathrm{C}>\mathrm{G}$ locus was critical for distinguishing the effects of miR-1236 on FOXL2 expression.

AGO3 as the major miRISC component for miR-1236-mediated FOXL2 variant mRNA 


\section{degradation}

Because AGO2 is known to act primarily on the 3'-UTR of target mRNAs (Hafner et al., 2010) and a recent study demonstrated that $\mathrm{AGO} 3$ is also associated with slicer activity (Park et al., 2017), we investigated the possibility that AGO3 can regulate RISC activity against the variant FOXL2 mRNA by recognizing the mutated site in its CDS. Each AGO was knocked down using siRNAs, and changes in the levels of WT and variant FOXL2 mRNAs were examined in KGN cells. Of interest, we found that AGO3 knockdown preferentially increased mRNA expression of the FOXL2 variant without affecting that of WT FOXL2 (Fig 4A). In contrast, AGO2 knockdown increased both the WT and variant mRNAs (Fig 4A), indicating that WT FOXL2 mRNA is degraded by AGO2-mediated miRNAs targeting the 3'-UTR, as previously described (Dai, Sun et al., 2013, Luo, Wu et al., 2015, Wang, Li et al., 2015). Depletion of either AGO1 or AGO4 did not affect the levels of the WT and variant FOXL2 mRNAs (Fig 4A). Consistent with the effects on the mRNA levels, increased FOXL2 protein levels were observed in KGN cells following the depletion of either AGO2 or AGO3 (Fig 4B). To determine whether miR-1236 mediated these effects, AGO-depleted KGN cells were transfected with miR-1236, and changes in FOXL2 mRNA-expression levels were evaluated by allele-specific real-time RT-PCR. miR-1236 overexpression did not alter WT FOXL2 mRNA expression in cells with AGO1, AGO2, AGO3, or AGO4 depletion (Fig 4C; left graph). In contrast, miR-1236 transfection downregulated marginally variant FOXL2 mRNA expression in AGO3-knockdown cells (Fig 4C; right graph). miR-1236 transfection was partially effective in AGO2-knockdown cells, but efficiently downregulated variant FOXL2 mRNA levels in AGO1- or 4-depleted cells (Fig 4C; right graph). In addition, to ascertain the role of AGO3 in the activity of miR-1236 in promoting variant FOXL2 mRNA decay, changes in FOXL2 mRNA-expression levels were determined in miR-1236-KO 
cells after silencing each AGO. Our results were similar to those shown in Fig 4A when the control cell line expressing miR-1236 (miR-1236 ${ }^{+/+}$) was used in these experiments (Fig 4D; left graph). In sharp contrast, depletion of AGO1, 3, or 4 failed to increase the level of variant FOXL2 mRNA in miR-1236-KO cells (miR-1236--) (Fig 4D; right graph). Consistent with the results shown in Fig 4A, AGO2 depletion increased both WT and variant FOXL2 mRNA expression in miR-1236/- cells (Fig 4D; right graph).

To assure miRISC formation between AGO3 and miR-1236, the level of enriched miR-1236 in KGN cell immunoprecipitates with each AGO was determined following transfection of FLAGtagged AGOs, miR-1236, and a pGL3c-CDS-variant FOXL2 construct (Fig 3A). We found that variant FOXL2 mRNA was highly enriched in the AGO3 immunoprecipitate compared to the other AGO immunoprecipitates (Fig 4E). We further detected the in vivo formation of an miRISC comprised of endogenously expressed variant FOXL2 mRNA, miR-1236, and AGO3. The variant FOXL2 transcript was highly incorporated into the AGO3 immunoprecipitate, whereas negligible WT FOXL2 was incorporated (Fig 4F). Preferential incorporation of the variant FOXL2 transcript with AGO3 was reversed by transfection of the miR-1236-G mutant into KGN cells, in which predominant incorporation of WT FOXL2 mRNA occurred with a concomitant decrease in the FOXL2 protein level (Fig 4F). Together, these results indicate that a functional miRISC consisting of AGO3, miR-1236, and the variant FOXL2 mRNA preferentially formed in KGN cells.

KGN cells express all four AGOs, and a comparison of their relative abundances indicated that $A G O 3$ was the most abundant (Appendix Fig S5). Further, we analyzed the relative abundances of $A G O$ mRNAs in individual AGCT tissues from patients, using high-throughput deep sequencing. As shown in Fig 4G, we observed dramatically higher expression of $A G O 3$ mRNA-expression levels compared to those of $A G O 1, A G O 2$, and $A G O 4$ in 20 independent 
patients with AGCT, supporting a previously unidentified role of AGO3 as a functional miRISC component in AGCT cells.

\section{Identification of DHX9 as a functional component for AGO3-miRISC regulation of variant FOXL2 mRNA}

We further investigated potential functional AGO3-miRISC components that could regulate expression of the variant FOXL2 mRNA. Since most miRNAs target in CDS regions in plants(Iwakawa \& Tomari, 2013), candidate human proteins were selected based on searches for homologous genes in plants that regulate the activities of miRISCs, AGO2-binding proteins, and RNA-binding proteins. Among them, silencing DHX9, an ATP-dependent RNA helicase A that has been reported to function as a siRNA-loading and-recognition factor for AGO2-siRISC assembly (Fu \& Yuan, 2013, Robb \& Rana, 2007), prominently affected the abundance of variant FOXL2 mRNA (Fig 5A). In particular, DHX9 silencing restored the variant FOXL2 mRNA level to that of the WT mRNA, involving a 6-fold increase of variant FOXL2 mRNA compared to a 1.7-fold increase of the WT mRNA (Fig 5A). In contrast, depletion of GW182, a well-known miRISC component that associates with AGO2, increased the abundances of both the WT and variant FOXL2 mRNAs (Fig 5A). Consistent with these effects on the mRNA level, DHX9- or GW182depletion also increased expression of the FOXL2 protein (Fig 5B). Immunoprecipitation analysis of AGOs with DHX9 or GW182 showed that DHX9 exhibited stronger binding affinity to AGO3, whereas GW182 bound AGO2 more tightly (Fig 5C). In addition, we determined the functional role of DHX9 for in vivo AGO3-miRISC formation with the variant FOXL2 mRNA. Consistent with the data shown in Fig 4F, a predominant incorporation of the variant FOXL2 transcript over the WT transcript in AGO3 immunoprecipitates was observed (Fig 5D). However, DHX9 
depletion significantly decreased the incorporation of variant FOXL2 mRNA in AGO3 immunoprecipitates without affecting the incorporation of WT FOXL2 mRNA (Fig 5D). These results imply that DHX9 served as a critical factor required for AGO3-miRISC-associated miR1236 function.

\section{Oncogenic function of miR-1236 in AGCT cells}

Next, we investigated the oncogenic effects of miR-1236 in AGCT cells. We found that transfecting KGN cells with an miR-1236 mimic or anti-miR-1236 significantly decreased or increased the numbers of annexin-V-positive apoptotic cells, and increased or decreased the cellular viability, respectively (Fig 6A, 6B, Appendix Fig S6A, and S6B). Overexpression of other anti-miRNAs, which showed no significant effects on FOXL2 expression (Fig 2A and 2B), did not alter KGN cell viability (Appendix Fig S6C). Moreover, treatment with the miR-1236 mimic accelerated cell cycle progression to $\mathrm{S}$ phase, whereas anti-miR-1236 induced cell cycle arrest at $\mathrm{G}_{0} / \mathrm{G}_{1}$ phase (Fig $6 \mathrm{C}$ and $6 \mathrm{D}$ ). Transfection of either miR-1236 or anti-miR-1236 in FOXL2silenced cells failed to alter the numbers of apoptotic cells, cell cycle, and cell viability (Fig 6A6D, Appendix Fig S6D, and S6E), indicating that the effects of miR-1236 on KGN cells were FOXL2-dependent. The effect of FOXL2 on GCT cell migration was also examined using Transwell chambers, and we found that miR-1236 or anti-miR-1236 transfection promoted or suppressed cell migration, respectively, and these effects were abolished upon FOXL2 depletion (Fig 6E and 6F). Transfecting miR-1236 into COV434 cells did not alter either cell viability or cell migration and had no effect on FOXL2 protein expression (Fig 6G and $6 \mathrm{H}$ ), validating the $402 \mathrm{C}>\mathrm{G}$ allele-specific oncogenic effects of miR-1236. Additionally, we confirmed the oncogenic properties of miR-1236 using miR-1236-KO KGN cells and obtained results that were consistent 
with the effects observed after anti-miR-1236 transfection. miR-1236-/ KGN cells exhibited significantly reduced cell survival, proliferation, and migration compared to control KGN cells, and miR-1236 $6^{-/+} \mathrm{KGN}$ cells showed intermediate activities (Fig 6I, 6J, and 6K). In sharp contrast, the oncogenic characteristics were not altered in miR-1236-- COV434 cells (Fig 6L).

\section{In vivo suppression of metastasis by miR-1236 KO and inverse expression between miR-1236 and the variant FOXL2 mRNA in tissues from AGCT patients}

We further performed an in vivo xenograft mouse experiment using the miR-1236 $6^{-/} \mathrm{KGN}$ cells and examined the effect of miR-1236 loss on AGCT metastasis. Xenografting control KGN cells resulted in AGCT metastasis to the intestine in mice (Fig 7A and 7B). In contrast, miR-1236-/- cellxenografted mice showed significantly fewer metastasized tumor nodules (Fig 7A and 7B). By analyzing the relative abundances of FOXL2 transcripts in these tumors, we confirmed that the miR-1236-KO tumors expressed more variant FOXL2 mRNA than WT mRNA (Fig 7C). These in vivo results provided further support that miR-1236 acts as a critical molecule for AGCT metastasis by preferentially targeting the variant FOXL2 mRNA.

Moreover, we examined whether the aggressiveness of AGCT was indeed linked to the ability of miR-1236 to downregulate mRNA expression of the $402 \mathrm{C}>\mathrm{G} F O X L 2$ variant in patients with AGCT. Clinical tissues from AGCT patients (exhibiting metastasis or no evidence of metastasis) were examined for miR-1236 and FOXL2 mRNA expression. Notably, increased miR1236 and decreased $402 \mathrm{C}>\mathrm{G}$ FOXL2 mRNA levels were evident in metastatic AGCT tissues compared to non-metastatic AGCT tissues (Fig 7D and 7E). In contrast, the expression of WT FOXL2 mRNA was similar in both AGCT groups (Fig 7F). Moreover, comparative analysis of the miR-1236 and FOXL2 mRNA-expression levels in tissues from AGCT patients revealed a strong 
inverse correlation between miR-1236 and variant FOXL2 mRNA expression (Fig 7G). Such a correlation was not observed between miR-1236 and WT FOXL2 mRNA (Fig 7H). Together, these results provided further support that miR-1236 caused haploinsufficiency of the tumor-suppressor FOXL2 by inducing degradation of the variant FOXL2 mRNA following recognition of the $402 \mathrm{C}>\mathrm{G}$ locus as a target site, suggesting that miR-1236 plays an important etiological role in $\operatorname{AGCT}($ Fig 7I).

\section{DISCUSSION}

Data from recent studies have suggested that miRNAs can target CDS sites in human cells, and the presence of functional miRNA recognition elements in CDSs was addressed in a recent human study (Cai, Cao et al., 2015, Duursma, Kedde et al., 2008, Elcheva et al., 2009, Forman et al., 2008, Schnall-Levin et al., 2011, Wang, Long et al., 2012, Zhang et al., 2018). However, the regulatory mechanism underlying miRNA activity against the CDS of target genes is largely unknown. The general conceptual agreement that miRNAs target 3'-UTRs mostly arises from the idea that translating ribosomes occupy the CDS region and interfere with RISC formation. Thus, the binding of a miRISC to the CDS region of a transcript has been considered a less efficient mechanism of action than binding to the 3'-UTR (Bartel, 2009, Gu, Jin et al., 2009). However, a recent report showed that RISC formation in the CDS region causes translation repression, but do not appear to alter the overall ribosome occupancy on the target mRNA (Zhang et al., 2018), indicating the existence of disparate mechanism for translation repression of target mRNA by CDS-targeted miRNAs. In addition, over $70 \%$ of mammalian genes generate mRNA transcripts with differing lengths and 3'-UTR sequences due to alternative cleavage and polyadenylation, 
which would abolish some miRNA-binding sites (Tian \& Manley, 2017). Accordingly, variations in 3'-UTR sequences would decrease the efficiency of miRNA-mediated target mRNA degradation, which is often observed with oncogenes in cancer (Mayr \& Bartel, 2009, Mayr, Hemann et al., 2007). Therefore, targeting CDSs can assure effective downregulation of gene expression by miRNA, especially for disease-associated genes whose expression levels need to be tightly controlled.

miR-1236, the trans-acting RNA regulator identified in this study, is a mirtron located in an intron of the negative-elongation factor complex, member E (NELFE) gene (Okamura, Hagen et al., 2007, Ruby, Jan et al., 2007, Wen, Ladewig et al., 2015). The genomic sequences of the miR1236 region are well conserved from lower vertebrates (including cavefish, lizards, and chickens) to mammalian vertebrates (Appendix Fig S7). The steady state level of miR-1236 expression seems to be more than 300 copies per KGN cell, based on northern blot analysis of small RNAs purified from $2 \times 10^{7} \mathrm{miR}-1236^{+/+} \mathrm{KGN}$ cells, which showed a radioactive intensity similar to 10 fmol of miR-1236 mimics (Appendix Fig S4I). According to a very recent miRNA profiling data by Kim et al (Kim, Kim et al., 2019), in which they developed and adopted bias-minimized accurate quantification by sequencing (AQ-seq) technology, miR-1236 was fairly well expressed as being in the top $50 \%$ of abundance among all miRNAs detected in human cells. Cumulative recent data revealed altered various cellular responses after modulating miR-1236 expression levels in diverse cell types (An, Ma et al., 2019, Chen, Teng et al., 2016, Gao et al., 2015, Jones, Li et al., 2012, Ma, Shen et al., 2014, Sato, Yoshimura et al., 2012, Thoma, 2015, Wang, Tang et al., 2016, Wang et al., 2014, Wang, Liu et al., 2018, Zhu, Wang et al., 2018). In this study, miR1236 selectively targeted the mutated $402 \mathrm{C}>\mathrm{G}$ locus in the FOXL2 CDS, without affecting WT FOXL2 mRNA expression. Preferential targeting of the mutated ' $\mathrm{G}$ ' allele by miR-1236 was also 
reported in recent single-nucleotide polymorphism (SNP) studies: specific miR-1236 binding to the $\mathrm{G}$ allele over the $\mathrm{C}$ allele (rs11536889) in the 3'-UTR of Toll-like receptor 4 (Zhao, Feng et al., 2019) and specific miR-1236 targeting of the G allele over the T allele (rs4246215) in the 3'-UTR of Flap endonuclease 1 (Nanda, Kumar et al., 2018). Furthermore, our in vivo and in vitro analysis of the phenotypes of miR-1236 KO cells collectively showed that miR-1236 acted as an oncomiR in AGCT cells by causing selective variant FOXL2 mRNA degradation (Fig 6 and 7).

For miR-1236 activity against variant FOXL2 mRNA, we identified AGO3 as a key AGO protein (Fig 5). For over two decades, AGO2 has been considered as the key AGO protein in miRISC formation. However, AGO3 may have a distinct, but overlapping functionality for mRNA degradation, considering its slicer ability, the presence of the same conserved motif in the catalytic center for mRNA cleavage, and its ability to interact with a similar spectrum of RNA transcripts (Azuma-Mukai et al., 2008, Huang, Li et al., 2014, Landthaler, Gaidatzis et al., 2008, Meister et al., 2004, Park et al., 2017). This study provides evidence supporting this notion, considering that AGO3 depletion completely restored the variant FOXL2 mRNA-expression level to the WT level; that an in vivo miRISC was comprised of endogenously expressed variant FOXL2 mRNA, miR1236, and AGO3; and that the abundance of AGO3 was highest among the AGOs in AGCT tissues (Fig 4). Thus, we conjecture that the association of AGO3-RISC with target RNAs could be stabilized or promoted by interactions with distinct binding partner proteins, thereby facilitating target mRNA decay in the CDS. We discovered DHX9 as one of such proteins, which interacted preferentially with AGO3 (Fig 5C). DHX9 depletion increased variant FOXL2 mRNA expression to the WT level, and variant FOXL2 association with AGO3 decreased markedly in DHX9depleted cells (Fig 5A, 5B, and 5D). Compromised target mRNA incorporation and processing was not due to inefficient miR-1236 incorporation into AGO3-miRISC after DHX9 depletion 
(Appendix Fig S8). In contrast to effects of DHX9 depletion, depletion of GW182, of which association with $\mathrm{AGO} 2$ is essential for gene silencing by miRNAs in animals (Eulalio, Tritschler et al., 2009), increased the abundances of both the WT and variant FOXL2 mRNAs (Fig 5A and B), indicating that GW182 is required for miRISC action on the $3^{\prime}$-UTR present in both FOXL2 mRNAs. In addition, GW182 preferentially bound AGO2 (Fig 5C), suggesting the presence of preferential binding partners for each AGO. While the detailed regulatory mechanism by which this non-canonical miRISC involving AGO3 and DHX9 targets the variant FOXL2 CDS needs to be studied further, it is worthwhile to note findings of a recent study showing that CDS-targeted miRNAs require extensive base-pairing at the $3^{\prime}$ side rather the $5^{\prime}$ seed in a manner independent of GW182 expression (Zhang et al., 2018), which overlap with characteristics of miR1236.

Previously, we showed that the $134 \mathrm{C}>\mathrm{W}$ missense mutant protein of FOXL2 caused by the $402 \mathrm{C}>\mathrm{G}$ mutation in FOXL2 induced serine 33 hyperphosphorylation by GSK3 $\beta$, thereby accelerating ubiquitin-mediated proteasomal degradation of the mutant protein (Kim et al., 2014). Here, we demonstrated that the mutation dramatically destabilized variant FOXL2 mRNA via the allele-specific activity of miR-1236. Our findings suggest an etiological model for FOXL2mediated AGCT development; selective degradation of the variant FOXL2 mRNA by an miRISC composed of AGO3, DHX9, and miR-1236 promotes a strong allelic imbalance of FOXL2 expression, which is aggravated by accelerated degradation of the mutant FOXL2 protein. These processes result in FOXL2 haploinsufficiency and insufficient suppression of AGCT development (Fig 7I). In 2009, Shah et al reported RNA sequencing results of four AGCTs, in which they observed various ratios of the variant and WT FOXL2 mRNA levels (9:1; 1:1, 4:6 and 6:4) (Shah et al., 2009). In the present study, we observed a dramatic decrease in the variant FOXL2 mRNA levels compared to WT mRNA levels in 46 AGCT patients. Further studies are need to investigate 
how this discrepancy arises from. One possibility is that the RNA-seq study by Shah et al focused on expression of both FOXL2 mRNAs rather than measurement of relative abundance of WT versus variant mRNAs. In fact, total sequencing and mapped reads in their study were not enough to accurately quantify gene expression. To obtain coverage over the full-sequence diversity of complex transcript libraries, including rare and low-expressed transcripts, up to 500 million reads are required (Fu, $\mathrm{Xu}$ et al., 2014). Our RNA-seq study generated, on average, 134,312,269 total sequence reads and approximately 71,531 Mbp of total mapped base using Illumina HiSeq 2500 for 20 AGCT samples. In addition, we employed three other methods to assess the relative abundance of the WT versus variant FOXL2 mRNA and obtained a consistent allelic imbalance.

In conclusion, our study provides a pathogenic mechanism in which a disease-associated heterozygous missense mutation can induce strong degradation of a variant mRNA by an alternative miRISC, which largely contributes to the haploinsufficiency of the gene and, consequently, development of the associated disease. We identified miR-1236 as an oncogenic miRNA in AGCT, suggesting a promising therapeutic target and prognostic parameter for patients with AGCT. Our study also provides evidence of the importance of nucleotide substitutions, such as somatic mutations and SNPs, in the CDS in regulating gene expression at the level of mRNA stability. A research approach that diverges from focusing mainly on the effects of missense mutations on protein activity may uncover many previously unsuspected mechanisms involving the regulation of mRNA stability by phenotype-associated missense mutations. In addition, we identified miR-1236 as an oncogenic miRNA in AGCT, suggesting a promising therapeutic target and prognostic parameter for patients with AGCT. 


\section{MATERIALS AND METHODS}

\section{Cells culture and reagents}

Human AGCT-derived KGN cells (Riken, Tsukuba, Japan) and JGCT-derived COV434 cells (Sigma-Aldrich, St. Louis, MO, USA) were cultured in Dulbecco's modified Eagle's medium (DMEM)-Ham's F12 (Caisson, North Logan, UT, USA) and DMEM (Caisson), respectively. 293T cells (American Type Culture Collection) were cultured in DMEM. The media were supplemented with $10 \%$ fetal bovine serum (FBS) and 1\% penicillin-streptomycin (Caisson). The cells were grown in $5 \% \mathrm{CO}_{2}$ at $37^{\circ} \mathrm{C}$. Other reagents were purchased from Sigma-Aldrich, unless otherwise indicated.

\section{Plasmids}

Plasmids expressing Myc-tagged variants of WT FOXL2 and the C134W variant were prepared as described previously(Kim \& Bae, 2014, Kim et al., 2011, Park, Shin et al., 2010). A 231-bp coding region (including nucleotide residue 402) of FOXL2 containing the putative miRNArecognition site was amplified from gDNA of KGN cells using the following primers (Cosmo Genetech, Seoul, Korea): CDS-F (5'-CATGCCATGGCAAAGGGCTGGCAAAATAG-3'), CDSR (5'-CATGCCATGGGGCGCCTCCGGCCCCGAAGAG-3'), 3'-UTR-F (5'GCTCTAGAAGGGCTGGCAAAATAGCA-3'), and 3'-UTR-R (5'GCTCTAGACGGCGCCTCCGGCCCCGA-3'). The amplified fragment was then cloned into the pGL3-control vector (Promega, Madison, WI, USA) at the NcoI or XbaI sites (restriction enzymes from Takara Bio, Shiga, Japan) in the CDS or 3'-UTR of the luciferase gene, respectively, generating pGL3c-CDS-FOXL2s and pGL3c-UTR-FOXL2s. The mammalian expression vectors, FLAG/HA-tagged AGO1 (Addgene plasmid \#10820), AGO2 (Addgene plasmid \#10822), AGO3 
(Addgene plasmid \#10823), and AGO4 (Addgene plasmid \#10824) were gifts from Dr. Thomas Tuschl(Meister et al., 2004).

\section{Human subjects and GCT tissues}

Formalin-fixed paraffin-embedded (FFPE) block sections of AGCT $(n=46)$ specimens from patients who visited the Seoul Asan Medical Center and the Bundang CHA Women's Hospital were analyzed. The present study was reviewed and approved by the Seoul Asan Medical Center and the Bundang CHA Women's Hospital Institutional Review Board. Informed consent was obtained from all subjects who participated in this study. This study was carried out in compliance with approved guidelines.

\section{gDNA and RNA extraction}

Total RNA from FFPE sections was extracted using the PureLink ${ }^{\mathrm{TM}}$ FFPE Total RNA Isolation kit (Invitrogen, Carlsbad, CA, USA), following the manufacturer's protocol. Total RNA in cultured cells was isolated using the TRIzol Reagent (Invitrogen), according to the manufacturer's instructions. gDNA was extracted from the deparaffinized tissues and cells using an Intron G$\mathrm{DEX}^{\mathrm{TM}}$ Genomic DNA Extraction Kit (Intron, Seongnam, Korea), according to the manufacturer's protocol.

\section{RNA library construction and ultra-deep RNA sequencing}

Total RNA concentrations were calculated using Quant-IT RiboGreen (Invitrogen). To determine the $\%$ of RNA fragments $>200 \mathrm{bp}$ in length, samples are run on the TapeStation RNA ScreenTape (Agilent Technologies, Waldbronn, Germany). A sequencing library was constructed using $100 \mathrm{ng}$ 
of total RNA and a TruSeq RNA Access Library Prep Kit (Illumina, Inc., San Diego, CA, USA), according to the manufacturer's protocols. Briefly, total RNA was first fragmented into small pieces using divalent cations, at an elevated temperature. The cleaved RNA fragments were copied into first strand cDNA using SuperScript II reverse transcriptase (Invitrogen, cat\#18064014) and random primers. Second-strand cDNA synthesis was performed using DNA Polymerase I, RNase $\mathrm{H}$, and dUTP. The cDNA fragments were subjected to an end-repair process, involving the addition of a single 'A' base and then adapter ligation. The products were then purified and enriched by 15 cycles of PCR to create the cDNA library. All libraries were normalized, and six libraries were pooled into a single hybridization/capture reaction. The pooled libraries were incubated with a cocktail of biotinylated oligonucleotides corresponding to coding regions of the genome. Targeted library molecules were captured via hybridized biotinylated oligonucleotide probes using streptavidin-conjugated beads. After two rounds of hybridization/capture reactions, the enriched library molecules were subjected to a second round of PCR amplification in 10 cycles. The captured libraries were quantified using KAPA Library Quantification Kits for Illumina Sequencing platforms according to the qPCR Quantification Protocol Guide (Kapa Biosystems, catalog number KK4854) and qualified using the TapeStation D1000 ScreenTape assay (Agilent Technologies, catalog number 5067-5582). The indexed libraries were then loaded into an Illumina HiSeq 2500 instrument (Illumina, Inc.), and paired-end $(2 \times 100 \mathrm{bp})$ sequencing was performed by Macrogen, Inc. (Seoul, Korea). We generated, on average, 134,312,269 total sequence reads and approximately 71,531 Mbp of total mapped base.

\section{Pyrosequencing}

The PyroMark PCR Kit (Qiagen, Hilden, Germany) was used for pyrosequencing with a forward 
primer (Pyro-FOXL2-F: 5'-AGAAGGGCTGGCAAAATAGCATC-3') and reverse biotinylated primer (Pyro-FOXL2-R: 5'-CCGGAAGGGCCTCTTCAT-3'), or a reverse primer (Pyro-FOXL2R2: 5'-TAGTTGCCCTTCTCGAACATGTC-3') and a forward biotinylated primer (Pyro-FOXL2F2: 5'-CATCGCGAAGTTCCCGTTCTA-3'). The PCR products were purified using streptavidin Sepharose HP beads (GE Healthcare, Buckinghamshire, UK), followed by hybridization with the sequencing primers (FOXL2-seqF: 5'-CGCAAGGGCAACTACT-3' or FOXL2-seqR2: 5'CCTTCTCGAACATGTCT-3'), as described in the PyroMark Q48 vacuum workstation guide (Qiagen). The sequencing data were analyzed using PyroMark Q48 software (Qiagen). The Pyrosequencing was performed and analyzed by Macrogen, Inc.

\section{Allele-specific PCR analysis}

To amplify each FOXL2 allele, allele-specific primers were designed with a $3^{\prime}$ mismatch at the variable nucleotide at 402. The PCR primers used for FOXL2 amplification were the FOXL2-279F primer (5'-GAATAAGAAGGGCTGGCAAAAT-3'), the WT-specific reverse primer (5'CCTTCTCGAACATGTCTTCG-3'), and the 402C $>$ G-specific reverse primer $\left(5^{\prime}-\right.$ CCTTCTCGAACATGTCTTCC-3'). For GAPDH amplification, the GAPDH-F (5'AGGGGCCATCCACAGTCTT-3') and GAPDH-R (5'-AGCCAAAAGGGTCATCATCTCT-3') primers were used. PCR was performed in $20-\mu 1$ reactions containing 50 ng gDNA or cDNA with DMSO (10\%). PCR was performed for 34 cycles using 2 annealing temperatures: $50^{\circ} \mathrm{C}$ for cDNA from FFPE sections and $60^{\circ} \mathrm{C}$ for cDNA from cell lines. SP-Taq DNA polymerase and $2 \mathrm{X}$ HOT MasterMix with Dye were purchased from Cosmo Genetech and MGmed (Seoul, Korea), respectively. The PCR products were electrophoresed on a $2 \%$ agarose gel and visualized under ultraviolet (UV) light. 


\section{Reverse transcription-quantitative real-time PCR (RT-qPCR) analysis}

Following confirmation of the quality and quantity of extracted total RNA samples with a Nanodrop 2000 (Thermo Scientific, Wilmington, DE, USA), cDNA was synthesized using an iScript cDNA Synthesis Kit (Bio-Rad Laboratories, Hercules, CA, USA). Samples for RT-qPCR were prepared in a final volume of $10 \mu \mathrm{l}$ and analyzed using Applied Biosystems's SYBR Green PCR master mix (Bio-Rad Laboratories) during 40 cycles of amplification. RT-qPCR was performed on a CFX-96 Thermal Cycler and Detection System (Bio-Rad Laboratories). The same primers described above for the allele-specific PCR analysis were used for RT-qPCR analysis of FOXL2 and GAPDH expression. Additional PCR primers used for RT-qPCR analysis were as follows: $\quad$ Dicer-F $\quad$ (5'-TCTCTTTCCCAACTGGCATC-3'), Dicer-R $\quad$ (5'GGTGGTTCGTTTTGATTTGC-3'), ZEB2-F (5'-CAAGAGGCGCAAACAAGC-3'), ZEB2-R (5'-GGTTGGCAATACCGTCAT-3'), BCL-2-F (5'-GTGGAGGAGCTCTTCAGGGA-3'), BCL2-R (5'-AGGTGCCGGTTCAGGTACTC-3'), p21-F (5'-TGTCCGTCAGAACCCATGC-3'), p21R (5'-AAAGTCGAAGTTCCATCGCT-3'), FIS-1-F (5'-ACCTGGCCGTGGGGAACTACC-3'), FIS-1-R (5'-AGTTCCTTGGCCTGGTTGTTCTGG-3'), AFP-F $\quad$ (5'CACGGATCCAACTTGAGGCTGTCATTGC-3'), AFP-R (5'CGGAATTGATAAGGAAATCTCACATAAAAGTC-3'), ZEB1-F _ (5'ATGCAGCTGACTGTGAAGGT-3'), and ZEB1-R (5'-GAAAATGCATCTGGTGTTCC-3'). Gene-expression levels were quantified using the $\Delta \Delta \mathrm{Ct}$ method. All primers were purchased from Cosmo Genetech.

For miRNA analysis, $\sim 10 \mathrm{ng}$ of total RNA was reverse transcribed using the TaqMan® microRNA Reverse Transcription Kit (Applied Biosystems, Foster City, CA, USA) and the 
reverse-transcription primers from the TaqMan ${ }^{\circledR}$ microRNA Assay Kit (Applied Biosystems, $h s a$ miR-1236 [Assay ID: 002761]; RNU6B [Assay ID: 001093]). RT-qPCR was performed in a CFX96 Thermal Cycler and Detection System, using the TaqMan® microRNA Universal PCR Master Mix (Applied Biosystems) and TaqMan probes from the TaqMan® microRNA Assay Kit, according to the manufacturer's instructions. miRNA-expression levels were normalized to endogenous $R N U 6 B$ expression.

\section{mRNA-decay rate}

To assess mRNA turnover, RNA synthesis was terminated by adding $5 \mu \mathrm{g} / \mathrm{mL}$ ActD (SigmaAldrich) to the cell culture medium. At different time points $(0,0.5,1,2,4$, and $8 \mathrm{~h})$ after ActD addition, the cells were harvested, and total RNA was isolated using the TRIzol reagent following the manufacturer's protocol. mRNA levels were determined by real-time PCR, as described above.

\section{RNA interference}

The target sequences of the siRNAs used in this study were as follows: siFOXL2 (5'GGCAUCUACCAGUACAUCAdTdT-3'), siAGO1 (5'-GCACGGAAGUCCAUCUGAAUU-3' and 5'-GAGAAGAGGUGCUCAAGAAUU-3'), $\quad$ siAGO2

GCACGGAAGUCCAUCUGAAUU-3' and 5'-GCAGGACAAAGAUGUAUUAUUdTdT-3'), siAGO3 (5'-GCAUCAUUAUGCAAUAUGAUU-3', 5'-GAAAUUAGCAGAUUGGUAAUU-3', and 5'-CAAGAUACCUUACGCACAAUU-3'), $\quad$ siAGO4

GGCCAGAACUAAUAGCAAUUU3' and 5'-GGCCAGAACUAAUAGCAAUUU-3'), siDHX9 (5'-CCAGGCAGAAATTCATGTGTG-3' and 5'-CAAAUCAUCUGUUAAUUGUdTdT-3'), siGW182 (5'-UGAUUGUUAGGCAUCUGGCdTdT-3' and 5'-GCCAGAUGCCUAACAAUCA- 
$3^{\prime}$

siADARBP1(5'-GAUAGACACCCAAAUCGUAdTdT-3'), siDDX20

(5'-

GGAAAUAAGUCAUACUUGG-3')， siFKBP5 (5'-GGAGCAACAGUAGAAAUCCdTdT-3'), siGEMIN4 (5'-GGCACUGGCAGAAUUAACA-3'), siGPKOW

GAAGAAGCAUCUGAUUACCdTdT-3'), siLIG4 (5'-GCUAGAUGGUGAACGUAUG-3'), siMSI1 (5'-GGAGAAAGUGUGUGAAAUUdTdT-3'), siNOTCH2 GGAGGUCUCAGUGGAUAUAdTdT-3'), siPAFAH1B1

UUUAGUCUCAGAUCCUGUUGCUUCAdTdT-3'), siPPID (5'-GCAGGGAGCAAUUGACAG UdTdT-3'), and siYTHDF1 (5'-CCGCGUCUAGUUGUUCAUGAA-3'). The sequence of the control siRNA was 5'-CCUACGCCACCAAUUUCGU-3'. All siRNAs were purchased from Bioneer (Seoul, Korea). Sense and antisense oligonucleotides were annealed in the presence of annealing buffer (Bioneer).

\section{Immunoblot analysis}

KGN cells $\left(1 \times 10^{6}\right)$ and COV434 cells $\left(0.3 \times 10^{6}\right)$ were transfected with the indicated plasmids or oligonucleotides using Lipofectamine 2000 (Invitrogen), according to the manufacturer's instructions. Cell lysates were prepared and subjected to sodium dodecyl sulfate-polyacrylamide gel electrophoresis (SDS-PAGE) for subsequent immunoblotting with the respective antibodies. The protein signals on the membranes were detected using a ChemiDoc XRS + System Imager (Bio-Rad Laboratories), and the intensity of each band was quantified using Quantity One software (Bio-Rad Laboratories). For all immunoblot images presented in this manuscript, the membrane was sectioned according to the estimated molecular weights of the proteins of interest and probed 
with the indicated antibodies. All cropped blots were processed under the same experimental conditions. The following antibodies were used in this study: rabbit anti-FOXL2 (Park et al., 2010), rabbit anti-AGO1 (5053S; Cell Signaling Technology, Danvers, MA, USA), rat anti-AGO2 (11A9; Helmholtz Zentrum München, Germany), rabbit anti-AGO3 (5054S; Cell Signaling Technology), rabbit anti-AGO4 (6913S; Cell Signaling Technology), mouse anti-FLAG (F1804; Sigma-Aldrich), rabbit anti-DHX9 (ab26271; Abcam, Cambridge, MA, USA), rabbit anti-GW182 (NBP1-28751; Novus Biologicals, Littleton, CO, USA), mouse anti-Myc (2276S; Cell Signaling Technology), rabbit anti-GAPDH (sc-25778; Santa Cruz Biotechnology, Santa Cruz, CA, USA) and rabbit control-IgG (sc-2027; Santa Cruz Biotechnology).

\section{miRNAs and antisense miRNAs}

Sense-strand RNA oligonucleotides for miR-1236 (5'-CCUCUUCCCCUUGUCUCUCCAG-3'), miR-1236-G (5'-CCUCUUCGCCUUGUCUCUCCAG-3'), miR-1236-U $\quad$ (5'CCUCUUCUCCUUGUCUCUCCAG-3'), and the non-specific control RNA (5'CCUCGUGCCGUUCCAUCAGGUAGUU-3')(Song, Yoon et al., 2013) were supplied by Genolution Pharmaceuticals, Inc. (Seoul, Korea). Antisense miRNAs for mature miR-1236 (5'CTGGAGAGACAAGGGGAAGAGG-3'), miR-145 (5'-AGGGATTCCTGGGAAAACTGGAC3'), $\quad$ miR-204 (5'-AGGCATAGGATGACAAAGGGAA-3'), miR-423-3p $\quad$ (5'ACTGAGGGGCCTCAGACCGAGCT-3'), and miR-484 (5'ATCGGGAGGGGACTGAGCCTGA-3'), and a negative control miRNA (22-mer scrambled probe with a random sequence of 5'-GTGTAACACGTCTATACGCCCA-3') (Nielsen, Jorgensen et al., 2011), with no known complementary sequence target among human transcripts, were purchased from Cosmo Genetech. 


\section{Primer-extension analysis}

KGN cells were transfected with the empty pCMV vector or the pCMV-FOXL2-402C $>$ G plasmid for $48 \mathrm{~h}$, and total RNA extracted using TRIzol. Total RNAs were extracted from KGN cells, COV434 cells, and AGCT tissues from three patients. Reverse transcription of total RNA was performed with poly (dT) and random hexamers (Invitrogen), according to the manufacturer's protocol. First-strand cDNA was prepared using a forward primer (F; 5'CGCGAGGGCGGCGGCGAGCGCAAC-3') and a reverse primer (R; 5'CTTCATGCGGCGGCGGCGCCGGTA-3'), and gel-purified using the QIAquick Gel Extraction Kit (Qiagen, Hilden, Germany). The reverse primer R3 (5'-GCGCCGGTAGTTGCCCTTCTC-3') was labeled at the $5^{\prime}$ end using $\left[\gamma_{-}{ }^{32} \mathrm{P}\right]$-ATP (PerkinElmer Inc., Waltham, MA, USA) and T4 polynucleotide kinase (Takara). The extension reaction was performed with the AccuPower ${ }^{\circledR}$ DNA Sequencing Kit (Bioneer), and the reaction products were resolved on a $10 \%$ denaturing polyacrylamide gel and visualized by autoradiography.

\section{Full-length cDNA preparation using the CAGE method}

Full-length cDNA was generated by the CAGE method (Takahashi, Lassmann et al., 2012). Briefly, $5 \mu \mathrm{g}$ of total RNA was prepared from KGN cells. cDNA was reverse transcribed using reverse transcriptase (Takara), biotinylated with Biotin (Long Arm) Hydrazide (Vector Laboratories, Burlingame, CA, USA), and cap-trapped to capture 5'-completed cDNAs using Streptavidin C1 Dynabeads (Invitrogen). 


\section{Genomic engineering of CRISPR/Cas9-nickase-mediated miR-1236 KO cell lines}

miR-1236 KO cells were generated based on a protocol described by Ran et al.(Ran et al., 2013). Briefly, to generate vectors encoding the Cas9 (D10A) nickases, pSpCas9n(BB)-2A-GFP (Addgene, Cambridge, MA, USA) was mutagenized by PCR amplification. The primers used for site-specific mutagenesis were D10A-F (5'-TAGAGGTACCCGTTACATAAC-3'), D10A-R (5'CTGAAGATCTCTTGCAGATAG-3'), Mut-D10A-F

TACAGCATCGGCCTGGCCATCGGC-3'), and Mut-D10A-R GGTGCCGATGGCCAGGCCGATGCT-3'). Four guide RNAs were designed targeting the protospacer adjacent motif (PAM) sequence at the miR-1236* region (sgRNA-miR-1236-1 and 2) or miR-1236 region (sgRNA-miR-1236-3 and -4) (Appendix Fig S4A and S4E), using CRISPR DESIGN (http://crispr.mit.edu/). To generate plasmids targeting miR-1236* or miR-1236, the pX458(D10A)-miR-1236-5p or pX458(D10A)-miR-1236-3p dual-guide oligonucleotide primers, respectively, were cloned into the pX458(D10A) vector. KGN or COV434 cells $\left(1 \times 10^{6}\right)$ were cultured in 100-mm dishes and transfected with $5 \mu \mathrm{g}$ of each CRISPR plasmid. The transfected cells were cultured for $24 \mathrm{~h}$, harvested, and resuspended in phosphate buffered saline (PBS; $\mathrm{Ca}^{2+} / \mathrm{Mg}^{2+}$-free, $1 \mathrm{mM}$ EDTA, $25 \mathrm{mM}$ HEPES $\mathrm{pH}$ 7.0), containing 1\% heat-inactivated FBS. They were then sorted by flow cytometry (based on green fluorescent protein signaling), using a BD FACSAria II cell sorter (BD Bioscience, San Jose, CA, USA). Cells were sorted into individual wells of 96-well plates and then further expanded.

\section{T7 endonuclease I (T7E1) assays}

A gDNA fragment (762-bp) harboring miR-1236 was amplified with the primers, 5'GATGGATGAAGCTTCCA-3' and 5'-ACTCAGAATGGTACAGC-3'. The purified PCR products 
were denatured and reannealed in NEBuffer 2 (New England BioLabs, Ipswich, MA, USA), using a thermocycler. The hybridized PCR products were digested with T7E1 (New England BioLabs) for $2 \mathrm{~h}$ and resolved on $2 \%$ agarose gels.

\section{Genotyping for miR-1236 KO}

Allelic deletion was confirmed using the TOPcloner ${ }^{\mathrm{TM}}$ TA Core Kit (Enzynomics, Daejeon, Korea) and DNA sequencing (Cosmo Genetech).

\section{Northern blot analysis}

Total RNA (including miRNAs) was extracted from cultured cells using TRIzol (Invitrogen). Then, the small RNA species were isolated and concentrated using the mirVana PARIS Kit (Ambion). Small RNA fractions from cells $(\sim 1.5 \mu \mathrm{g})$ were separated on a $15 \%$ polyacrylamide gel containing $8 \mathrm{M}$ urea, visualized by ethidium bromide staining, and then transferred to a Hybond-XL membrane (Amersham Bioscience). Subsequently, the RNA was immobilized on the membrane with a ultraviolet cross-linker (UVP) and hybridized with a 5' end-labeled-oligonucleotide. AntimiR-1236 (5'-CTGGAGAGACAAGGGGAAGAGG-3') and anti-miR-21 TCAACATCAGTCTGATAAGCTA-3') were used as probes. The radioactive signals were analyzed using a Bio-Rad phosphorimager and the Quantity One image-analysis software package (Bio-Rad).

\section{Luciferase-reporter assays}

Luciferase assays were performed as described previously (Kim et al., 2011). 


\section{In vitro transcription}

In vitro transcription of 230-bp CDS sequences that included nucleotide 402 of WT and $402 \mathrm{C}>\mathrm{G}$ FOXL2 mRNA was performed using the MegashortScript ${ }^{\mathrm{TM}}$ T7 Kit (Thermo Scientific, Rockford, IL, USA). To generate the T7-FOXL2 DNA template, pCMV-FOXL2-WT and pCMV-FOXL2C134W (Kim et al., 2011) were used as templates and amplified by PCR, with a primer containing the $\mathrm{T} 7$ promoter sequence, T7-FOXL2-F

TAATACGACTCACTATAGGGAGGGCTGGCAAAATAGCA-3') and T7-FOXL2-R (5'GGCGCCTCCGGCCCCGA-3'). RNA was transcribed in vitro using T7 RNA polymerase according to the manufacturer's instructions.

\section{In vitro-annealing kinetics between miR-1236 and FOXL2 transcripts}

We incubated 5'-labeled ${ }^{32} \mathrm{P}-\mathrm{miR}-1236$ (0.5 nM; PerkinElmer, Boston, MA, USA) with increasing concentrations of in vitro-transcribed WT or $402 \mathrm{C}>\mathrm{G}$ FOXL2 mRNAs $(0,2.5,12.5,25$, and 50 $\mathrm{nM})$ in hybridization buffer $(100 \mathrm{mM} \mathrm{NaCl}, 20 \mathrm{mM}$ Tris- $\mathrm{HCl}$ at $\mathrm{pH} 7.4$, and $10 \mathrm{mM} \mathrm{MgCl} 2)$ at $65^{\circ} \mathrm{C}$ for $5 \mathrm{~min}$. Then, the hybridization reactions were cooled slowly to room temperature. Aliquots were transferred into 1 volume (v) of stop buffer $(20 \mathrm{mM}$ Tris- $\mathrm{HCl}$ at $\mathrm{pH} 7.4,10 \mathrm{mM}$ EDTA, 2\% [v/v] SDS, $8 \mathrm{M}$ urea, $0.025 \%$ [v/v] bromophenol blue) and analyzed by $6 \%$ native PAGE. Band intensities reflecting FOXL2-miRNA complex formation were detected and quantified using a phosphorimager and the OptiQuant software package (Packard, Meriden, CT, USA).

\section{In vivo association of FOXL2 mRNAs or miR-1236 with RISC}

$293 \mathrm{~T}$ cells were cotransfected with miR-1236-G mimic, siDHX9, or the indicated plasmids for 48 
h. The cells were washed with cold $1 \times$ PBS, and RNA-protein complexes were cross-linked by UV-A irradiation $\left(0.15 \mathrm{~J} / \mathrm{cm}^{2}\right)$. In each case, $10 \%$ of the cells was removed and kept as the input samples, and remaining cells were lysed in buffer containing $25 \mathrm{mM}$ Tris- $\mathrm{HCl}$ at $\mathrm{pH} 7.4,150 \mathrm{mM}$ $\mathrm{KCl}, 0.5 \%$ NP-40, $2 \mathrm{mM}$ EDTA, $1 \mathrm{mM} \mathrm{NaF}, 0.5 \mathrm{mM}$ DTT, RNase inhibitor (Promega), 0.05\% Tween 20, and protease inhibitors (GeneDEPOT, Barker, TX, USA), and centrifuged at 7,000 $\times g$ for $15 \mathrm{~min}$ at $4^{\circ} \mathrm{C}$. Each lysate was pre-incubated with $2 \mu \mathrm{g} \mathrm{IgG}$ and $20 \mu \mathrm{l}$ Dynabeads (Invitrogen) for $4 \mathrm{~h}$ at $4^{\circ} \mathrm{C}$. Three milligrams of each lysate was precleared using a control rabbit IgGDynabeads complex for $30 \mathrm{~min}$ at $4^{\circ} \mathrm{C}$. Then, the cell lysates were re-incubated with $5 \mu \mathrm{g}$ FLAG antibody-coupled Dynabeads $(50 \mu \mathrm{l})$ overnight on a rotator at $4{ }^{\circ} \mathrm{C}$. After incubation, the beads were washed five times with a buffer $(300 \mathrm{mM} \mathrm{KCl}, 50 \mathrm{mM}$ Tris- $\mathrm{HCl} \mathrm{pH} 7.4,1 \mathrm{mM} \mathrm{MgCl}, 0.1 \%$ NP-40, $0.05 \%$ Tween 20) and incubated with DNase I for $10 \mathrm{~min}$ at $37^{\circ} \mathrm{C}$. The sample proteins were digested with proteinase $\mathrm{K}$, and RNA was extracted using an acidic phenol: chloroform mixture (5: 1, $\mathrm{pH} 4.3$ ) and precipitated with isopropanol in the presence of $10 \%$ of $3 \mathrm{M}$ sodium acetate (NaOAc; $\mathrm{pH}$ 5.2). The purified RNAs were reverse transcribed to cDNA with the FOXL2430-R primer (5'-GGTAGTTGCCCTTCTCGAAC-3'), which binds to a region downstream of the 402C $>$ G site. Then, the cDNA products were used for FOXL2 allele-specific RT-PCR or real-time RT-PCR analysis, with the FOXL2-279F primer. The relative abundance of miR-1236 was validated using TaqMan ${ }^{\circledR}$ microRNA assays. To detect endogenous association of AGO3mediated RISCs and FOXL2 mRNA, RNA-protein complexes formed in KGN cells $\left(3 \times 10^{7}\right)$ transfected with a control miRNA or miR-1236-G (10 nM), or a control siRNA or siDHX9 (200 $\mathrm{nM})$, were cross-linked via UV irradiation $\left(0.15 \mathrm{~J} / \mathrm{cm}^{2}\right)$. The lysates were incubated with $10 \mu \mathrm{l}$ of AGO3 antibody-coupled Dynabeads $(50 \mu \mathrm{l})$ overnight on a rotator at $4{ }^{\circ} \mathrm{C}$. The RNAs were purified as described above. 


\section{Cell-viability assay}

Cell-viability assays were performed as previously described (Kim et al., 2014).

\section{5-bromo-2'-deoxy-uridine cell-proliferation assay}

Cell $\left(1 \times 10^{4}\right)$ proliferation was measured using the 5-Bromo-2'-deoxy-uridine Labeling and Detection Kit III (Roche, Mannheim, Germany) (Jin, Lee et al., 2016).

\section{Cell-migration assay}

A chemotaxis migration assay was performed using Transwell Permeable Supports (8- $\mu \mathrm{m}$ pore size, 6.5-mm insert; Corning-Costar, Lowell, MA, USA). KGN cells $\left(1 \times 10^{6}\right)$ and COV434 cells $\left(0.3 \times 10^{6}\right)$ were transfected with either pcDNA3 or pcDNA3-Flag-FOXL2)(Park et al., 2010), or the indicated oligonucleotides. Cells were plated at a density of $2 \times 10^{5}$ cells/well in the top chamber containing DMEM/F12 and 1\% FBS, whereas the bottom chamber contained DMEM/F12 and 10\% FBS as a chemoattractant. After 2 to $6 \mathrm{~h}$ of incubation, the cells and medium were removed from the top chamber, and the migrated cells were fixed with $5 \%$ glutaraldehyde for $20 \mathrm{~min}$ and stained with $0.5 \%$ crystal violet for $20 \mathrm{~min}$. Images of the migrated cells were taken at $\times 100$ magnification under a bright-field microscope. Quantification was performed under a light microscope with $\times 200$ magnification by counting the number of migrated cells in five random fields per chamber. The data are presented as the mean \pm SEM of three independent experiments and are shown as the fold-change in the average number of cells.

\section{Apoptosis and cell-cycle analyses}


Detection of Annexin V-positive apoptotic cells and cell-cycle analysis were performed as previously reported (Jin et al., 2016, Kim et al., 2011).

\section{Tumor xenograft establishment and immunohistochemistry}

Control or miR-1236-KO (miR-1236-/- $\mathrm{KGN}$ cells $\left(5 \times 10^{6}\right)$ were suspended in $0.1 \mathrm{~mL}$ Matrigel (1: 1, v/v, Corning, Tewksbury, MA) and injected subcutaneously into 7-week-old BALB/c nu/nu immunodeficient mice (weights ranged between 18 and 20 g) (ORIENT BIO, Seongnam, Korea). Mice were euthanized 2 months later, and the numbers of intraperitoneal nodules were counted. Half of the nodules were excised, fixed in $4 \%$ neutral buffered formalin, and embedded in paraffin before preparing $5-\mu \mathrm{m}$ sections that were stained with hematoxylin. The other half of the nodules were excised, and total RNA was isolated using the TRIzol reagent (Invitrogen), according to the manufacturer's instructions. The animal guidelines were approved by the Chung-Ang University Institutional Animal Care and Use Committee (IRB\# CAU2012-0044), and the animals were treated as described in the protocol.

\section{Statistical analysis}

All details of the statistical analysis used in the experiments are included in the figure legends. Multiple-comparison analyses of values were performed using the Student-Newman-Keuls test, and Student's $t$-test was used for comparisons with control samples, using SAS version 9.2 (SAS Institute, Cary, NC, USA) and SigmaPlot (Systat Software, San Jose, CA, USA). The data are presented as mean $\pm \mathrm{SEM}$, and $P<0.05$ was considered to reflect as statistically significant difference. 


\section{Data availability}

Ultra-deep RNA Sequencing data have been deposited in the NCBI Sequence Read Archive (SRA) with the BioProject code "PRJNA555182".

\section{ACKNOWLEDGEMENTS}

We thank Drs. Wooseok Song, Hong-Man Kim, and Seunghwa Lee for helping with the primerextension and cell-migration experiments. We also thank Dr. Jae-Sung Woo for critical comments. This research was supported by the National Research Foundation of Korea (NRF), which is funded by the Ministry of Science, ICT, and Future Planning (2017R1A2B2011248; 2015R1A5A1008958; 2018R1A5A1025077; 2019R1H1A2080015; 2019R1A2C2086590).

\section{AUTHOR CONTRIBUTIONS}

K.L. and J.B. conceived and designed the study; K.L. and J.B. developed the methods; E.S., H.J., D.S.S., Y.L., and T.H.K. performed the experiments; Y.H., S.H., K.L., and J.B. analyzed and interpreted the data; E.S., H.J., K.L., and J.B. wrote and reviewed the manuscript; K.L. and J.B. supervised the study.

\section{COMPETING FINANCIAL INTERESTS}

The authors declare no competing financial interests. 


\section{REFERENCES}

An JX, Ma ZS, Ma MH, Shao S, Cao FL, Dai DQ (2019) MiR-1236-3p serves as a new diagnostic and prognostic biomarker for gastric cancer. Cancer Biomark

Azuma-Mukai A, Oguri H, Mituyama T, Qian ZR, Asai K, Siomi H, Siomi MC (2008) Characterization of endogenous human Argonautes and their miRNA partners in RNA silencing. Proc Natl Acad Sci U S A 105: $7964-9$

Bartel DP (2009) MicroRNAs: target recognition and regulatory functions. Cell 136: 215-33

Broughton JP, Lovci MT, Huang JL, Yeo GW, Pasquinelli AE (2016) Pairing beyond the Seed Supports MicroRNA Targeting Specificity. Mol Cell 64: 320-333

Cai Z, Cao R, Zhang K, Xue Y, Zhang C, Zhou Y, Zhou J, Sun H, Fu XD (2015) Oncogenic miR-17/20a Forms a Positive Feed-forward Loop with the p53 Kinase DAPK3 to Promote Tumorigenesis. J Biol Chem 290: 19967-75

Chen SY, Teng SC, Cheng TH, Wu KJ (2016) miR-1236 regulates hypoxia-induced epithelial-mesenchymal transition and cell migration/invasion through repressing SENP1 and HDAC3. Cancer Lett 378: 59-67

Chi SW, Zang JB, Mele A, Darnell RB (2009) Argonaute HITS-CLIP decodes microRNA-mRNA interaction maps. Nature 460: 479-86

Czech B, Hannon GJ (2011) Small RNA sorting: matchmaking for Argonautes. Nat Rev Genet 12: 19-31 Dai A, Sun H, Fang T, Zhang Q, Wu S, Jiang Y, Ding L, Yan G, Hu Y (2013) MicroRNA-133b stimulates ovarian estradiol synthesis by targeting Foxl2. FEBS Lett 587: 2474-82

Duursma AM, Kedde M, Schrier M, le Sage C, Agami R (2008) miR-148 targets human DNMT3b protein coding region. RNA 14: 872-7

Elcheva I, Goswami S, Noubissi FK, Spiegelman VS (2009) CRD-BP protects the coding region of betaTrCP1 mRNA from miR-183-mediated degradation. Mol Cell 35: 240-6

Eulalio A, Tritschler F, Izaurralde E (2009) The GW182 protein family in animal cells: new insights into domains required for miRNA-mediated gene silencing. RNA 15: 1433-42

Forman JJ, Legesse-Miller A, Coller HA (2008) A search for conserved sequences in coding regions reveals that the let-7 microRNA targets Dicer within its coding sequence. Proc Natl Acad Sci U S A 105: 14879-84

Fu GK, Xu W, Wilhelmy J, Mindrinos MN, Davis RW, Xiao W, Fodor SP (2014) Molecular indexing enables quantitative targeted RNA sequencing and reveals poor efficiencies in standard library preparations. Proc Natl Acad Sci U S A 111: 1891-6

Fu Q, Yuan YA (2013) Structural insights into RISC assembly facilitated by dsRNA-binding domains of human RNA helicase A (DHX9). Nucleic Acids Res 41: 3457-70

Gao R, Cai C, Gan J, Yang X, Shuang Z, Liu M, Li S, Tang H (2015) miR-1236 down-regulates alphafetoprotein, thus causing PTEN accumulation, which inhibits the PI3K/Akt pathway and malignant phenotype in hepatoma cells. Oncotarget 6: 6014-28 
Gu S, Jin L, Zhang F, Sarnow P, Kay MA (2009) Biological basis for restriction of microRNA targets to the 3' untranslated region in mammalian mRNAs. Nat Struct Mol Biol 16: 144-50

Hafner M, Landthaler M, Burger L, Khorshid M, Hausser J, Berninger P, Rothballer A, Ascano M, Jr., Jungkamp AC, Munschauer M, Ulrich A, Wardle GS, Dewell S, Zavolan M, Tuschl T (2010) Transcriptomewide identification of RNA-binding protein and microRNA target sites by PAR-CLIP. Cell 141: 129-41 Hausser J, Syed AP, Bilen B, Zavolan M (2013) Analysis of CDS-located miRNA target sites suggests that they can effectively inhibit translation. Genome Res 23: 604-15

Hock J, Meister G (2008) The Argonaute protein family. Genome Biol 9: 210

Huang H, Li Y, Szulwach KE, Zhang G, Jin P, Chen D (2014) AGO3 Slicer activity regulates mitochondrianuage localization of Armitage and piRNA amplification. J Cell Biol 206: 217-30

Iwakawa HO, Tomari Y (2013) Molecular insights into microRNA-mediated translational repression in plants. Mol Cell 52: 591-601

Jamieson S, Butzow R, Andersson N, Alexiadis M, Unkila-Kallio L, Heikinheimo M, Fuller PJ, Anttonen M (2010) The FOXL2 C134W mutation is characteristic of adult granulosa cell tumors of the ovary. Mod Pathol 23: 1477-85

Jin H, Lee K, Kim YH, Oh HK, Maeng YI, Kim TH, Suh DS, Bae J (2016) Scaffold protein FHL2 facilitates MDM2-mediated degradation of IER3 to regulate proliferation of cervical cancer cells. Oncogene 35 : 5106-18

Jones D, Li Y, He Y, Xu Z, Chen H, Min W (2012) Mirtron microRNA-1236 inhibits VEGFR-3 signaling during inflammatory lymphangiogenesis. Arteriosclerosis, thrombosis, and vascular biology 32: 633-42 Kertesz M, lovino N, Unnerstall U, Gaul U, Segal E (2007) The role of site accessibility in microRNA target recognition. Nat Genet 39: 1278-84

Kim H, Kim J, Kim K, Chang H, You K, Kim VN (2019) Bias-minimized quantification of microRNA reveals widespread alternative processing and 3 ' end modification. Nucleic Acids Res 47: 2630-2640

Kim JH, Bae J (2014) Differential apoptotic and proliferative activities of wild-type FOXL2 and blepharophimosis-ptosis-epicanthus inversus syndrome (BPES)-associated mutant FOXL2 proteins. The Journal of reproduction and development 60: 14-20

Kim JH, Kim YH, Kim HM, Park HO, Ha NC, Kim TH, Park M, Lee K, Bae J (2014) FOXL2 posttranslational modifications mediated by GSK3beta determine the growth of granulosa cell tumours. Nat Commun 5 : 2936

Kim JH, Yoon S, Park M, Park HO, Ko JJ, Lee K, Bae J (2011) Differential apoptotic activities of wild-type FOXL2 and the adult-type granulosa cell tumor-associated mutant FOXL2 (C134W). Oncogene 30: 165363

Landthaler M, Gaidatzis D, Rothballer A, Chen PY, Soll SJ, Dinic L, Ojo T, Hafner M, Zavolan M, Tuschl T (2008) Molecular characterization of human Argonaute-containing ribonucleoprotein complexes and their bound target mRNAs. RNA 14: 2580-96 
Liu J, Carmell MA, Rivas FV, Marsden CG, Thomson JM, Song JJ, Hammond SM, Joshua-Tor L, Hannon GJ (2004) Argonaute2 is the catalytic engine of mammalian RNAi. Science 305: 1437-41

Luo Y, Wu X, Ling Z, Yuan L, Cheng Y, Chen J, Xiang C (2015) microRNA133a targets Foxl2 and promotes differentiation of C2C12 into myogenic progenitor cells. DNA Cell Biol 34: 29-36

Ma L, Shen CJ, Cohen EA, Xiong SD, Wang JH (2014) miRNA-1236 inhibits HIV-1 infection of monocytes by repressing translation of cellular factor VprBP. PLoS One 9: e99535

Mayr C, Bartel DP (2009) Widespread shortening of 3'UTRs by alternative cleavage and polyadenylation activates oncogenes in cancer cells. Cell 138: 673-84

Mayr C, Hemann MT, Bartel DP (2007) Disrupting the pairing between let-7 and Hmga2 enhances oncogenic transformation. Science 315: 1576-9

Meister G, Landthaler M, Patkaniowska A, Dorsett Y, Teng G, Tuschl T (2004) Human Argonaute2 mediates RNA cleavage targeted by miRNAs and siRNAs. Mol Cell 15: 185-97

Nanda GG, Kumar MV, Pradhan L, Padhy B, Sundaray S, Das S, Alone DP (2018) rs4246215 is targeted by hsa-miR1236 to regulate FEN1 expression but is not associated with Fuchs' endothelial corneal dystrophy. PLoS One 13: e0204278

Nielsen BS, Jorgensen S, Fog JU, Sokilde R, Christensen IJ, Hansen U, Brunner N, Baker A, Moller S, Nielsen HJ (2011) High levels of microRNA-21 in the stroma of colorectal cancers predict short diseasefree survival in stage II colon cancer patients. Clinical \& experimental metastasis 28: 27-38

Okamura K, Hagen JW, Duan H, Tyler DM, Lai EC (2007) The mirtron pathway generates microRNA-class regulatory RNAs in Drosophila. Cell 130: 89-100

Park M, Shin E, Won M, Kim JH, Go H, Kim HL, Ko JJ, Lee K, Bae J (2010) FOXL2 interacts with steroidogenic factor-1 (SF-1) and represses SF-1-induced CYP17 transcription in granulosa cells. Molecular endocrinology 24: 1024-36

Park MS, Phan HD, Busch F, Hinckley SH, Brackbill JA, Wysocki VH, Nakanishi K (2017) Human Argonaute3 has slicer activity. Nucleic Acids Res 45: 11867-11877

Ran FA, Hsu PD, Lin CY, Gootenberg JS, Konermann S, Trevino AE, Scott DA, Inoue A, Matoba S, Zhang $Y$, Zhang F (2013) Double nicking by RNA-guided CRISPR Cas9 for enhanced genome editing specificity. Cell 154: 1380-9

Robb GB, Rana TM (2007) RNA helicase A interacts with RISC in human cells and functions in RISC loading. Mol Cell 26: 523-37

Ruby JG, Jan CH, Bartel DP (2007) Intronic microRNA precursors that bypass Drosha processing. Nature 448: 83-86

Sasaki T, Shiohama A, Minoshima S, Shimizu N (2003) Identification of eight members of the Argonaute family in the human genome. Genomics 82: 323-30

Sato K, Yoshimura A, Kaneko T, Ukai T, Ozaki Y, Nakamura H, Li X, Matsumura H, Hara Y, Ogata Y (2012) A single nucleotide polymorphism in $3^{\prime}$-untranslated region contributes to the regulation of Toll-like 
receptor 4 translation. J Biol Chem 287: 25163-72

Schmidt D, Ovitt CE, Anlag K, Fehsenfeld S, Gredsted L, Treier AC, Treier M (2004) The murine wingedhelix transcription factor Foxl2 is required for granulosa cell differentiation and ovary maintenance. Development 131: 933-42

Schnall-Levin M, Rissland OS, Johnston WK, Perrimon N, Bartel DP, Berger B (2011) Unusually effective microRNA targeting within repeat-rich coding regions of mammalian mRNAs. Genome Res 21: 1395403

Schnall-Levin M, Zhao Y, Perrimon N, Berger B (2010) Conserved microRNA targeting in Drosophila is as widespread in coding regions as in 3'UTRs. Proc Natl Acad Sci U S A 107: 15751-6

Schumer ST, Cannistra SA (2003) Granulosa cell tumor of the ovary. J Clin Oncol 21: 1180-9

Shah SP, Kobel M, Senz J, Morin RD, Clarke BA, Wiegand KC, Leung G, Zayed A, Mehl E, Kalloger SE, Sun M, Giuliany R, Yorida E, Jones S, Varhol R, Swenerton KD, Miller D, Clement PB, Crane C, Madore J et al. (2009) Mutation of FOXL2 in granulosa-cell tumors of the ovary. N Engl J Med 360: 2719-29 Song NJ, Yoon HJ, Kim KH, Jung SR, Jang WS, Seo CR, Lee YM, Kweon DH, Hong JW, Lee JS, Park KM, Lee KR, Park KW (2013) Butein is a novel anti-adipogenic compound. Journal of lipid research 54: 138596

Su H, Trombly MI, Chen J, Wang X (2009) Essential and overlapping functions for mammalian Argonautes in microRNA silencing. Genes Dev 23: 304-17

Takahashi H, Lassmann T, Murata M, Carninci P (2012) 5' end-centered expression profiling using capanalysis gene expression and next-generation sequencing. Nat Protoc 7: 542-61

Tay Y, Zhang J, Thomson AM, Lim B, Rigoutsos I (2008) MicroRNAs to Nanog, Oct4 and Sox2 coding regions modulate embryonic stem cell differentiation. Nature 455: 1124-8

Thoma C (2015) Kidney cancer: RNA activation in RCC: p21 and miR-1236 are a promising pair. Nat Rev Urol 12: 598

Tian B, Manley JL (2017) Alternative polyadenylation of mRNA precursors. Nat Rev Mol Cell Biol 18: 1830

Uhlenhaut NH, Jakob S, Anlag K, Eisenberger T, Sekido R, Kress J, Treier AC, Klugmann C, Klasen C, Holter NI, Riethmacher D, Schutz G, Cooney AJ, Lovell-Badge R, Treier M (2009) Somatic sex reprogramming of adult ovaries to testes by FOXL2 ablation. Cell 139: 1130-42

Wang C, Tang K, Li Z, Chen Z, Xu H, Ye Z (2016) Targeted p21(WAF1/CIP1) activation by miR-1236 inhibits cell proliferation and correlates with favorable survival in renal cell carcinoma. Urol Oncol 34 : 59 e23-34

Wang K, Long B, Jiao JQ, Wang JX, Liu JP, Li Q, Li PF (2012) miR-484 regulates mitochondrial network through targeting Fis1. Nat Commun 3: 781

Wang T, Li F, Tang S (2015) MiR-30a upregulates BCL2A1, IER3 and cyclin D2 expression by targeting FOXL2. Oncol Lett 9: 967-971 
Wang Y, Yan S, Liu X, Zhang W, Li Y, Dong R, Zhang Q, Yang Q, Yuan C, Shen K, Kong B (2014) miR1236-3p represses the cell migration and invasion abilities by targeting ZEB1 in high-grade serous ovarian carcinoma. Oncol Rep 31: 1905-10

Wang Z, Liu L, Guo X, Guo C, Wang W (2018) microRNA-1236-3p Regulates DDP Resistance in Lung Cancer Cells. Open Med (Wars) 14: 41-51

Wen J, Ladewig E, Shenker S, Mohammed J, Lai EC (2015) Analysis of Nearly One Thousand Mammalian Mirtrons Reveals Novel Features of Dicer Substrates. PLoS Comput Biol 11: e1004441

Xue Y, Ouyang K, Huang J, Zhou Y, Ouyang H, Li H, Wang G, Wu Q, Wei C, Bi Y, Jiang L, Cai Z, Sun H, Zhang K, Zhang Y, Chen J, Fu XD (2013) Direct conversion of fibroblasts to neurons by reprogramming PTB-regulated microRNA circuits. Cell 152: 82-96

Zhang K, Zhang X, Cai Z, Zhou J, Cao R, Zhao Y, Chen Z, Wang D, Ruan W, Zhao Q, Liu G, Xue Y, Qin Y, Zhou B, Wu L, Nilsen T, Zhou Y, Fu XD (2018) A novel class of microRNA-recognition elements that function only within open reading frames. Nat Struct Mol Biol 25: 1019-1027

Zhao X, Feng J, Zhang L, Zhao F, Li M, Du Y, Li Y, Wu Q, Li G (2019) One functional variant in the 3'untranslated region of TLR4 is associated with the elevated risk of ventilator-associated pneumonia in the patients with chronic obstructive pulmonary disease. J Cell Physiol

Zhu XP, Wang XL, Ma J, Fang YF, Zhang HJ, Zhang C, Feng MC (2018) Down-regulation of miR-1236-3p is correlated with clinical progression and unfavorable prognosis in gastric cancer. Eur Rev Med Pharmacol Sci 22: 5914-5919

Zuker M (2003) Mfold web server for nucleic acid folding and hybridization prediction. Nucleic Acids Res 31: 3406-15 


\section{FIGURE LEGENDS}

\section{Figure 1. Allelic imbalance of heterozygous FOXL2 transcripts in AGCT cells}

A, B Bar graph and box-and-whisker plots are presented, which show the allelic proportions of WT FOXL2 mRNA and 402C >G FOXL2 mRNA in AGCT tissues from 20 patients analyzed by ultra-deep RNA sequencing (A) and from 46 patients analyzed by pyrosequencing (B). The box plot represents the lower, median, and upper quartiles, and the whiskers represent the $95 \%$ confidence interval of the mean. The whiskers extend to the most extreme data points not considered outliers, and the outliers are represented as dots. Orange dotted boxes indicate that AGCTs from 20 patients analyzed for both ultra-deep RNA sequencing and pyrosequencing. Comparisons between groups were performed using Student's $t$-tests, and $p$ values are presented. C The relative abundances of WT and variant FOXL2 mRNA were analyzed in KGN and COV434 cells by pyrosequencing (left graph), allele-specific RT-PCR (middle graph) and real-time RT-PCR (right graph). gDNA was detected as a positive control. The relative abundances of the variant FOXL2 mRNA were normalized to that of WT mRNA (set to 1). FOXL2 mRNA levels detected by real-time RT-PCR were normalized to matching gDNA levels. The pyrosequencing data are presented from two independent experiments. The allele-specific semi-quantitative and real-time RT-PCR data are presented as the mean \pm SEM from three independent experiments. ${ }^{* * *} p<0.001$. n.d. not detected.

D RNA-decay rates of $\mathrm{WT}$ and $402 \mathrm{C}>\mathrm{G}$ FOXL2 mRNAs in KGN cells were determined after treatment with $5 \mu \mathrm{g} / \mathrm{mL}$ ActD for the indicated times. The estimated half-lives of each transcript are presented. The data are presented as the mean \pm SEM from three independent experiments.

Figure 2. Selective downregulation of the variant FOXL2 mRNA allele by miR-1236 
A, B Changes in WT and variant FOXL2 mRNA expression were assessed by RT-PCR (top) and real-time RT-PCR (bottom) (A) or by western blot analysis (B) after transfecting KGN cells with anti-miRNAs for $48 \mathrm{~h}$.

C FOXL2 protein levels after transfection of control or miR-1236 were assessed in KGN and COV434 cells.

D The mRNA levels of WT and variant FOXL2 in control, miR-1236 $6^{-/+}$, and miR-1236-- KGN cells, with or without miR-1236 transfection, were determined by RT-PCR (top) or real-time RTPCR (bottom).

E FOXL2 protein expression in control, miR-1236 $6^{-1+}$, and miR-1236 $6^{-/} \mathrm{KGN}$ cells, and two independent miR-1236/- (\#1 and \#2) COV434 cell lines were determined by western blotting. Representative gel images are also shown. All quantified results (mean $\pm \mathrm{SEM}$ ) are from at least three independent experiments. Different letters $(p<0.0001)$ or asterisks $\left({ }^{*} p<0.05\right)$ denote significant differences.

Figure 3. Allele-specific downregulation of FOXL2 mRNA by miR-1236, which targets $402 C>G$

A Schematic representation of the luciferase-reporter constructs used to assay miR-1236 activity against a CDS target site in FOXL2 mRNA. The 231-bp human FOXL2 segments harboring either the C402 (WT) or the G402 (mutant) nucleotide were inserted in-frame into the CDS of the luciferase gene in the pGL3 control vector.

B Luciferase activity of the reporter constructs shown in (A) were measured in KGN cells after transfection with an miR-1236 mimic for $48 \mathrm{~h}$.

C A schematic diagram of the luciferase-reporter constructs generated by inserting the predicted 
miR-1236-target sequences of WT and 402C >G FOXL2 mRNAs in the 3'-UTR of luciferase.

D Luciferase activities were measured in KGN cells, using the reporter constructs shown in (C), after transfection with a control miRNA or an miR-1236 mimic for $48 \mathrm{~h}$.

E, F miR-1236 mutants, in which the $\mathrm{C}$ that pairs with G402 of the FOXL2 mutant was substituted with either G (miR-1236-G) (E) or U (miR-1236-U) (F), were cotransfected into KGN cells with one of the reporter constructs described above. Luciferase activities were subsequently determined. Arrows indicate the mismatched sites.

G In vitro annealing kinetics of miR-1236 with 230 nt-long transcripts of WT or variant FOXL2.

${ }^{32} \mathrm{P}-$ labeled miR-1236 (0.5 nM) was incubated with increasing concentrations of synthetic FOXL2 transcripts $(0,2.5,12.5,25$, or $50 \mathrm{nM})$. FOXL2 mRNA-miR-1236 complexes were resolved on a $6 \%$ native gel and detected by autoradiography (left). The predicted $\mathrm{K}_{\mathrm{d}} \mathrm{S}$ for the $\mathrm{WT}$ and $402 \mathrm{C}>\mathrm{G}$ FOXL2 transcripts are presented in the right graph. The data are expressed as the mean \pm SEM from three independent experiments, performed in triplicate. $* * * p<0.001$

Figure 4. Identification of AGO3 as the major miRISC regulator for variant FOXL2 mRNA degradation

A, B Changes in WT and variant FOXL2 mRNA-expression levels were assessed by real-time RTPCR (A) or western blot analysis (B) after transfecting KGN cells with siRNAs against AGO mRNAs for $48 \mathrm{~h}$. The data (mean \pm SEM) are from three independent experiments, performed in triplicate.

C The mRNA levels of WT (left) and variant FOXL2 (right) were determined in KGN cells by real-time RT-PCR, after transfecting a control miRNA or miR-1236. The data (mean $\pm \mathrm{SEM}$ ) are from three independent experiments, performed in triplicate. 
D The mRNA levels of WT and the variant FOXL2 in control (left) and miR-1236 ${ }^{-/}$KGN cells (right) after transfecting siRNAs against AGO mRNAs were determined by allele-specific realtime RT-PCR. The data (mean \pm SEM) are from three independent experiments, performed in triplicate.

E $293 \mathrm{~T}$ cells were transfected with an miR-1236 mimic $(50 \mathrm{nM})$ for $24 \mathrm{~h}$, followed by cotransfection for $24 \mathrm{~h}$ with expression vectors encoding FLAG/HA-tagged variants of the indicated human AGOs and pGL3c-FOXL2-CDS. The empty p3XFLAG-CMV-10 vector was used as control. Co-immunoprecipitated mRNAs were reverse transcribed, and the cDNA products were used for allele-specific real-time PCR analysis of the FOXL2 variant (top). The immunoprecipitated-AGO proteins were detected by western blotting (bottom). The data (mean \pm SEM) are from three independent experiments.

F In vivo association of AGO3-mediated miRISC formation with FOXL2 mRNAs are shown. Following transfection of a control miRNA or the miR-1236-G mutant into KGN cells, AGO3mediated RISC-associated RNAs were isolated by immunoprecipitation with an anti-AGO3 antibody. IgG was used as a control. The co-immunoprecipitated mRNAs were reverse transcribed using a FOXL2-430-R primer binding downstream of the $402 \mathrm{C}>\mathrm{G}$ site. The cDNA products were used for FOXL2 allele-specific PCR analysis with the FOXL2-279F primer (Appendix Fig. S1), and a representative result (top left) is shown. Quantified real-time RT-PCR results (bottom left) are also presented. Western blot analysis of immunoprecipitated AGO3 and inputs are shown in the right panel. The data are presented as the mean \pm SEM of two independent experiments.

G RNA-seq analysis was performed to determine AGO-expression levels (transcripts per million) from the individual tissues from 20 independent AGCT patients. Different letters $(p<0.05)$ or asterisks $(* * * p<0.001)$ denote statistically significant differences. 
Figure 5. DHX9 as a preferential interactor with AGO3 and an essential molecule for AGO3mediated degradation of the variant FOXL2 mRNA

A Changes in WT and variant FOXL2 mRNA levels in KGN cells were assessed by real-time RTPCR after transfecting siRNAs against the indicated factors for $48 \mathrm{~h}$. The data are presented as the mean \pm SEM from three independent experiments, performed in triplicate.

B FOXL2 protein-expression levels were determined by western blotting after transfecting KGN cells with control, DHX9, or GW182 siRNAs for $48 \mathrm{~h}$. Quantification of FOXL2 protein expression is presented in the bottom panel. The data are presented as the mean \pm SEM from three independent experiments. ${ }^{* *} p<0.01, * * * p<0.001$.

C Relative binding affinities of DHX9 and GW182 to AGOs. 293T cells were transfected with expression vectors encoding the indicated FLAG/HA-tagged AGOs, and cell extracts were prepared and immunoprecipitated with an anti-FLAG antibody, followed by immunoblot analyses. The empty p3XFLAG-CMV-10 vector was used as a control. The band intensities of immunoprecipitated DHX9 and GW182 were quantified and normalized following pull-down with the indicated AGOs. The data are presented as the mean \pm SEM from three independent experiments. * and \# indicate statistically significant differences in the respective amounts of DHX9 or GW182 bound to AGO1 $(p<0.05)$.

D Following transfection of control siRNA or siDHX9 into KGN cells, AGO3-mediated RISCassociated RNAs were immunoprecipitated using an anti-AGO3 antibody. IgG was used as a control. Co-immunoprecipitated mRNAs were reverse transcribed using a FOXL2-430-R primer binding downstream of the $402 \mathrm{C}>\mathrm{G}$ site. The cDNA products were used for $F O X L 2$ allele-specific PCR analysis with a FOXL2-279F primer (Appendix Fig S1A), and a representative result 
obtained by RT-PCR (top) is shown. Quantified real-time RT-PCR results (middle) are also presented. Western blots of immunoprecipitated AGO3 and the inputs are shown in the bottom panel. The data are presented as the mean \pm SEM from three independent experiments.

Figure 6. FOXL2-mediated oncogenic effects of miR-1236 on cell death, cell cycle progression, and cell migration.

A-D KGN cells were transfected with $200 \mathrm{nM}$ of scrambled control or FOXL2-specific siRNAs for 24 h. Then, KGN cells were further transfected with $20 \mathrm{nM}$ of control miRNA, miR-1236, control anti-miRNA, or anti-miR-1236. The proportion of annexin-V-positive apoptotic cells (A and $\mathrm{B})$ and the population at S phase (C and D) were analyzed by flow cytometry. The data are presented as the mean \pm SEM of three independent experiments. Different letters denote statistically significant differences $(p<0.0001)$. Efficient silencing of FOXL2 using specific siRNAs was confirmed by western blotting. The data are presented in the bottom panels as the mean \pm SEM of three independent experiments, performed in triplicate.

E, F KGN cells were transfected with control siRNA or siFOXL2 for $24 \mathrm{~h}$. Then, KGN cells were further transfected with control miRNA or miR-1236 (E) or with control anti-miRNA or anti-miR1236 (F) for $48 \mathrm{~h}$, and Transwell-migration assays were performed. The migrated cells were imaged under a bright-field microscope (100× magnification). The results are from three independent experiments and represent fold-changes in the average number of cells/field (mean \pm SEM). Different letters denote statistically significant differences $(p<0.01)$.

G, H COV434 cells were transfected with miR-control or miR-1236 for $48 \mathrm{~h}$, after which cell viabilities $(\mathrm{G})$ and migration abilities $(\mathrm{H})$ were measured. Immunoblots showing no change in FOXL2 protein are presented in the top panel, and images of migrated cells are presented in the 
right panel.

I-K The properties of miR-1236 $6^{-/+}$and miR-1236-/- $\mathrm{KGN}$ cells versus control KGN cells were assessed by measuring cell viability (I), cell proliferation (J), and cell migration (K).

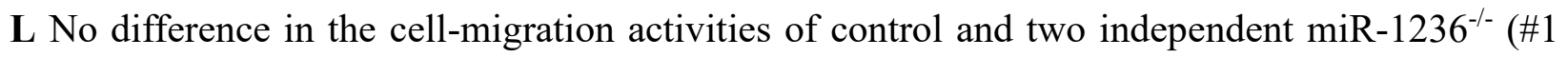
and \#2) COV434 cell lines. The migrated cells were imaged under a bright-field microscope (100× magnification; top) and the results (bottom) represent fold-changes in the average number of cells/field. The data are presented as the mean \pm SEM of three independent experiments. Different letters denote statistically significant differences $(p<0.0001)$.

Figure 7. Inhibition of in vivo metastasis by miR-1236 KO and inverse expression between miR-1236 and the variant FOXL2 mRNA in tissues from AGCT patients

A-C The effect of miR-1236 KO on AGCT metastasis was assessed, using an in vivo xenograft mice model. (A) Representative images of tumor nodules (white arrows) formed in the intestines of nude mice xenografted with control or miR-1236 $6^{-/-}$KGN cells are shown (left). Hematoxylin and eosin staining confirmed the pathological characteristics of the metastasized GCT nodules (right, black arrows). (B) The number of tumor nodules formed in the intestines was counted in control $(\mathrm{n}=8)$ and miR-1236-/- $(\mathrm{n}=8)$ mice. (C) Allele-specific real-time RT-PCR analysis of the WT and $402 \mathrm{C}>\mathrm{G}$ variant $F O X L 2$ mRNAs was performed using RNA extracted from tumor nodules from control or miR-1236 $6^{-/-}$mice. $* * p<0.01, * * * p<0.001$.

D-F Box-and-whisker plots showing the relative expression of miR-1236 (D), variant FOXL2 mRNA (E), and WT FOXL2 mRNA(F), respectively, in 32 patients with non-metastasized AGCTs and 14 patients with metastasized AGCTs. The relative miR-1236 levels were measured using a TaqMan ${ }^{\circledR}$ microRNA RT-qPCR assay, with expression normalized to $R N U 6 B$. The levels of 
$402 \mathrm{C}>\mathrm{G}$ or WT FOXL2 mRNA were determined by real-time RT-PCR, and the data were normalized to paired-gDNA levels. The relative levels of miR-1236 and FOXL2 mRNAs were quantified by setting the levels of AGCT \#1 to 1. Real-time RT-PCR was performed in triplicate for each specimen. The box plot represents the lower, median, and upper quartiles, and the whiskers represent the $95 \%$ confidence interval of the mean. The whiskers extend to the most extreme data points not considered outliers, and the outliers are represented as dots. Comparisons between groups were performed using Student's $t$-tests, and $p$ values are presented.

G, H The estimated regression line superimposed on the scatter plot of miR-1236 levels with 402C $>$ G FOXL2 mRNA (G) or WT FOXL2 mRNA (H) in AGCT samples $(\mathrm{n}=46)$ is shown, along with correlation coefficient (r) and $p$ values.

I The proposed model for FOXL2 haploinsufficiency induced by the $402 \mathrm{C}>\mathrm{G}$ mutation during AGCT development. 
A

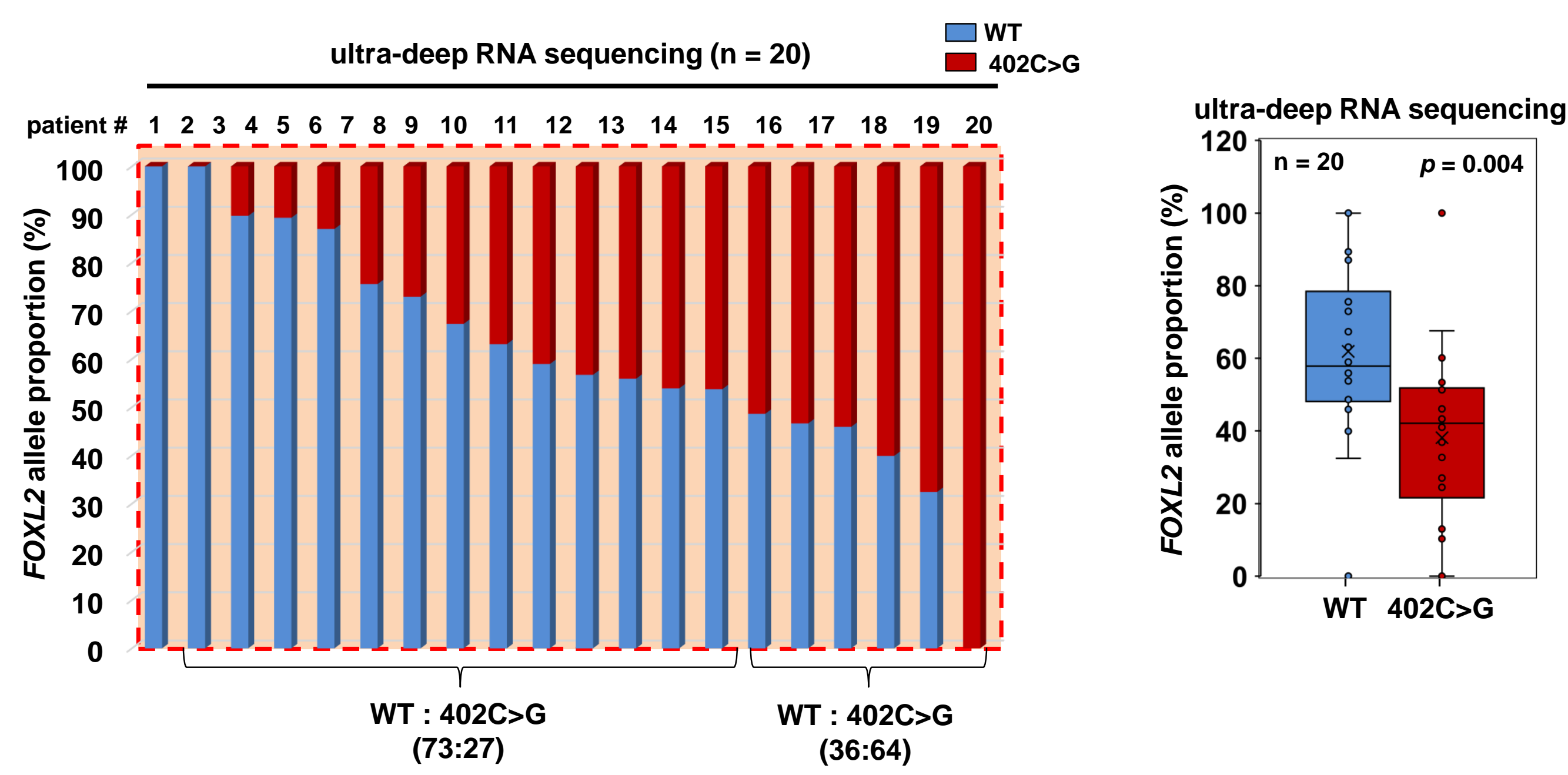

B

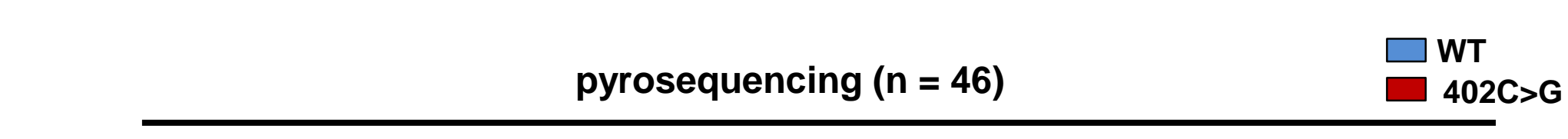

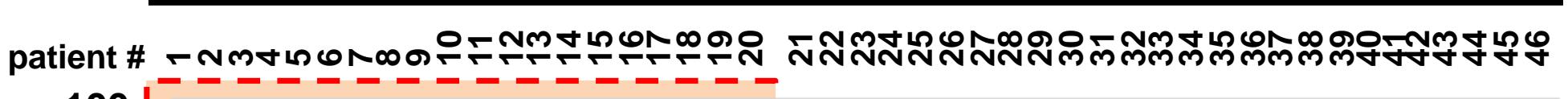
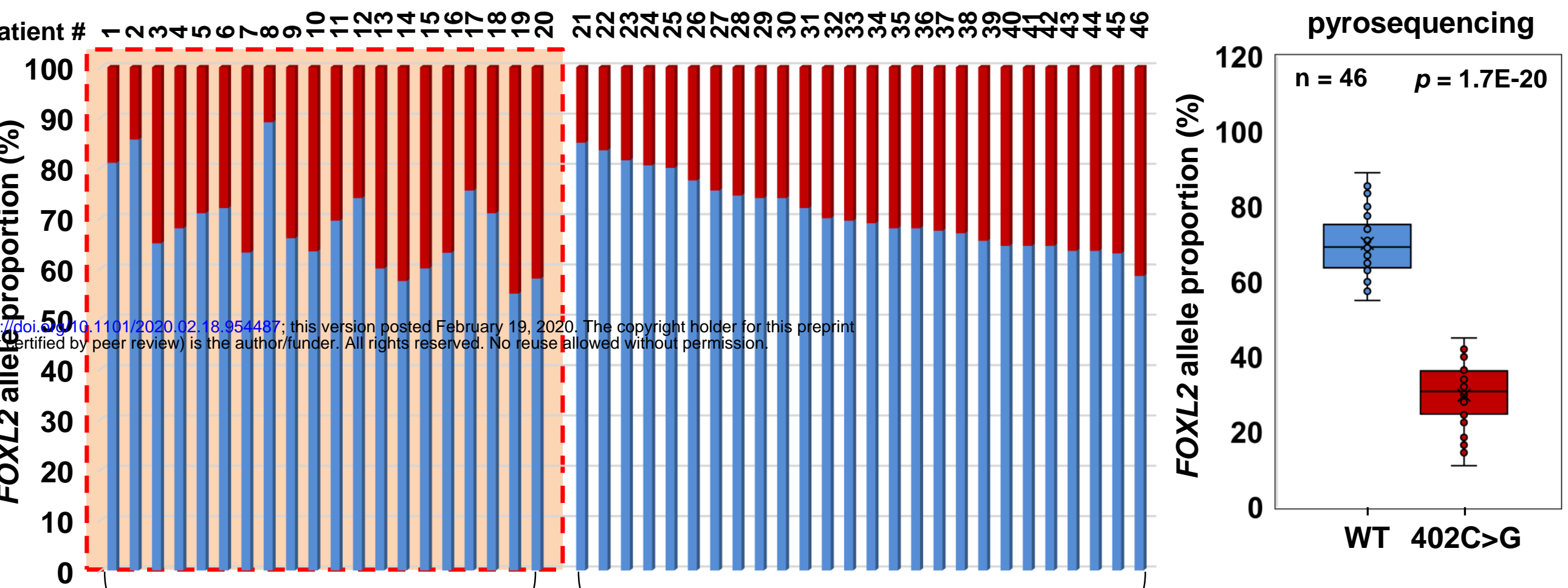

C

WT : $402 C>G$

(68:32)

WT : 402C>G

(71:29)
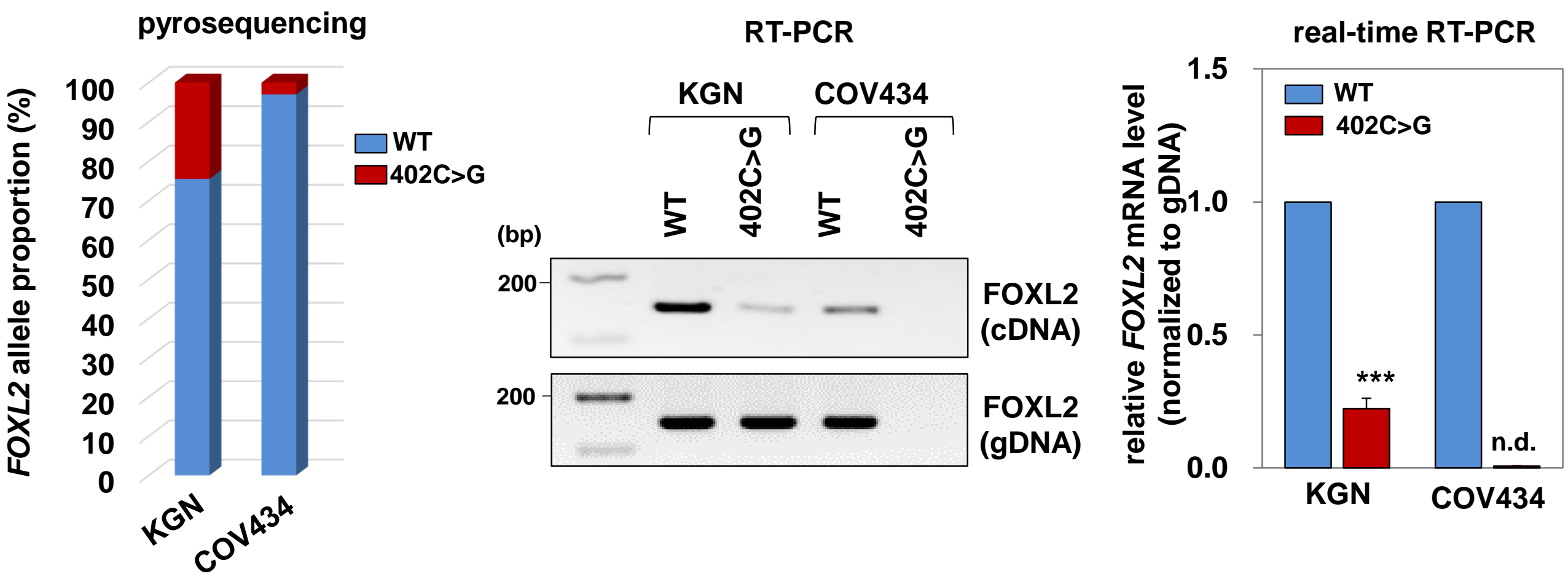

D
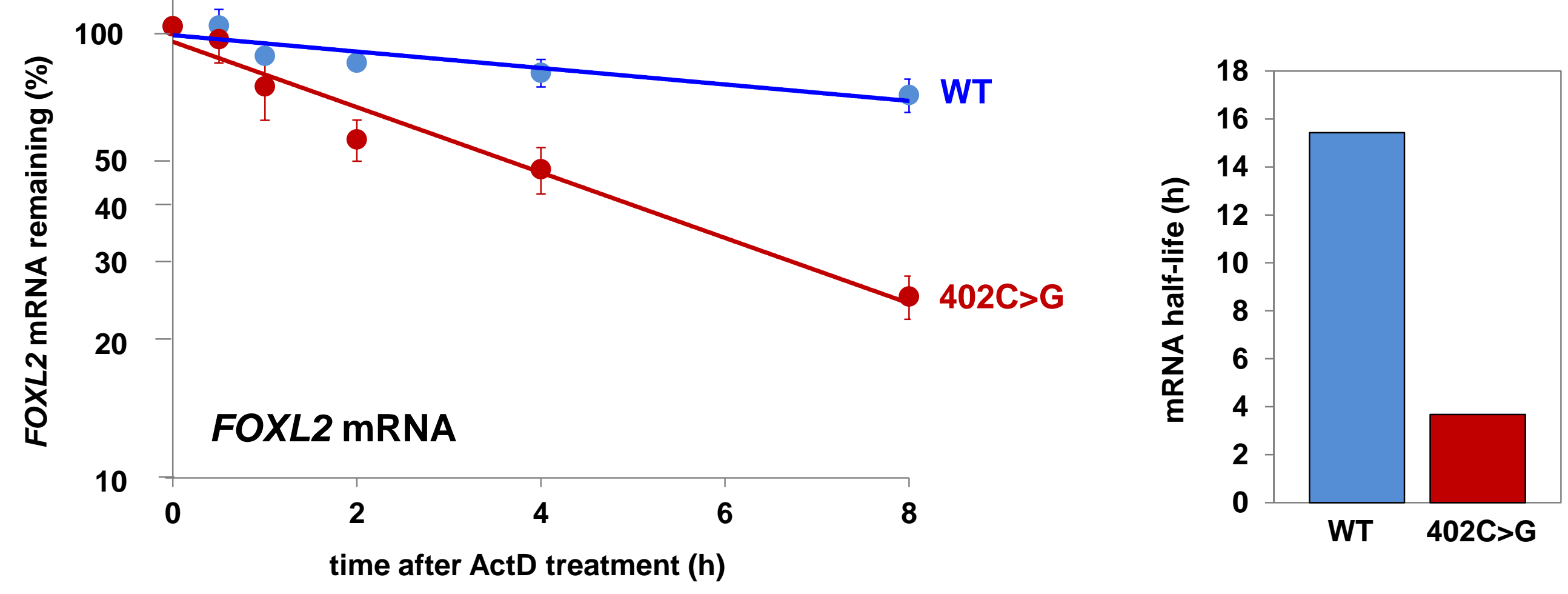
A

B

C
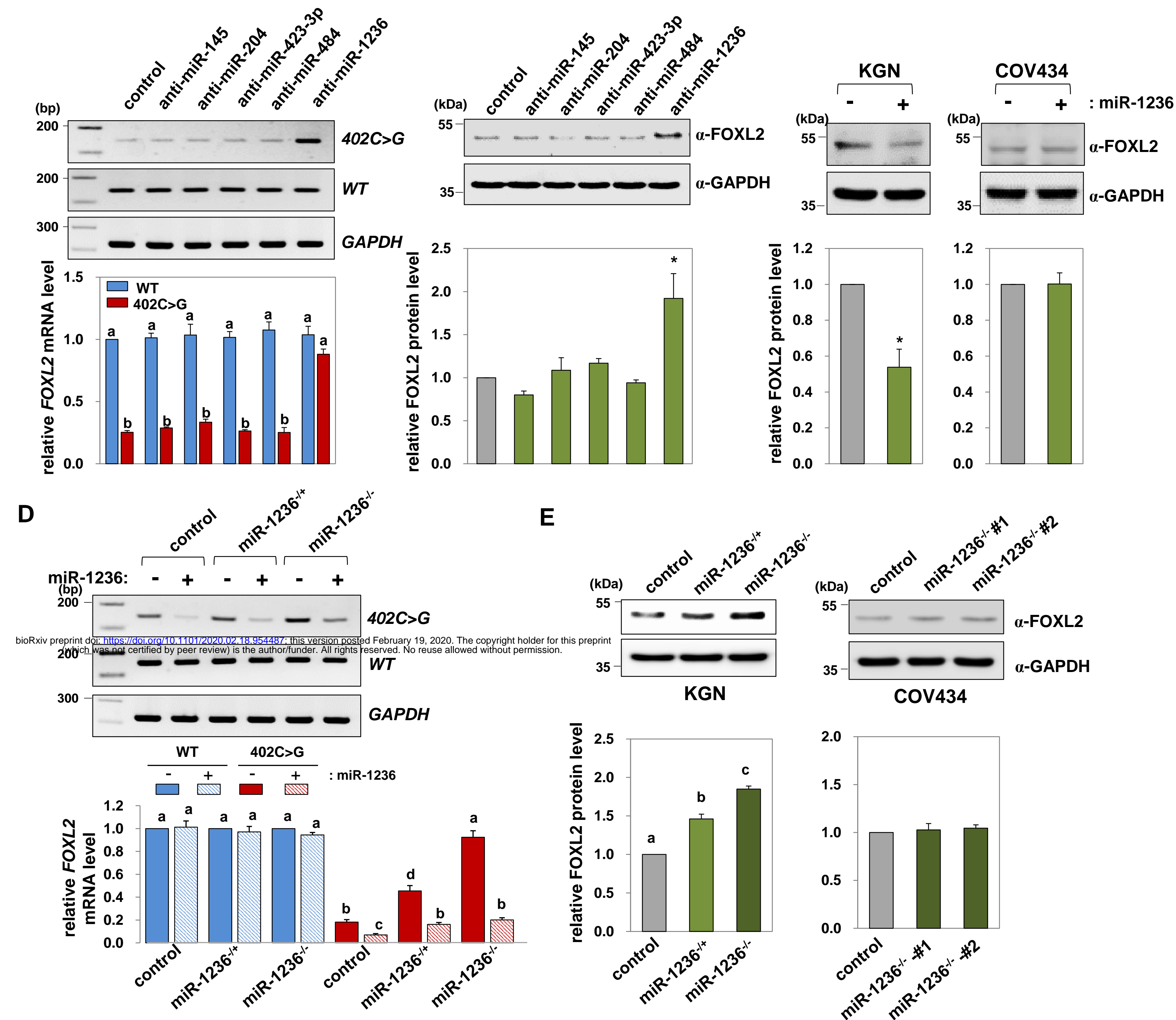

E
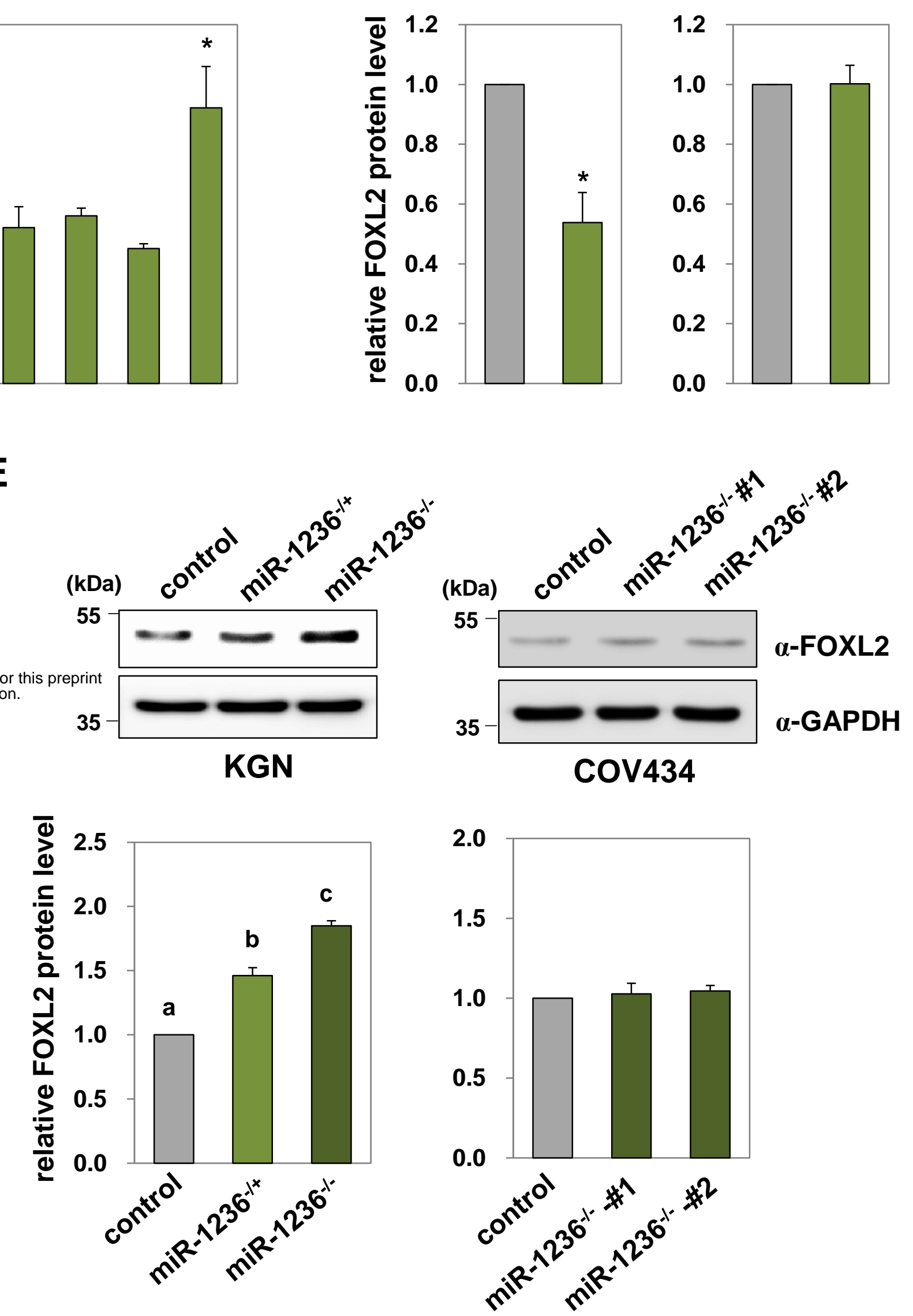
A

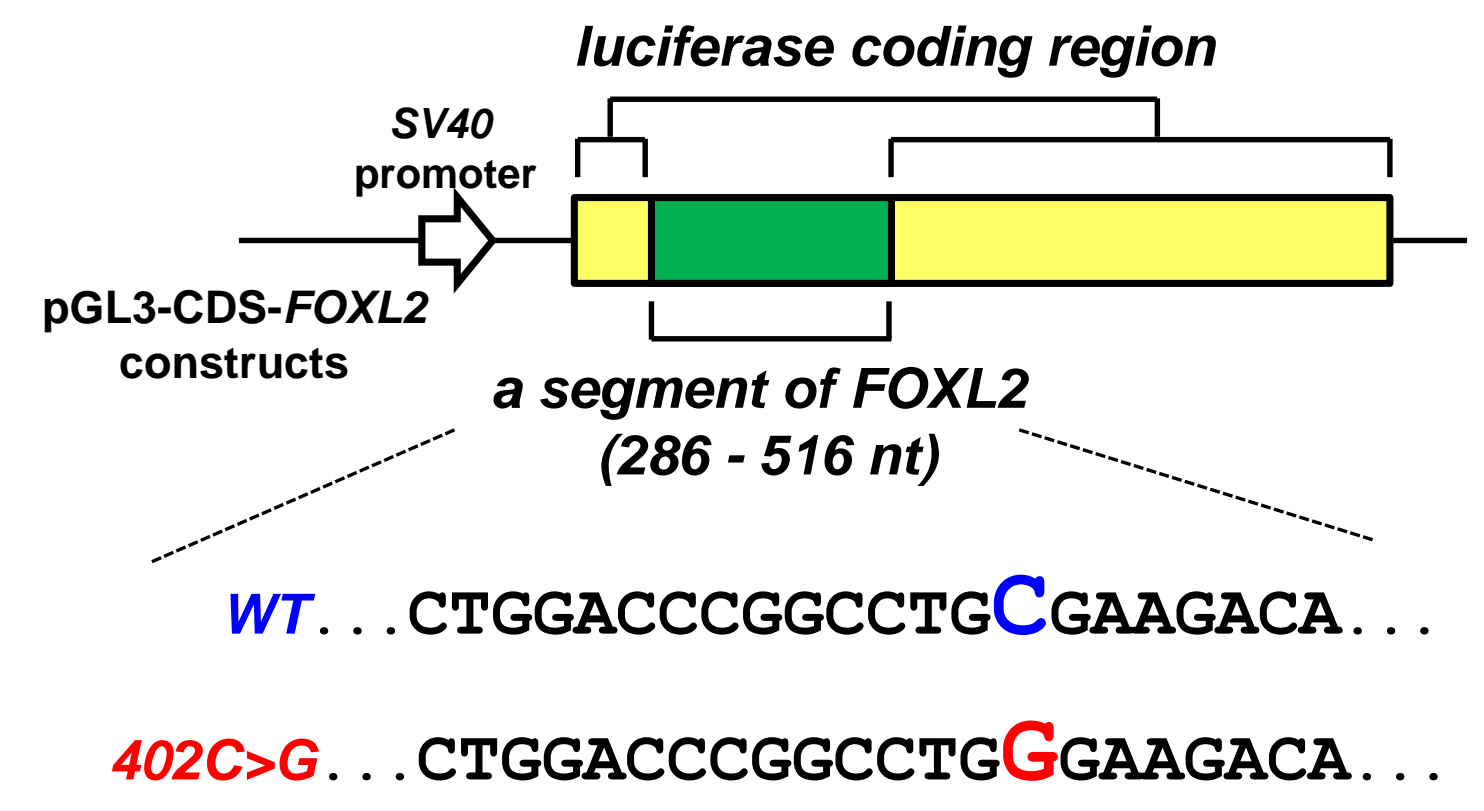

C

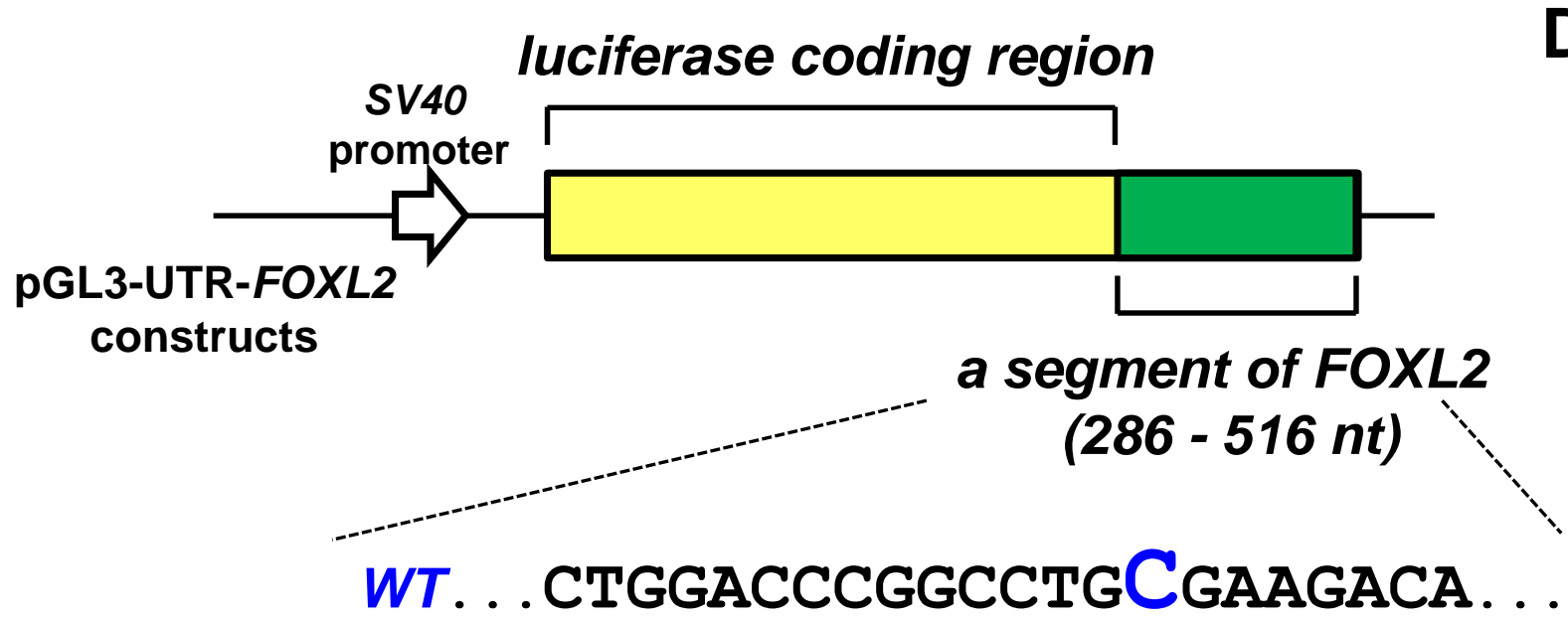

402C>G 2 GTGGACCCGGCCTGGGAAGACA.

E

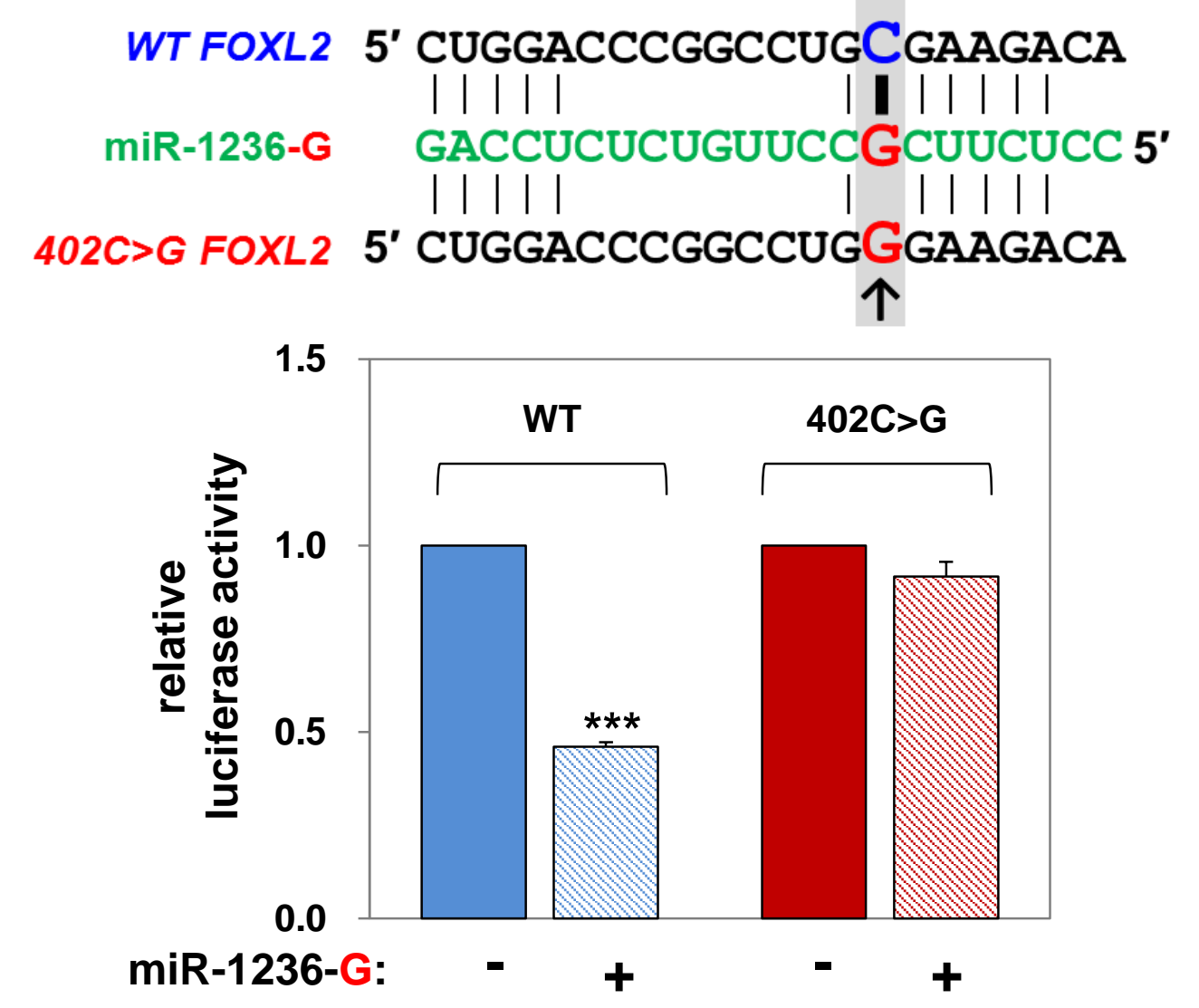

G

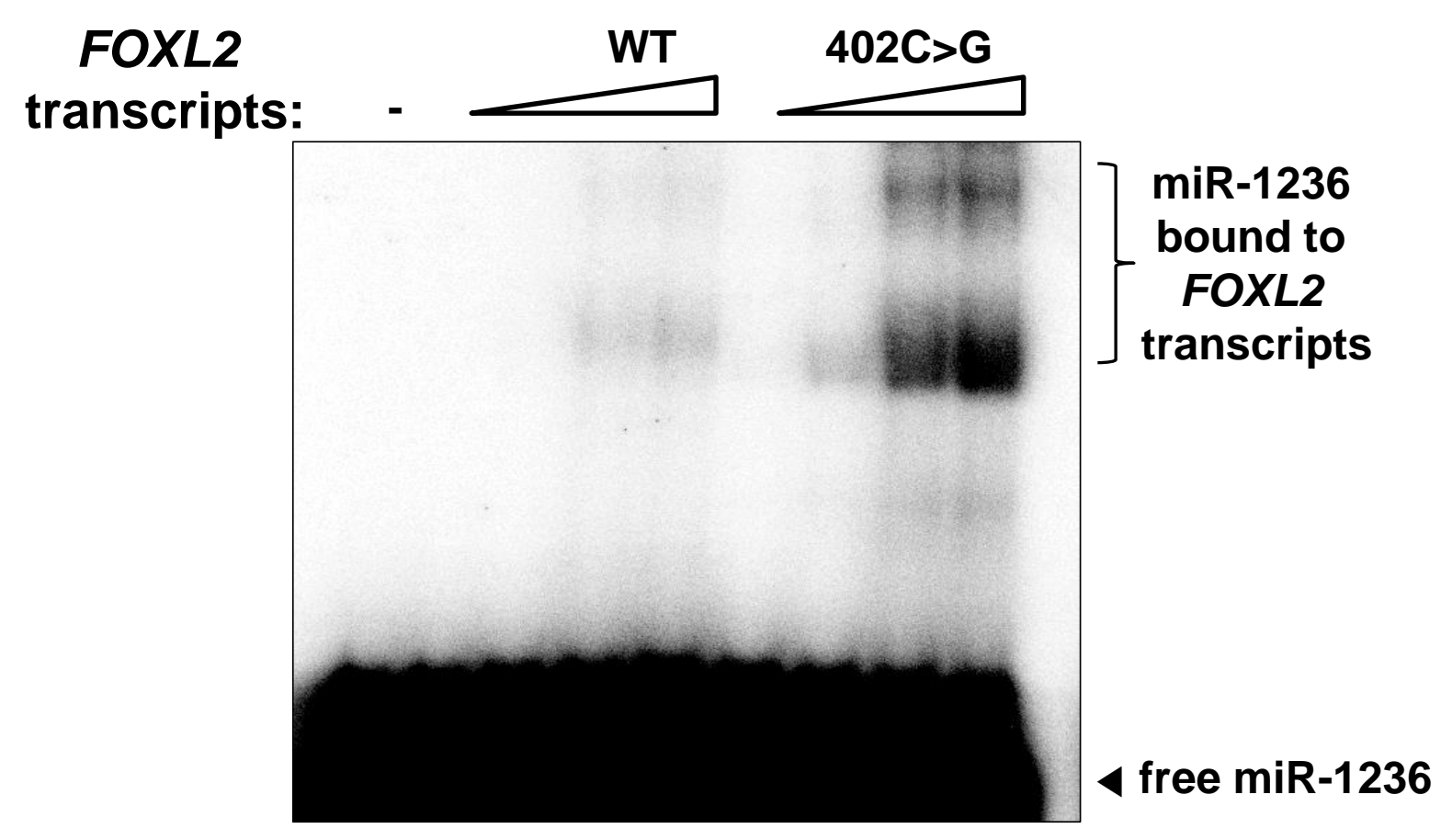

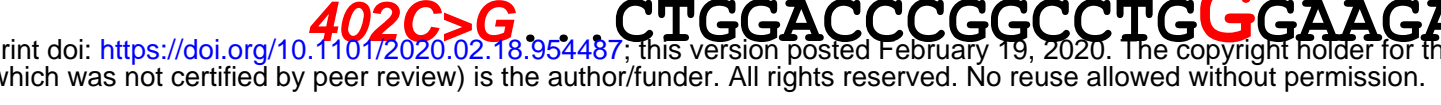
T236-G:
B WT FOXL2 5' CUGGACCCGGCCUGCGAAGACA $11|1|$
miR-1236 GACCUCUCUGUUCCCCUUCUCC 5'
$1|1| \mid$ 402C>G FOXL2 5' CUGGACCCGGCCUGGGAAGACA

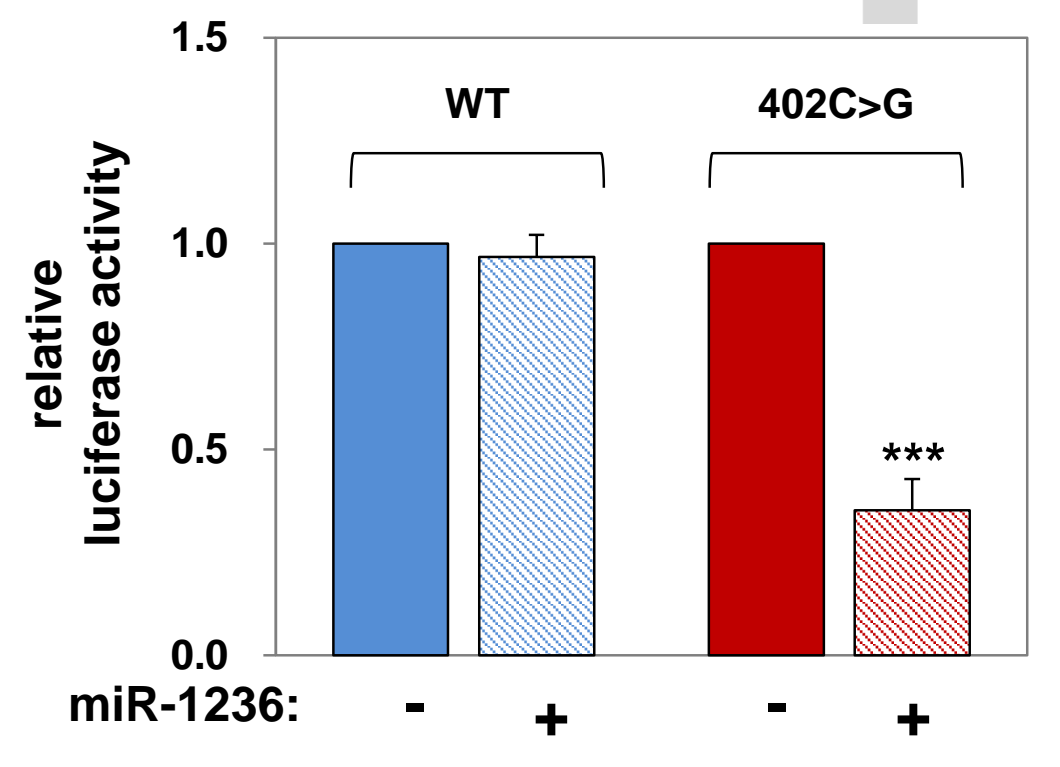

D

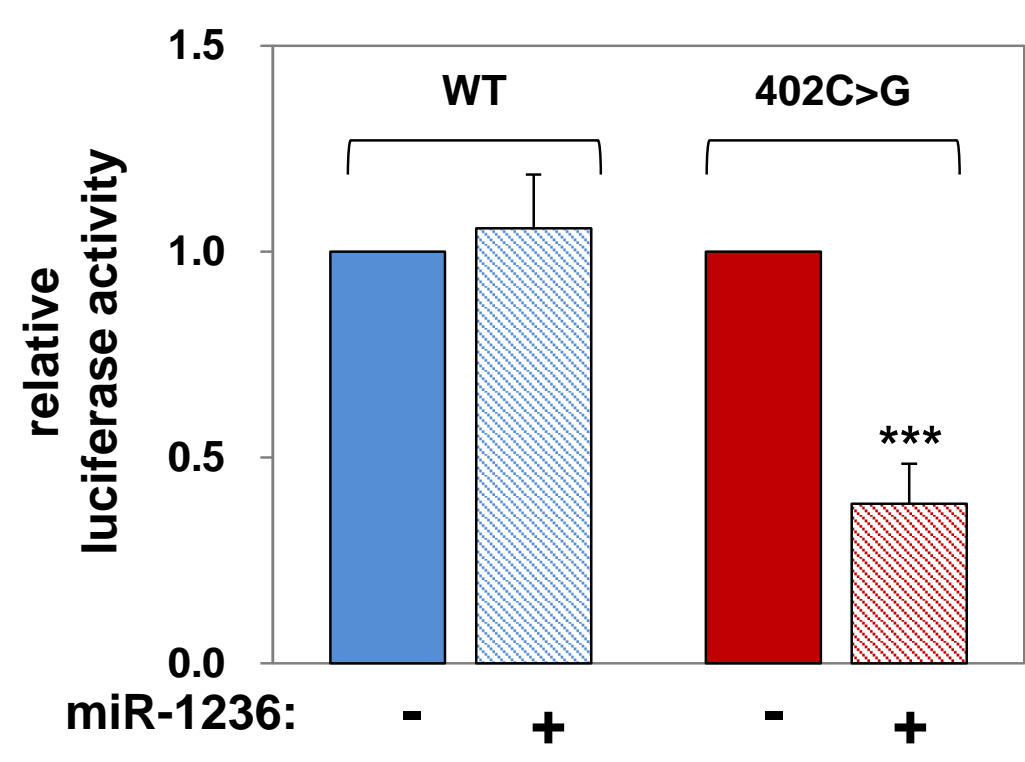

$\mathbf{F}$

WT FOXL2 5 ' CUGGACCCGGCCUGCGAAGACA ||||| | ||||| miR-1236-U GACCUCUCUGUUCCUCUUCUCC 5' ||||| | ||||| 402C>G FOXL2 5' CUGGACCCGGCCUGGGAAGACA

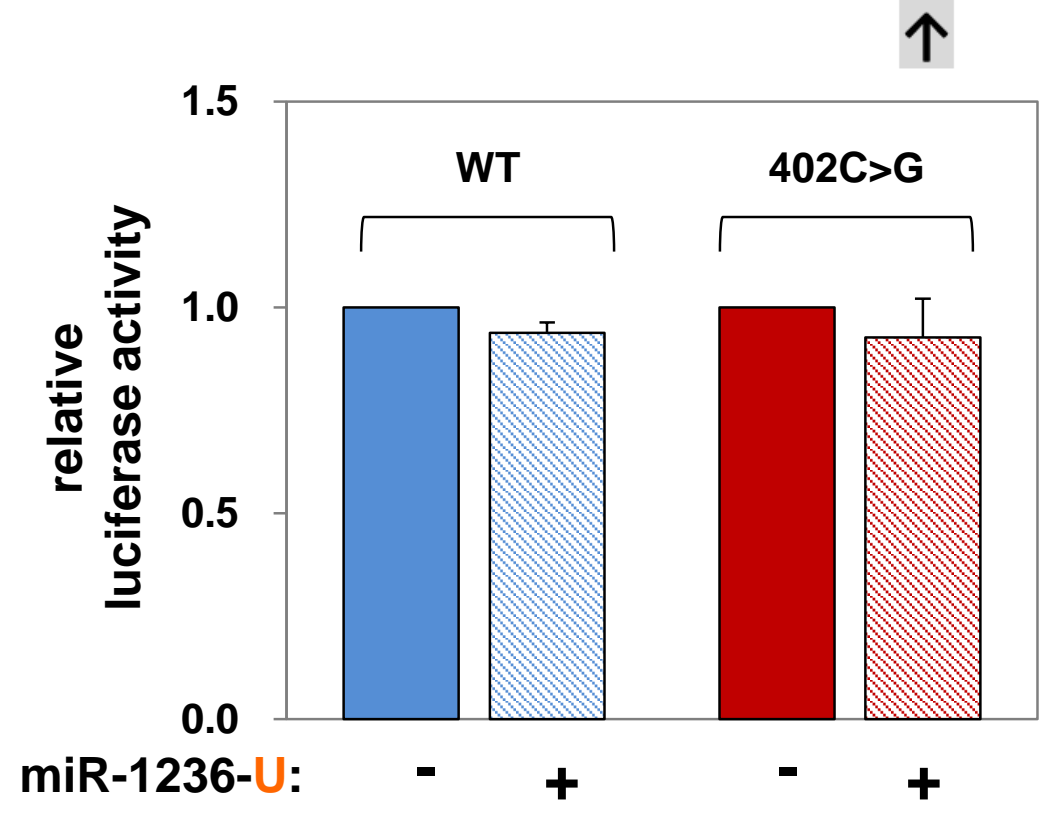

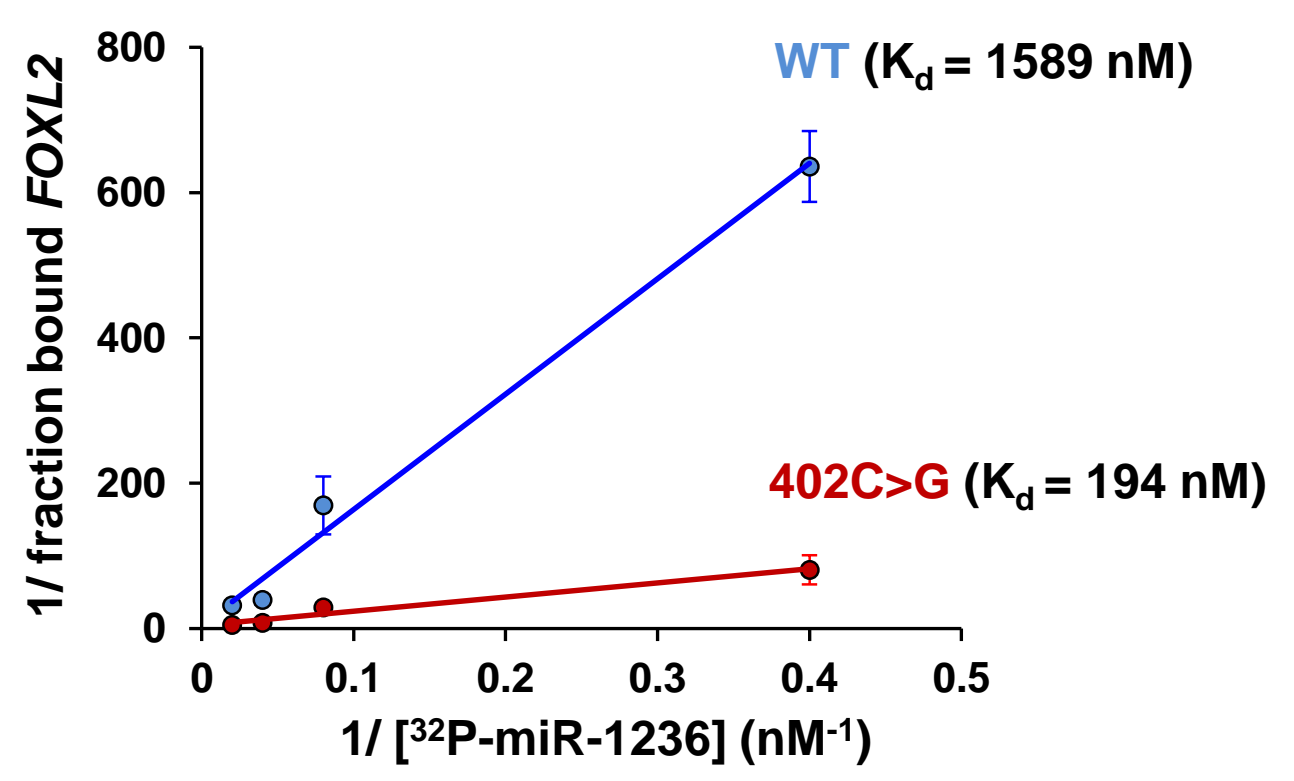


A

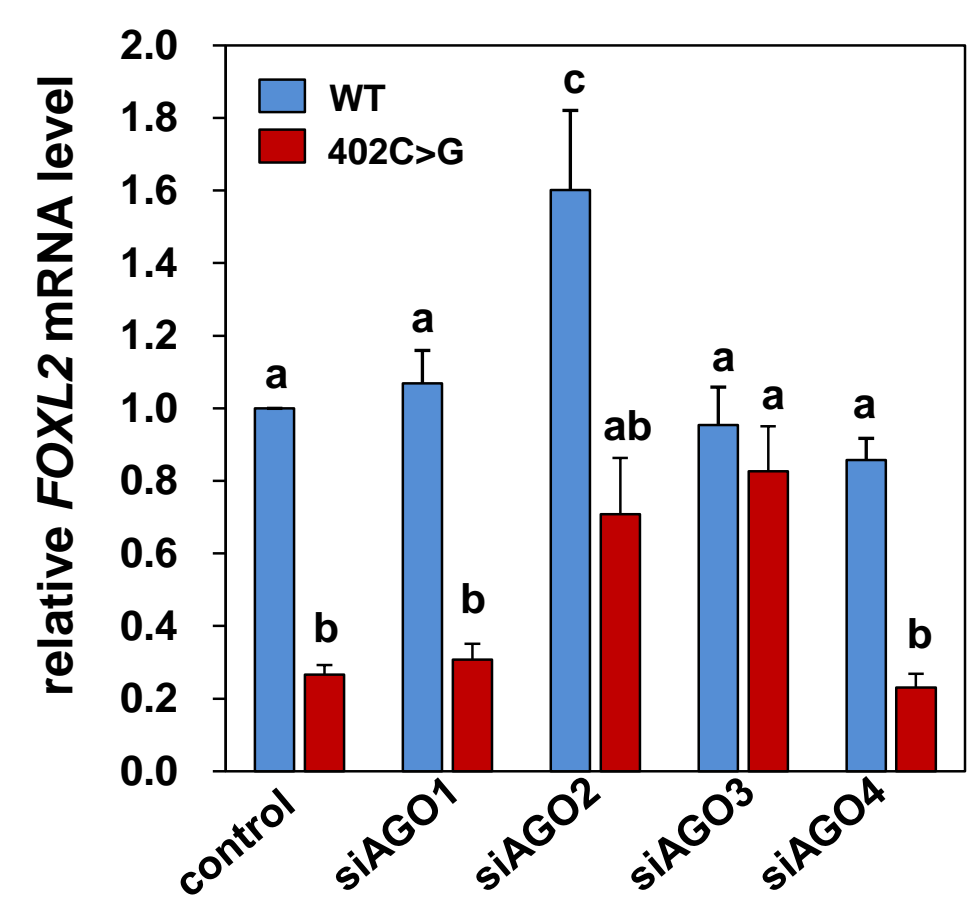

B
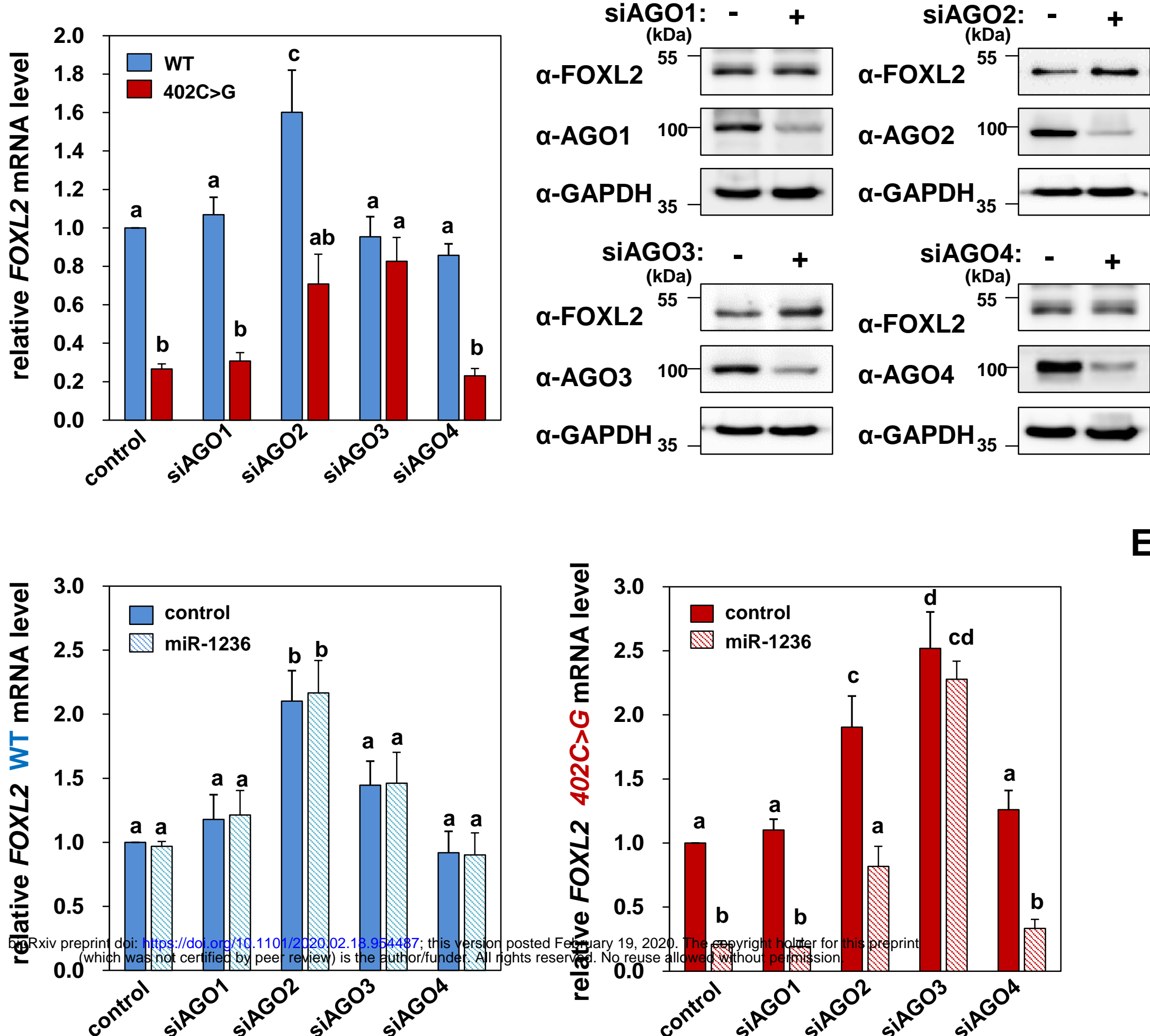

D

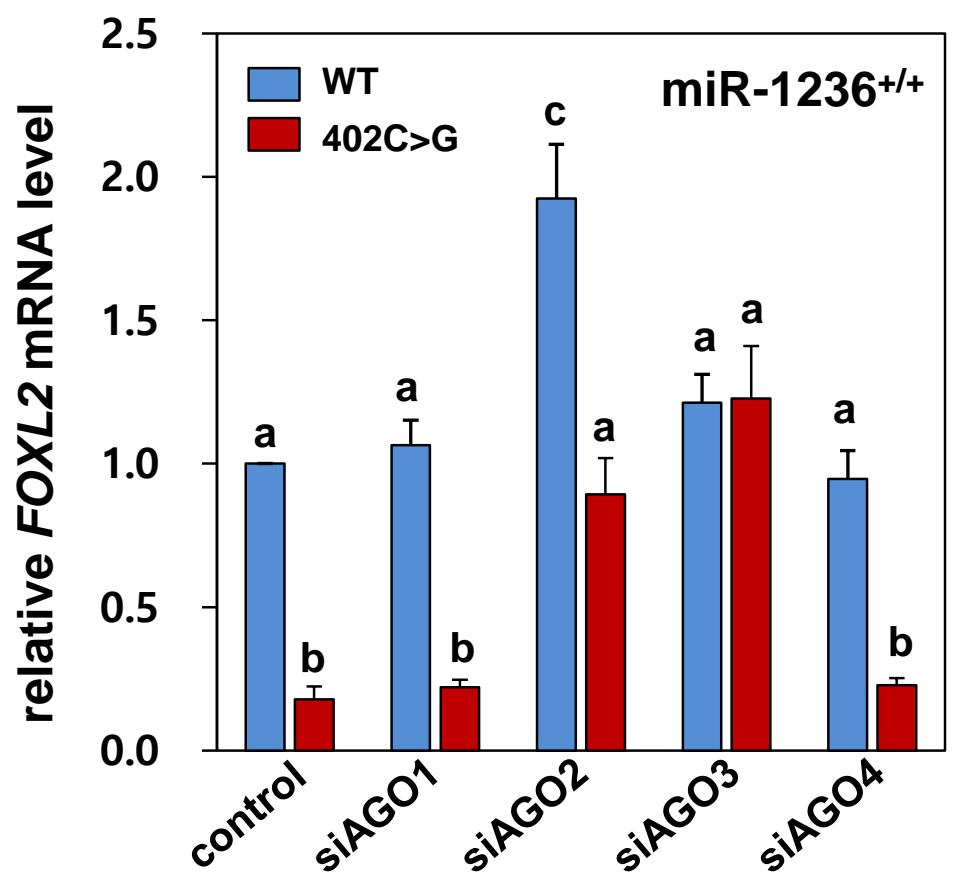

$\mathbf{F}$

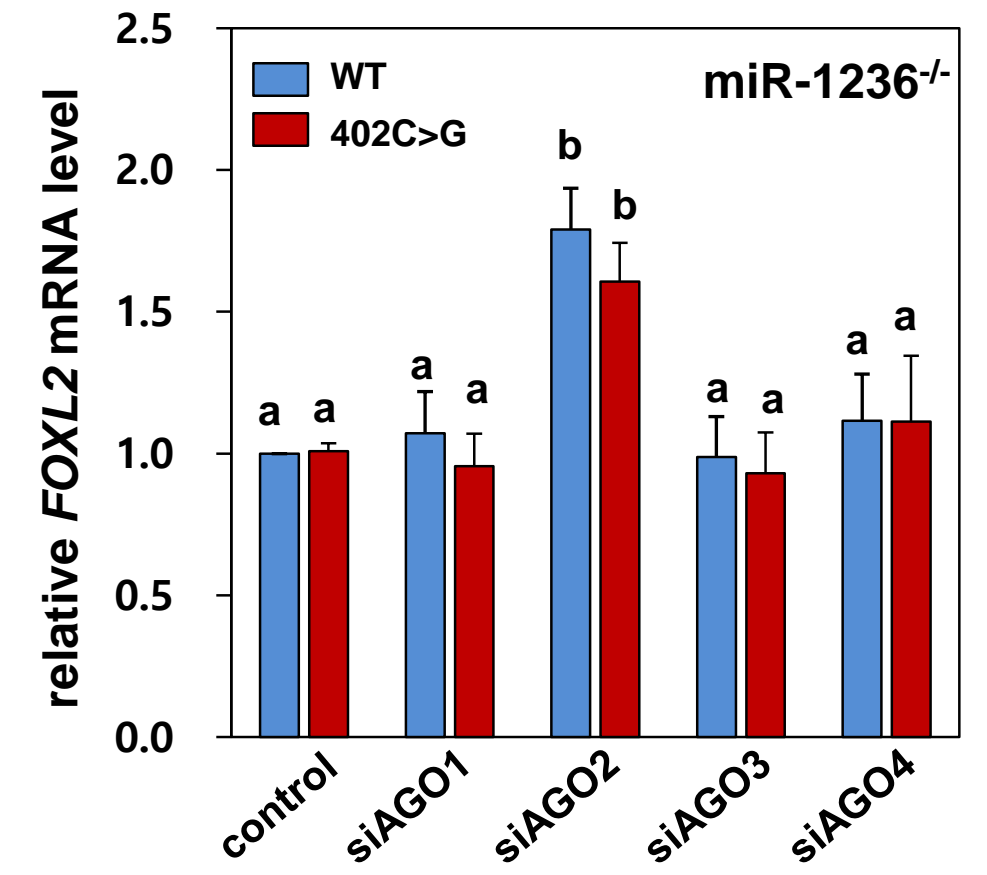

E
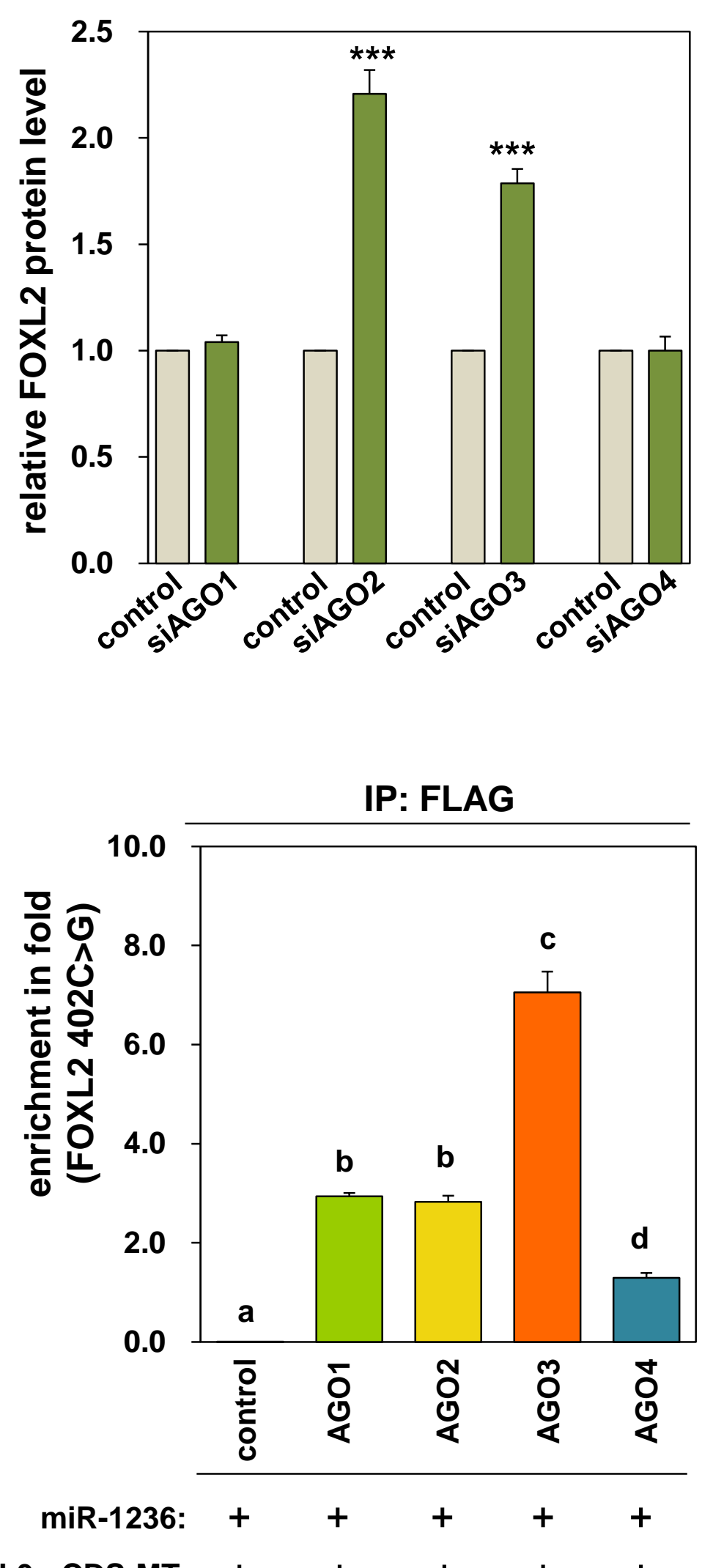

PGL3C-CDS-MT: +++++

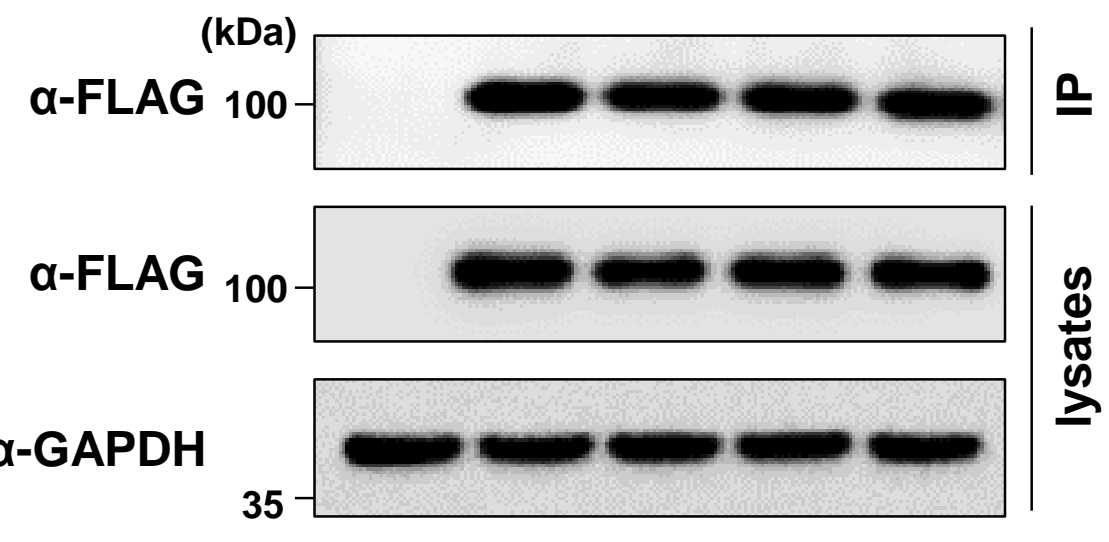

G

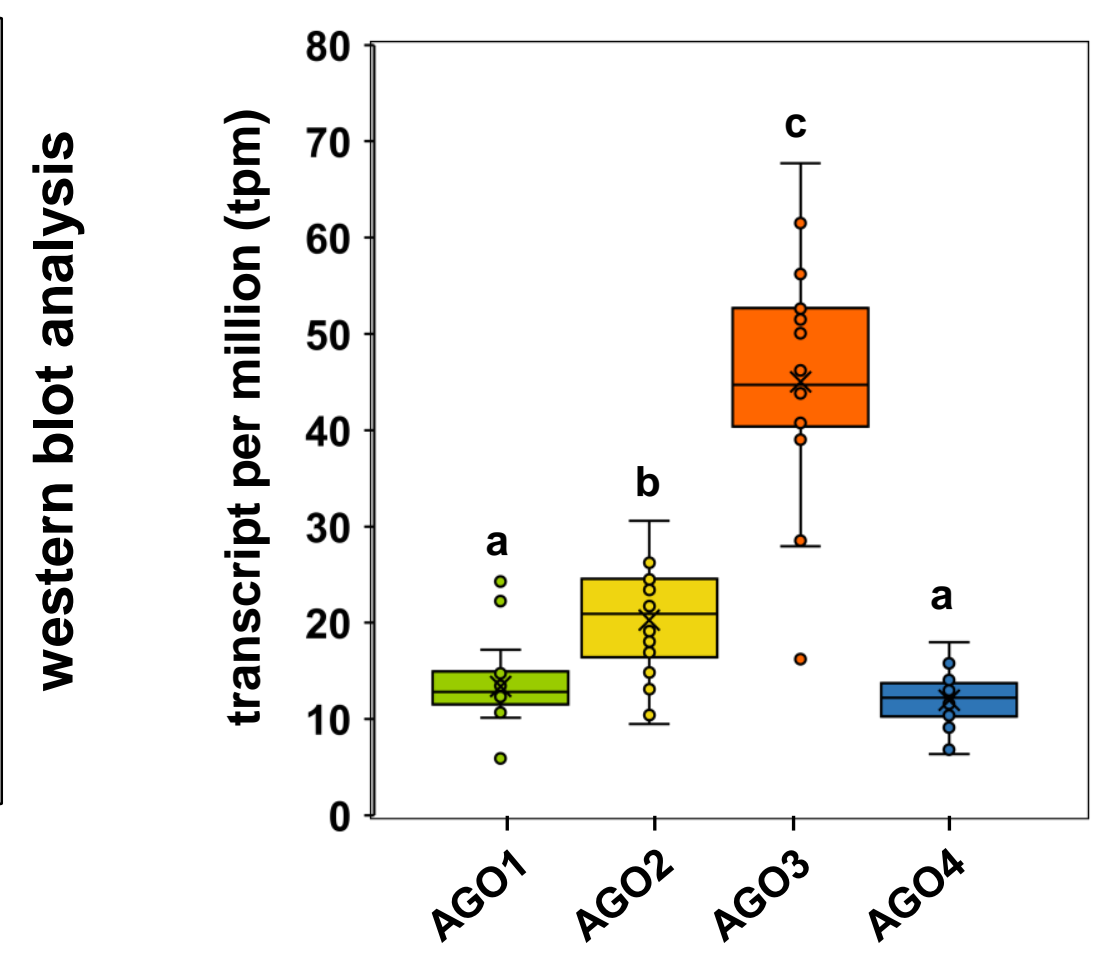


A

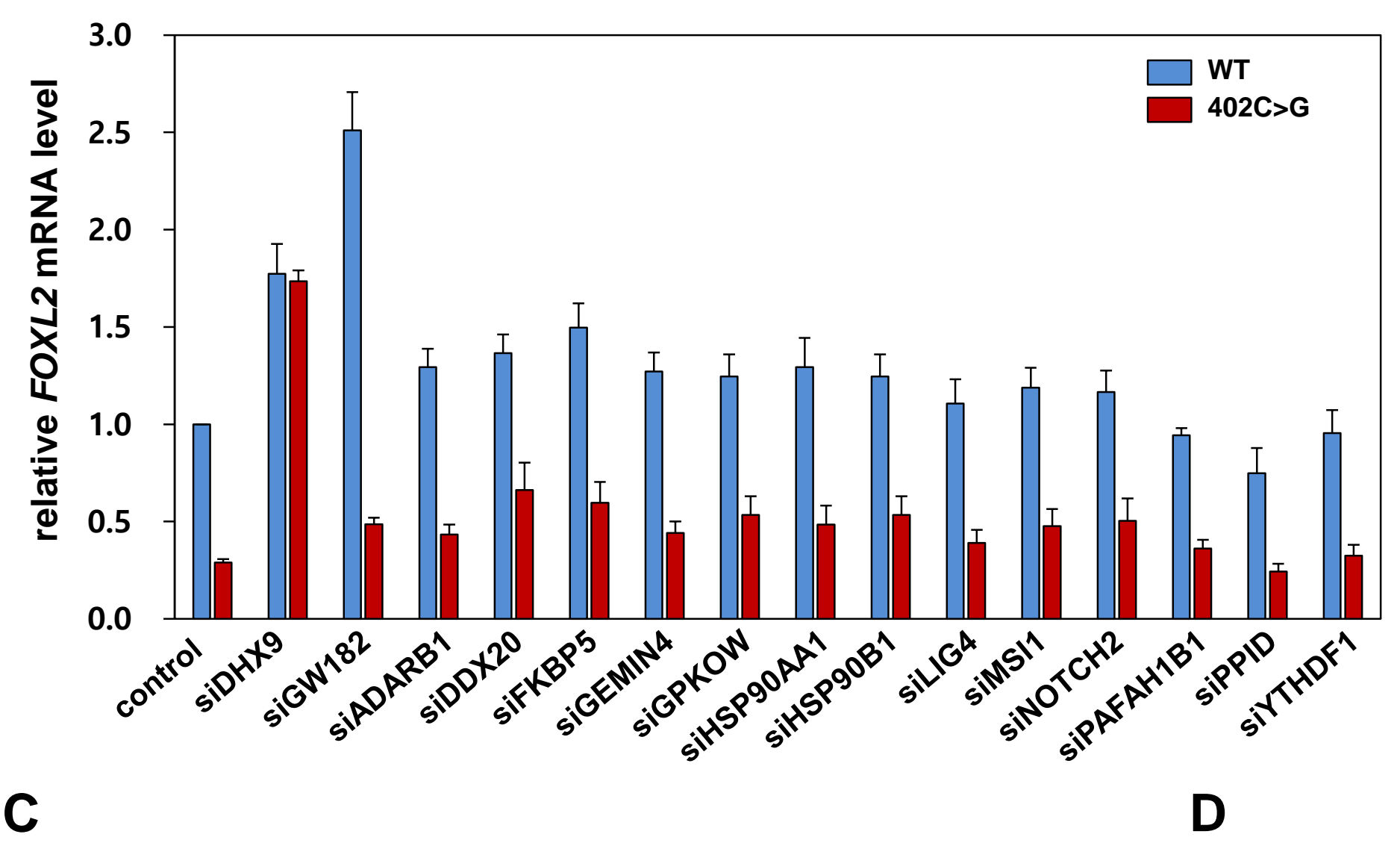

B

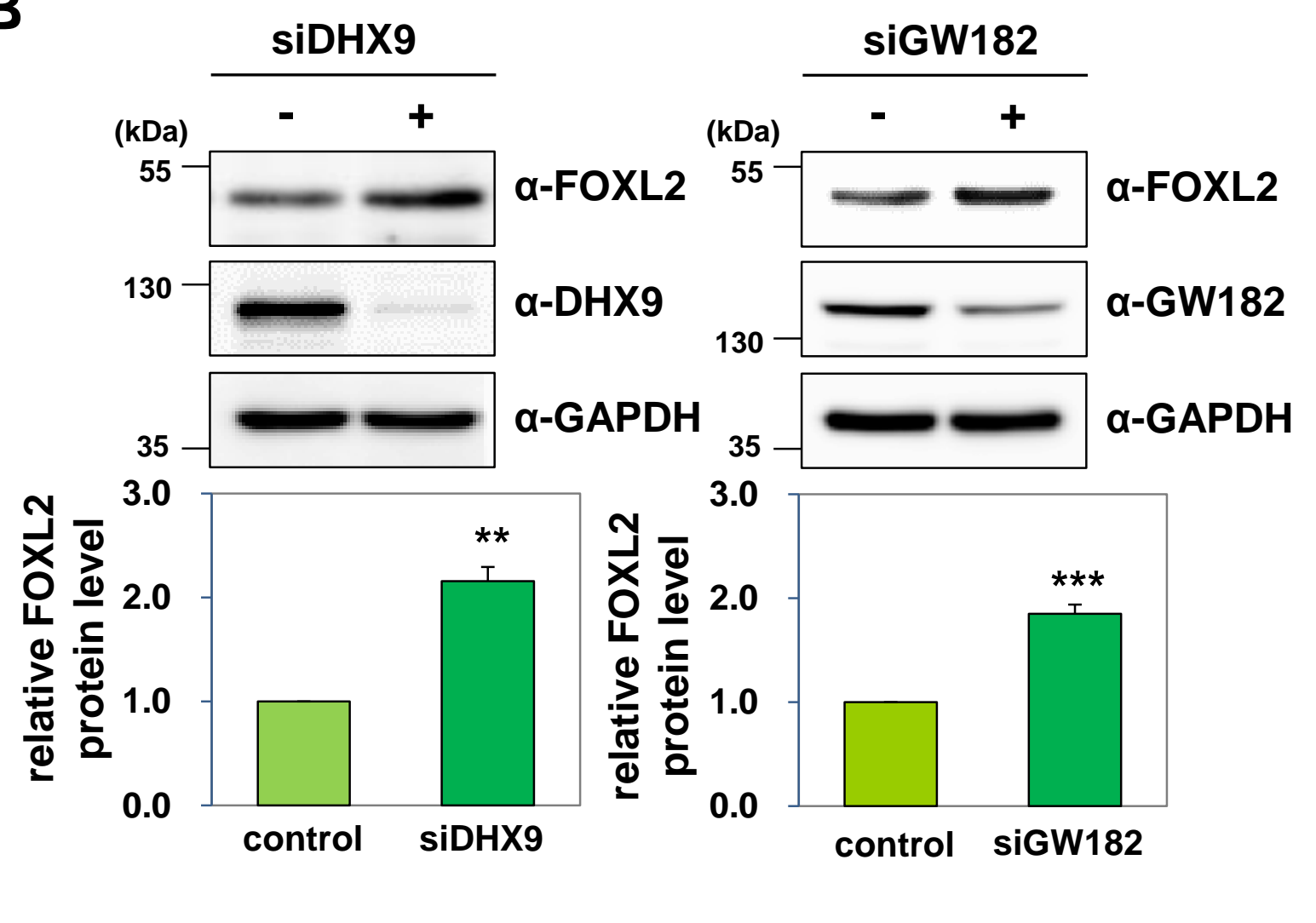

FLAG-tagged

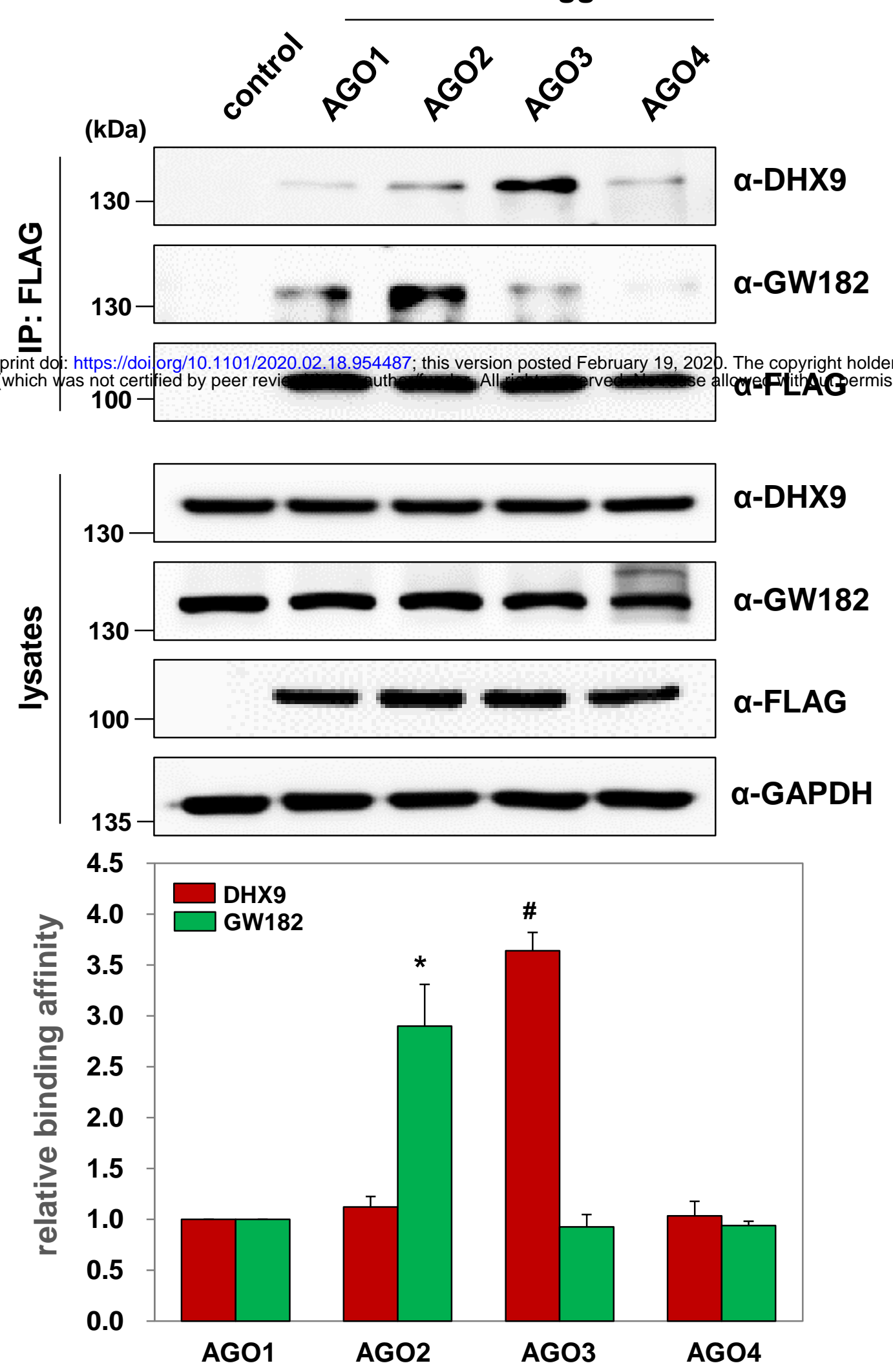

immunoprecipitates
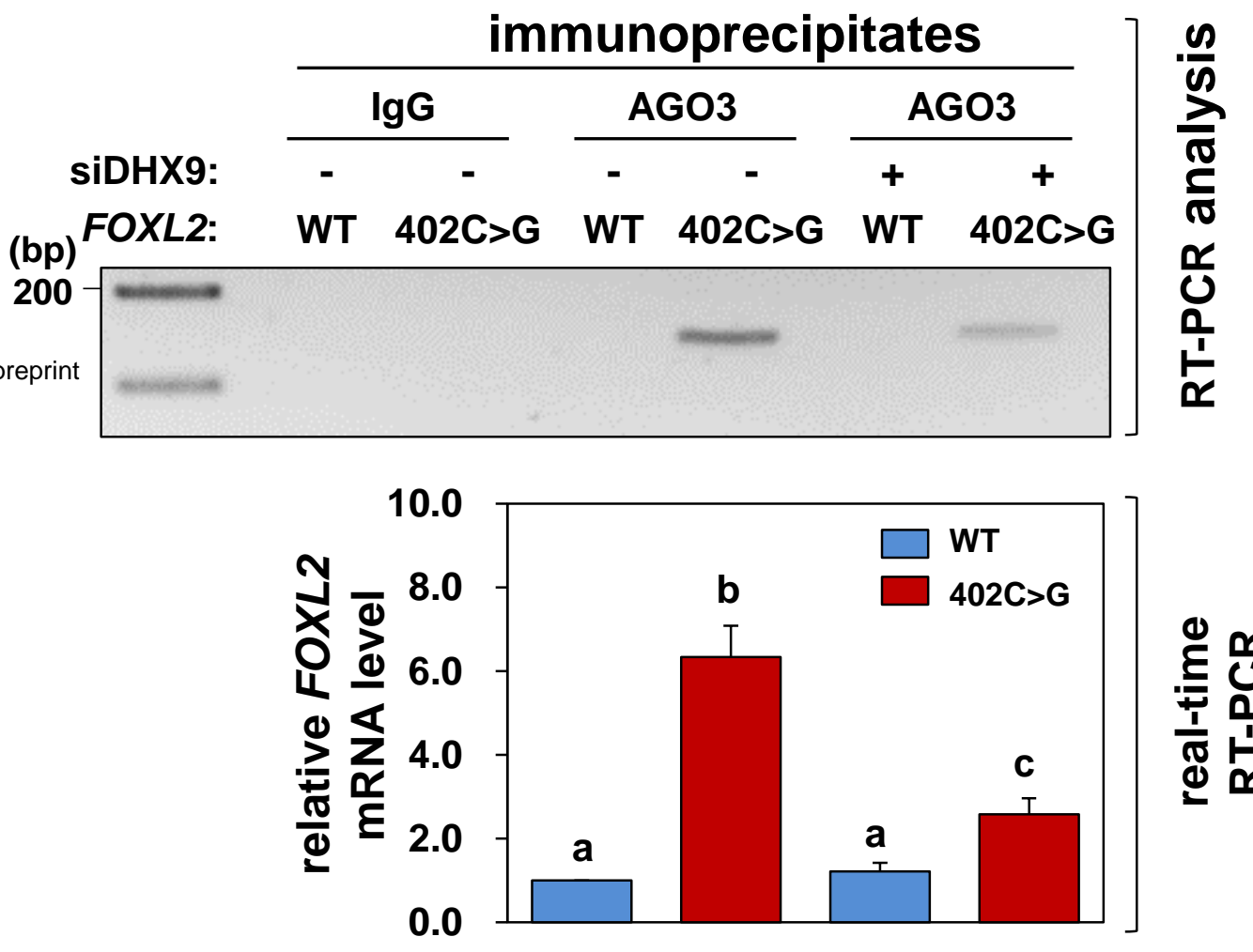

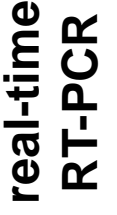

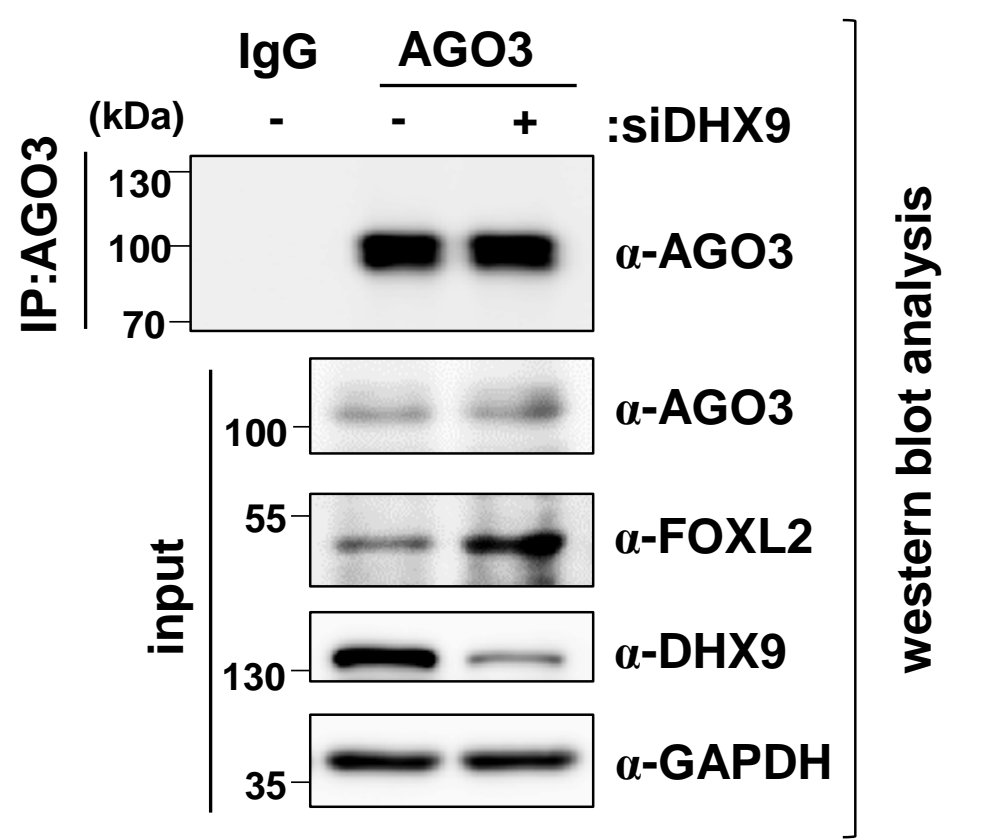


A

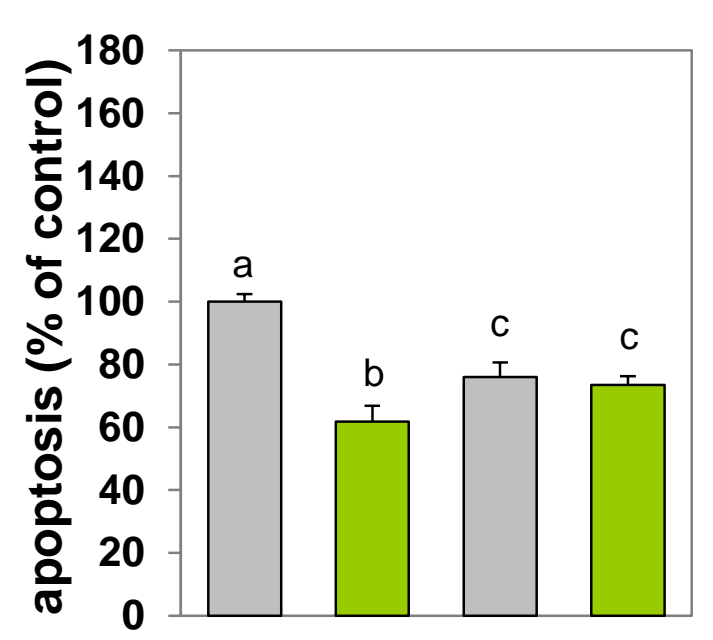

miR-1236: siFOXL2:
B

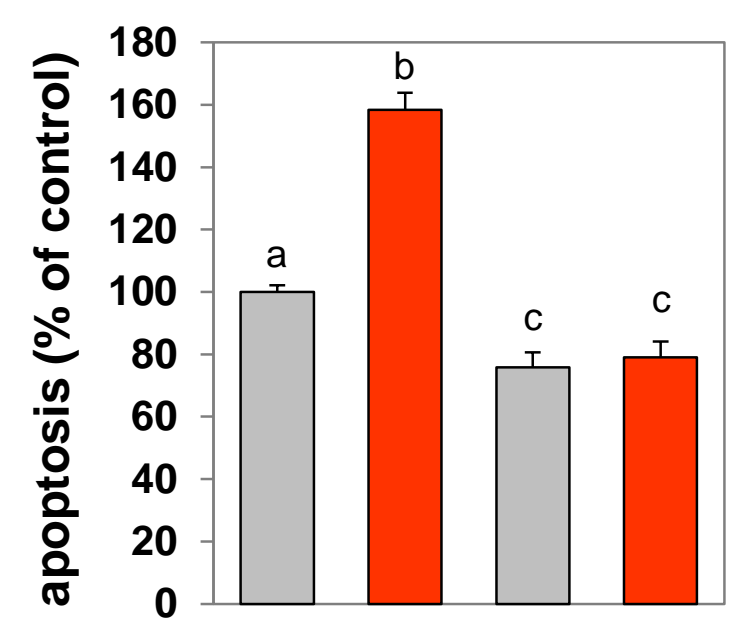

miR-1236:
C

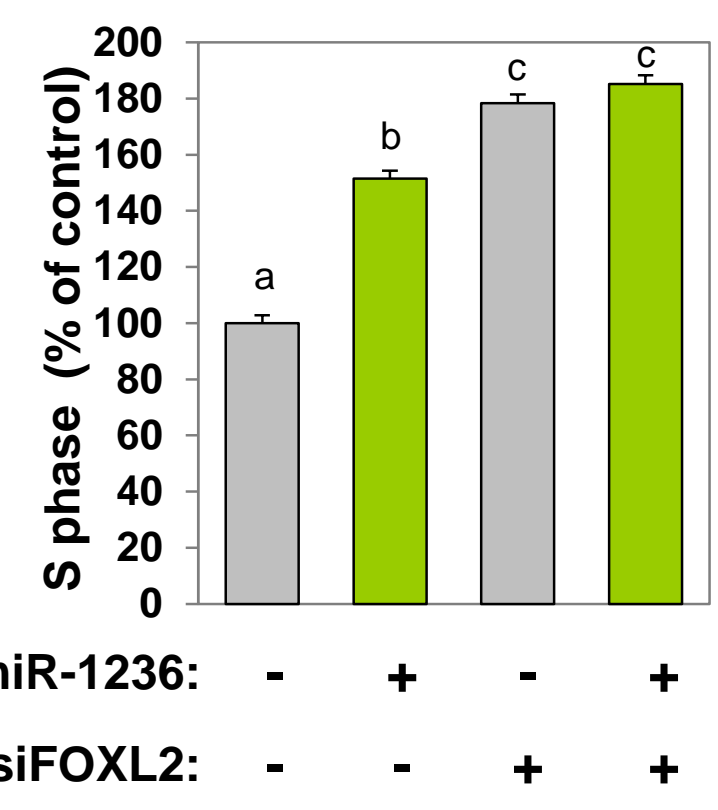

D

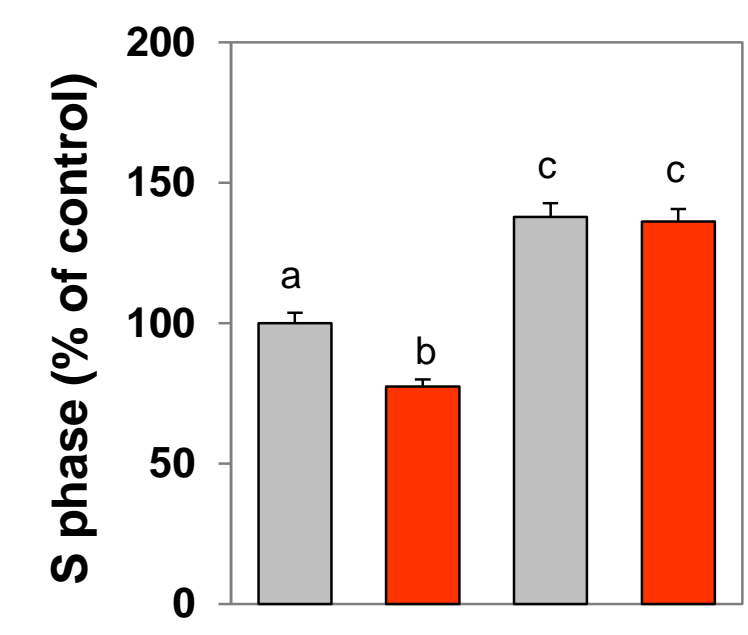

miR-1236:

SiFOXL2:
E
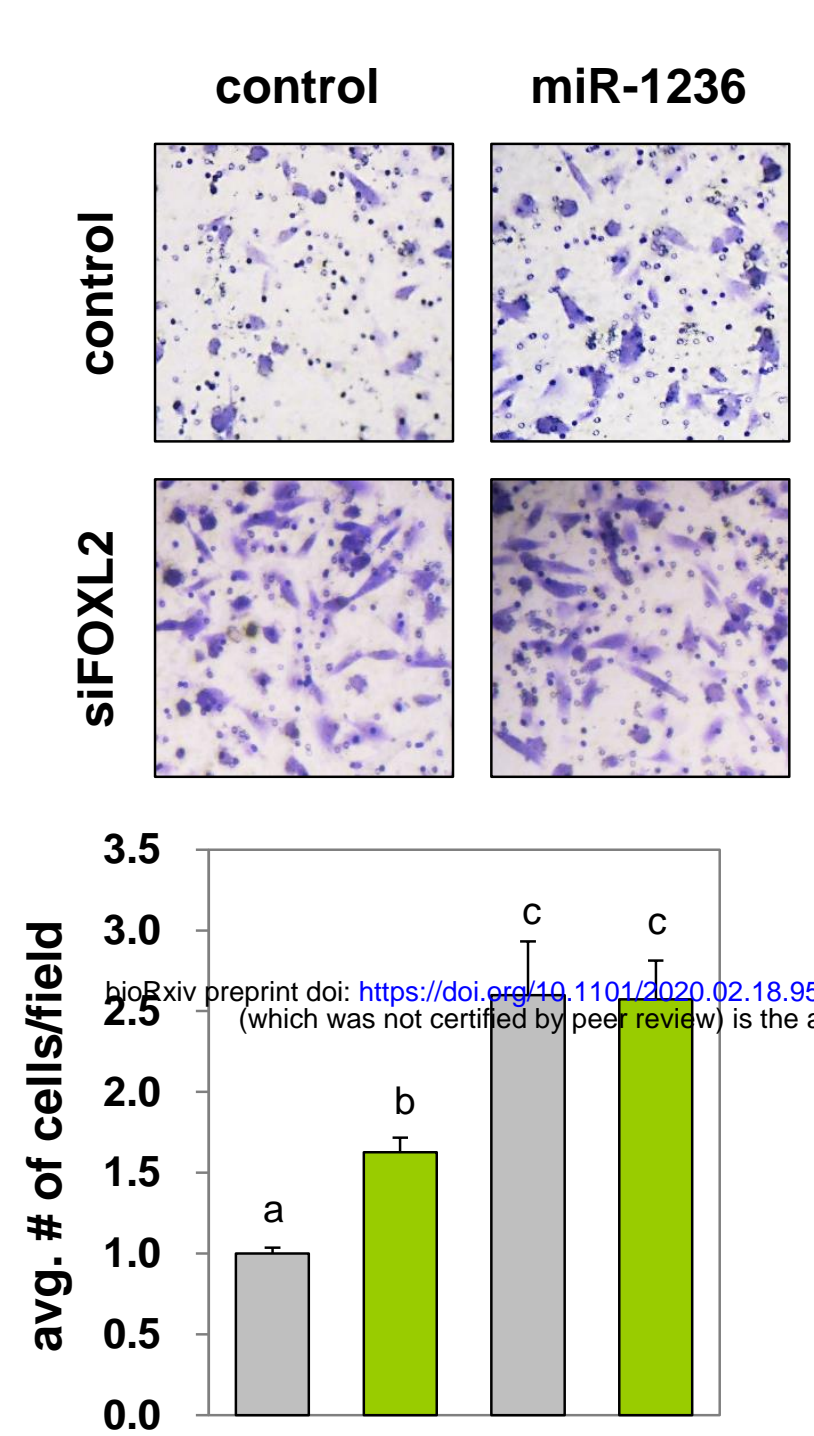

miR
$\mathbf{F}$

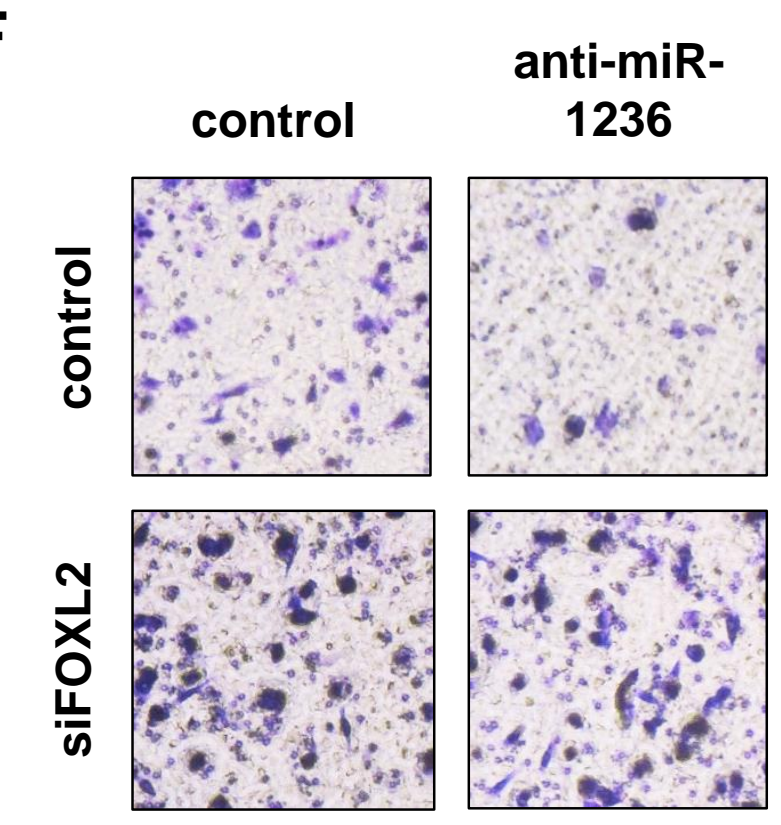

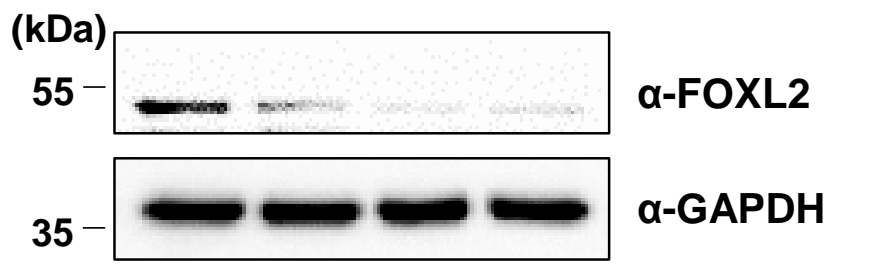

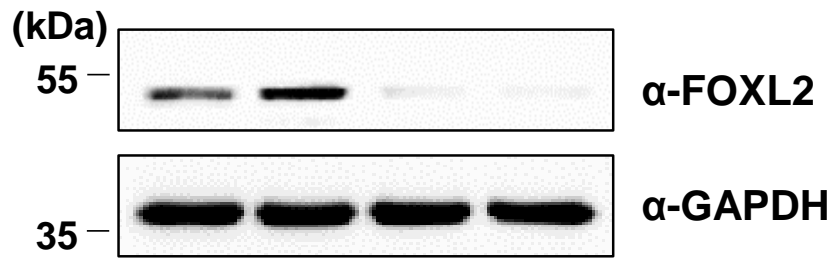

G

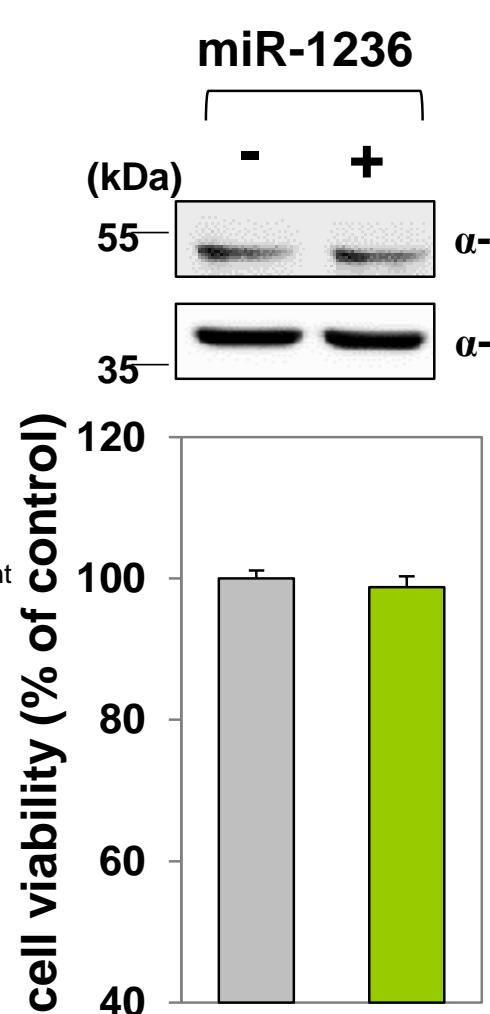

miR-1236:

anti-miR-1236:

J

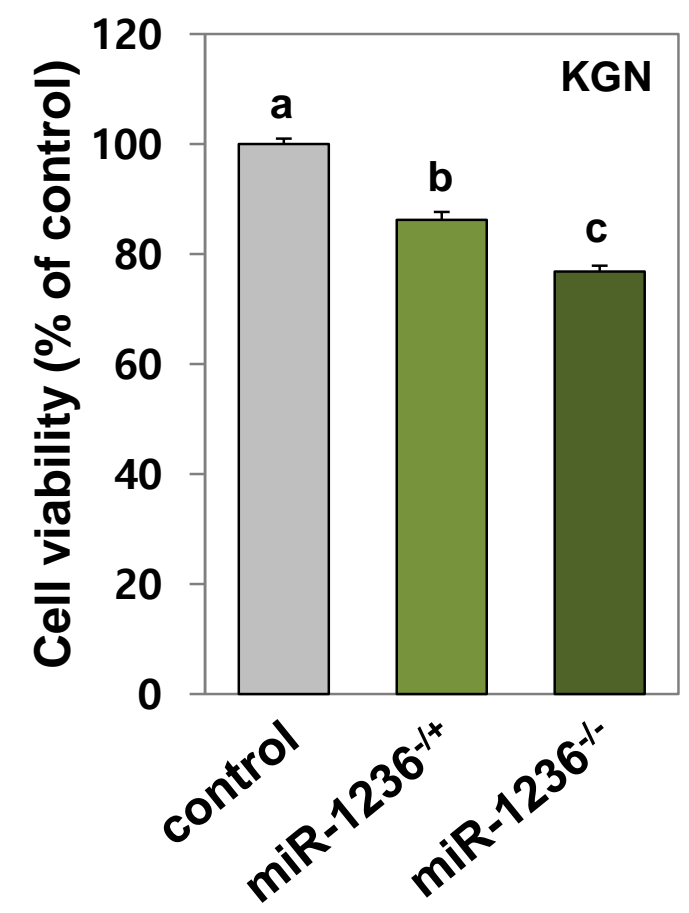

siFOXL2:

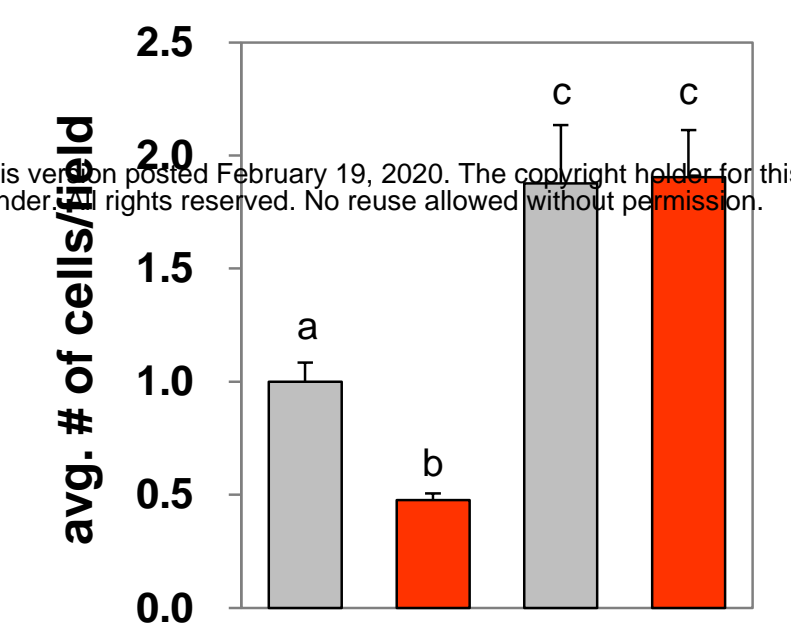

2.

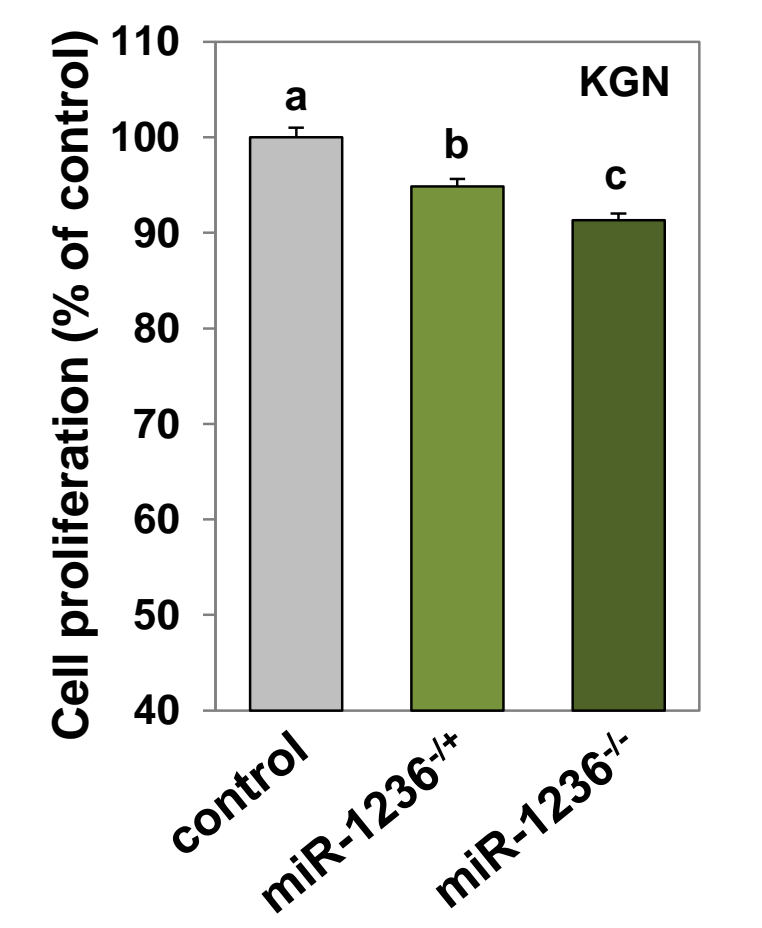

K

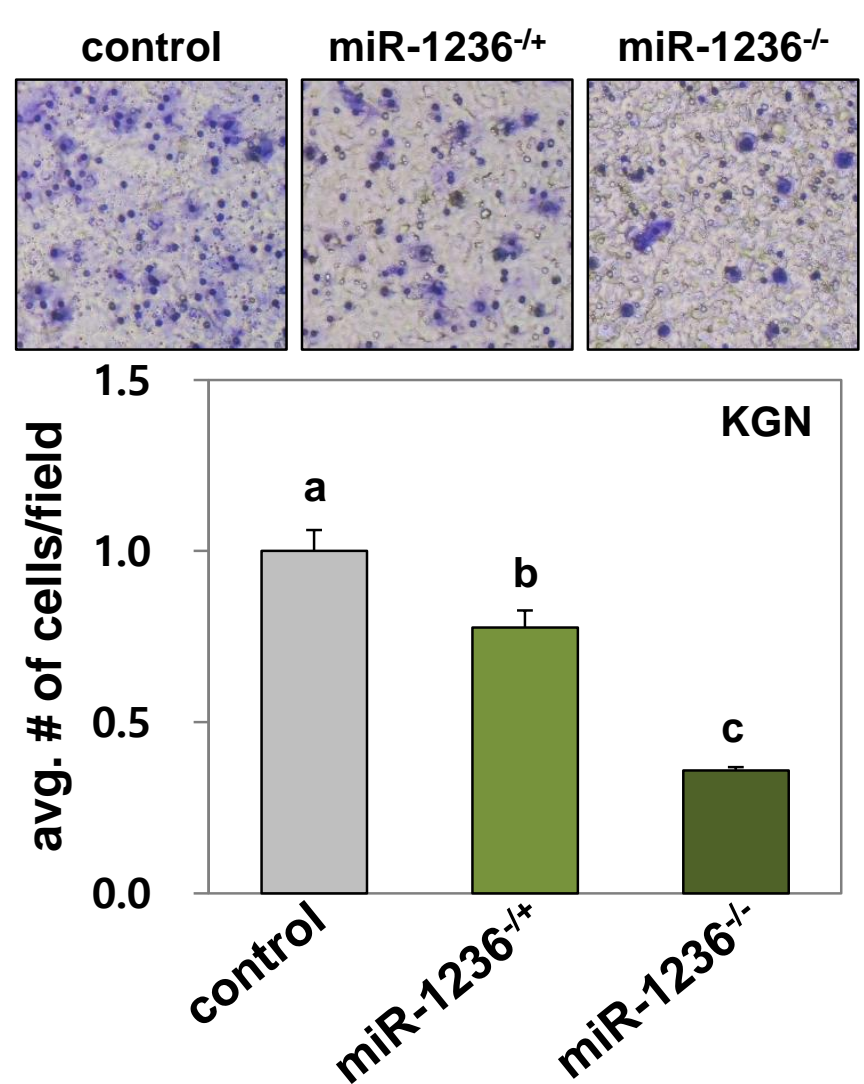

H

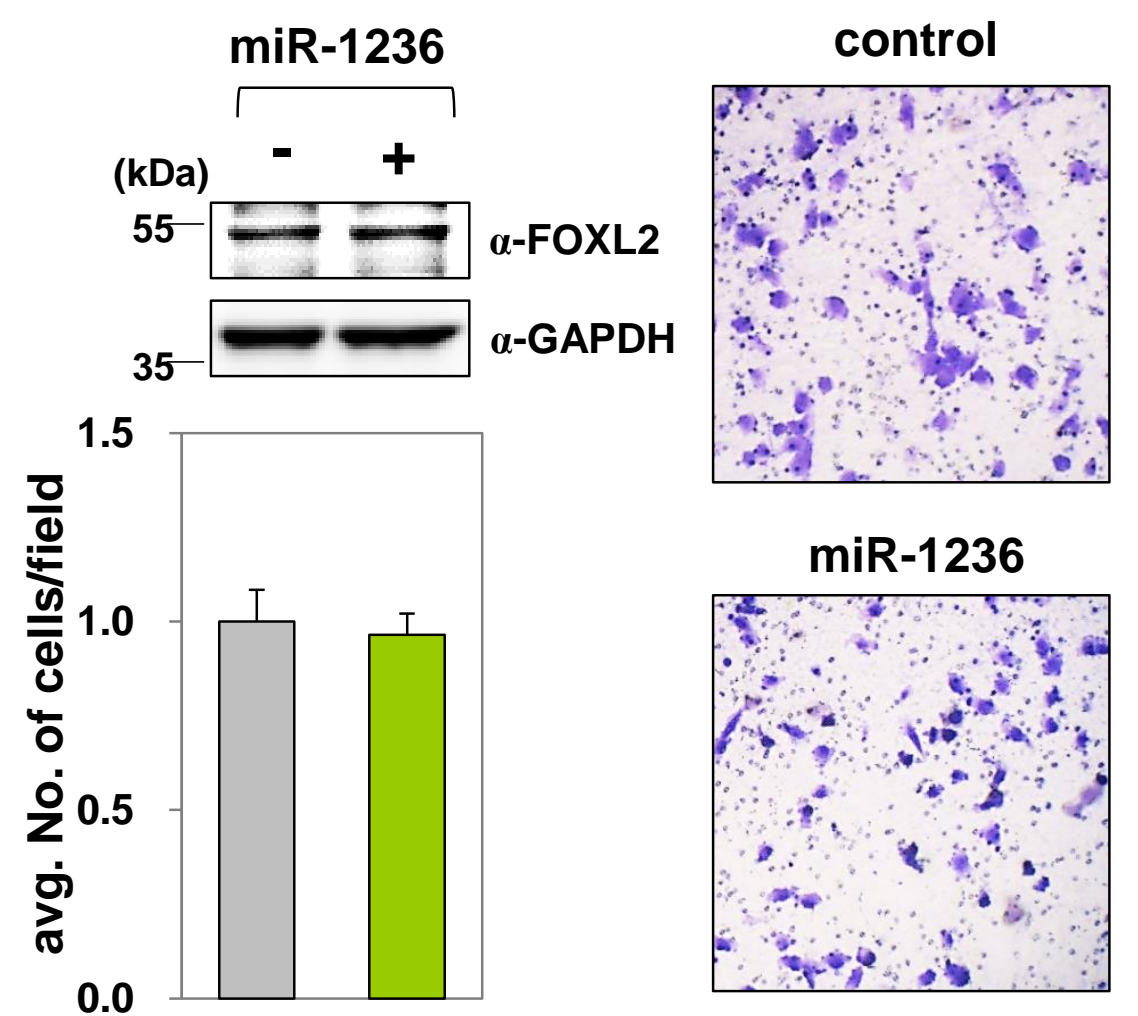

L

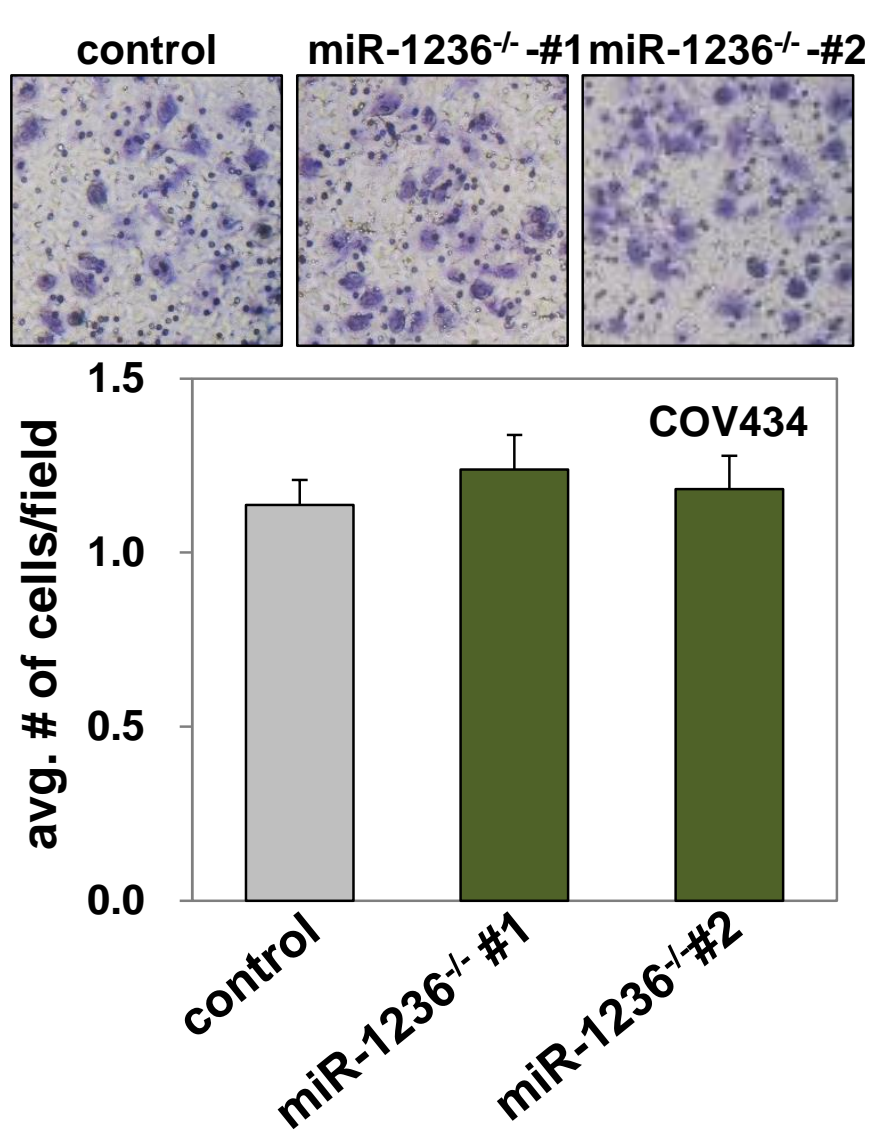


A
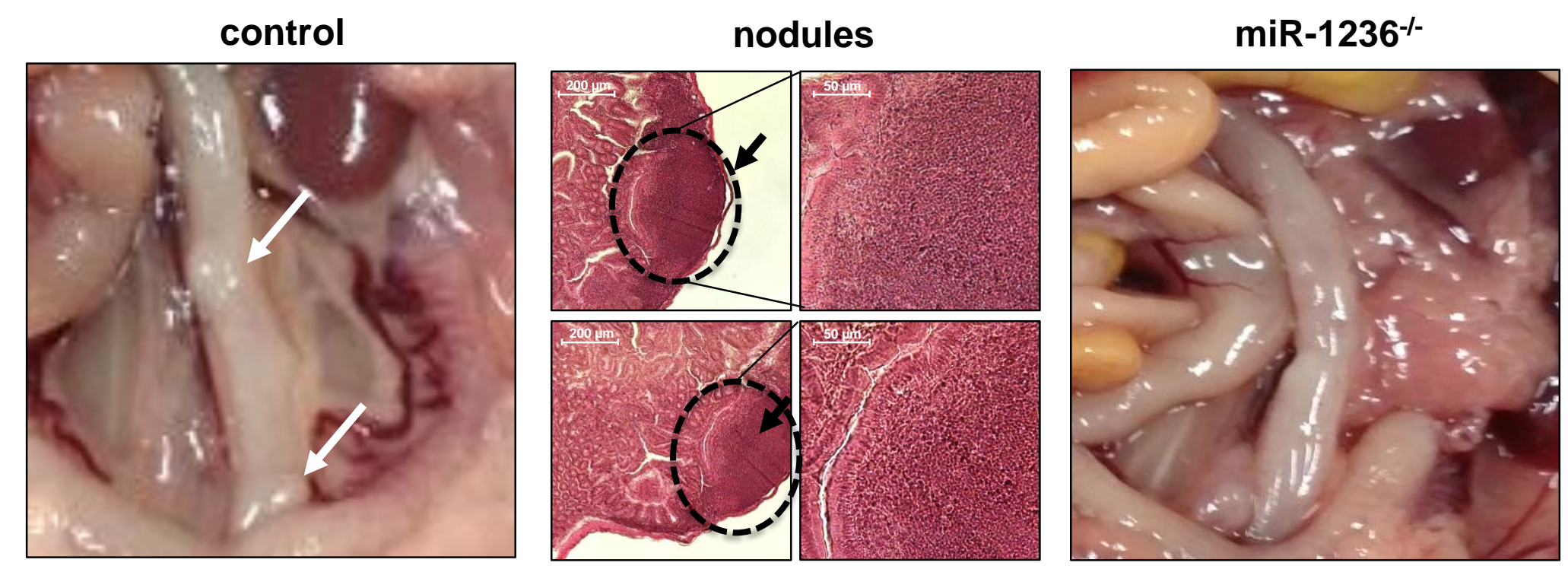

B

C
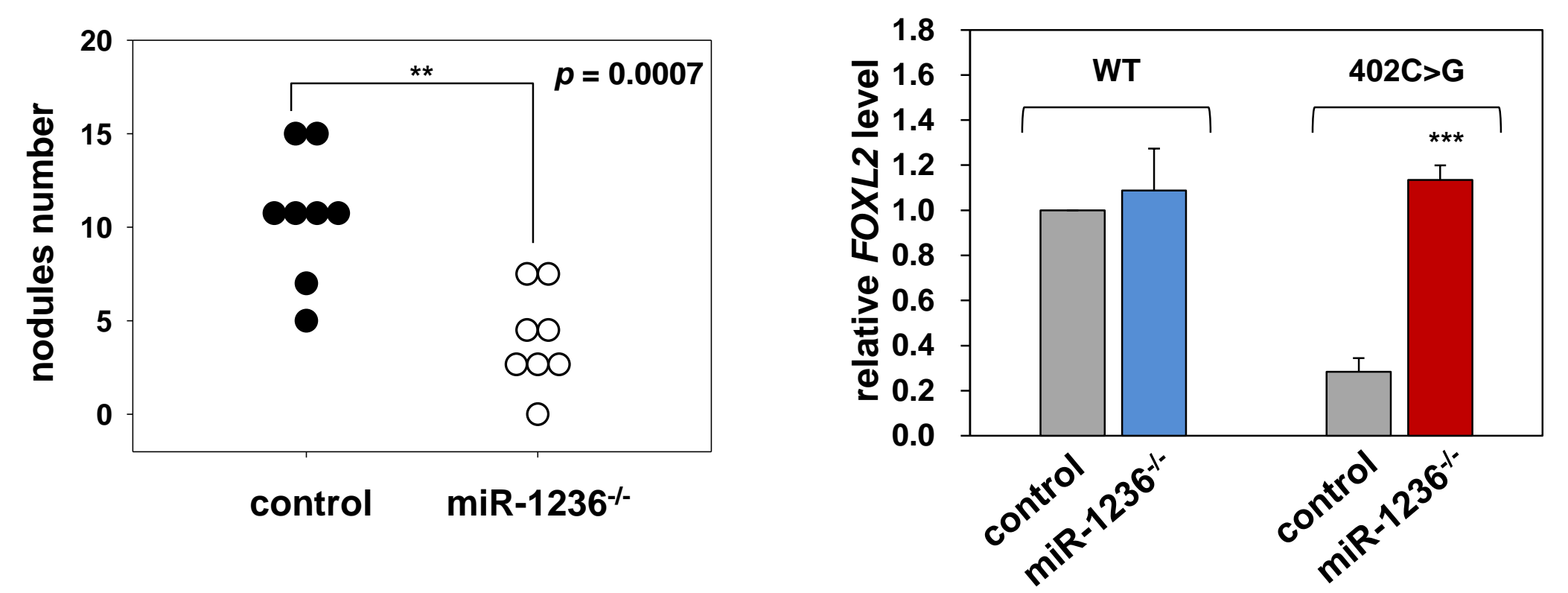

D

E

$\mathbf{F}$

bioRxiv preprint doi: https://doi.org/10.1101/2020.02.18.954487; this version pos

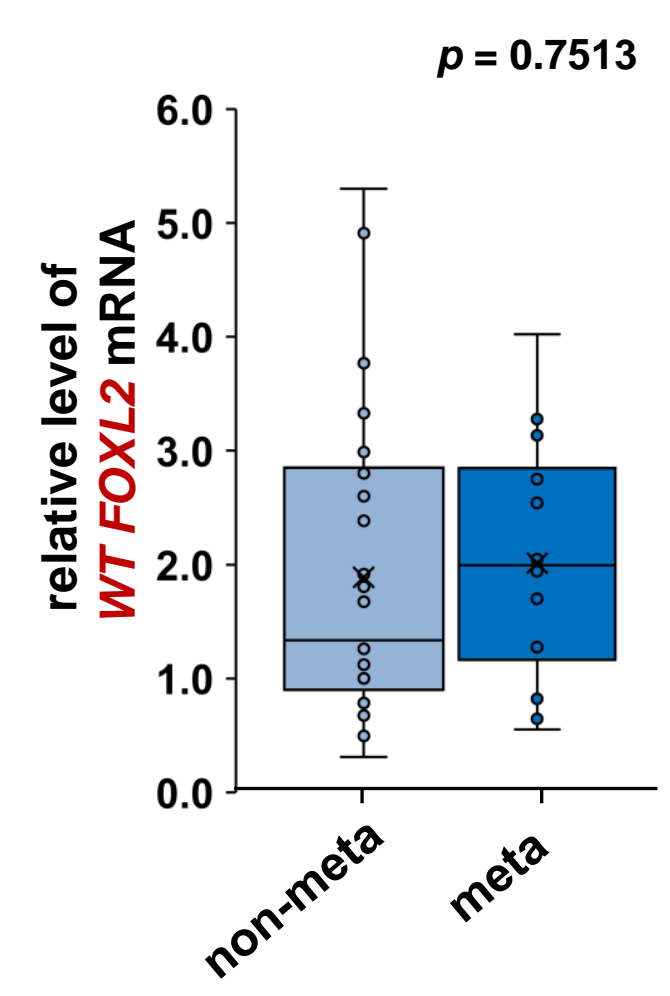

G

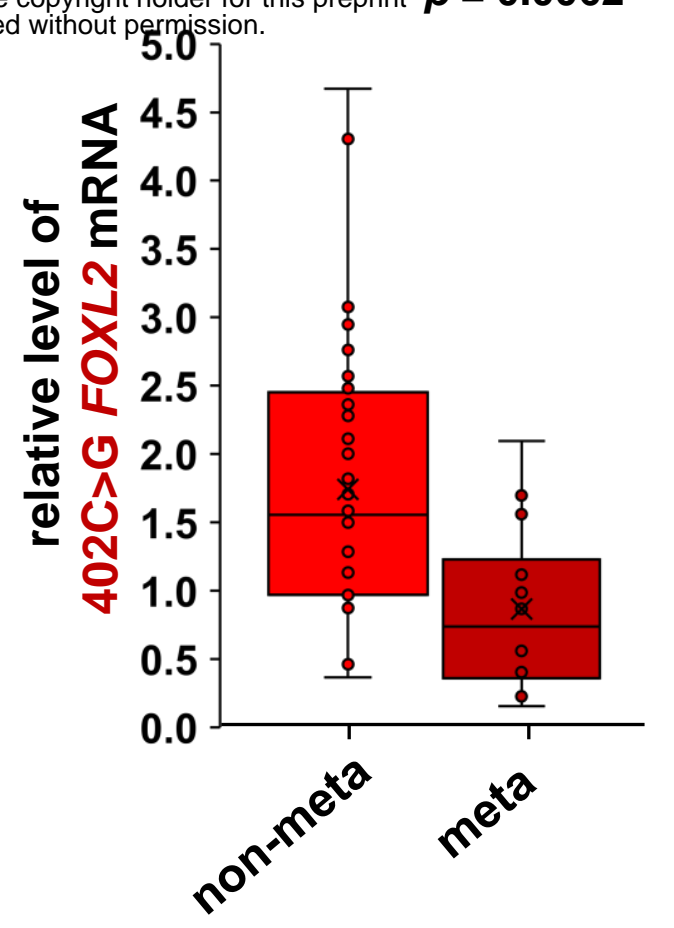

H

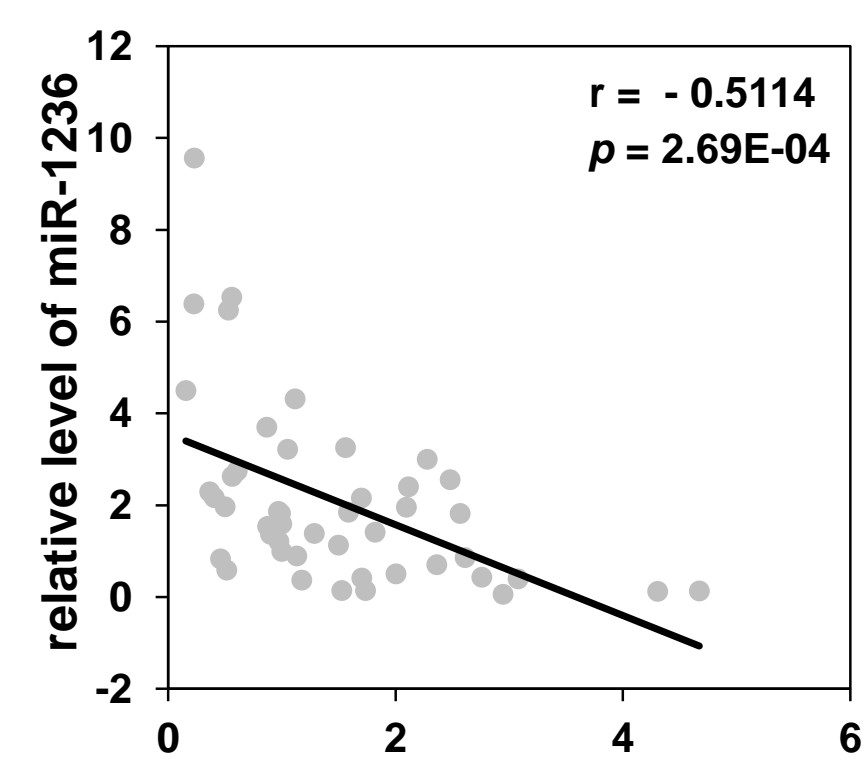

relative level of $402 \mathrm{C}>\mathrm{G}$ FOXL2 mRNA

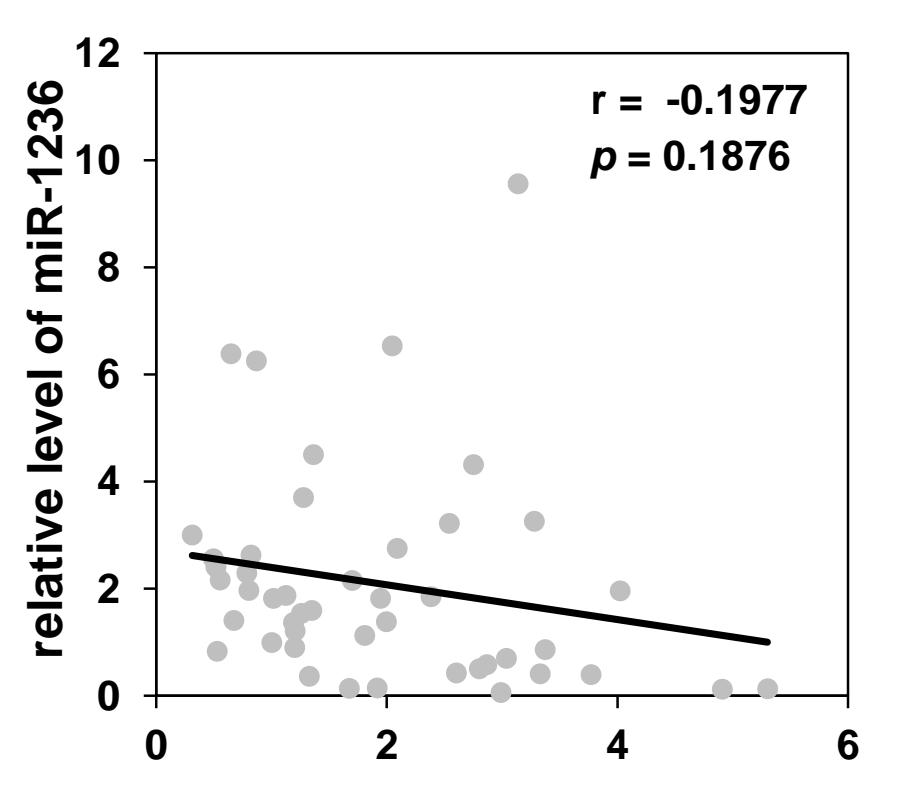

relative level of WT FOXL2 mRNA 


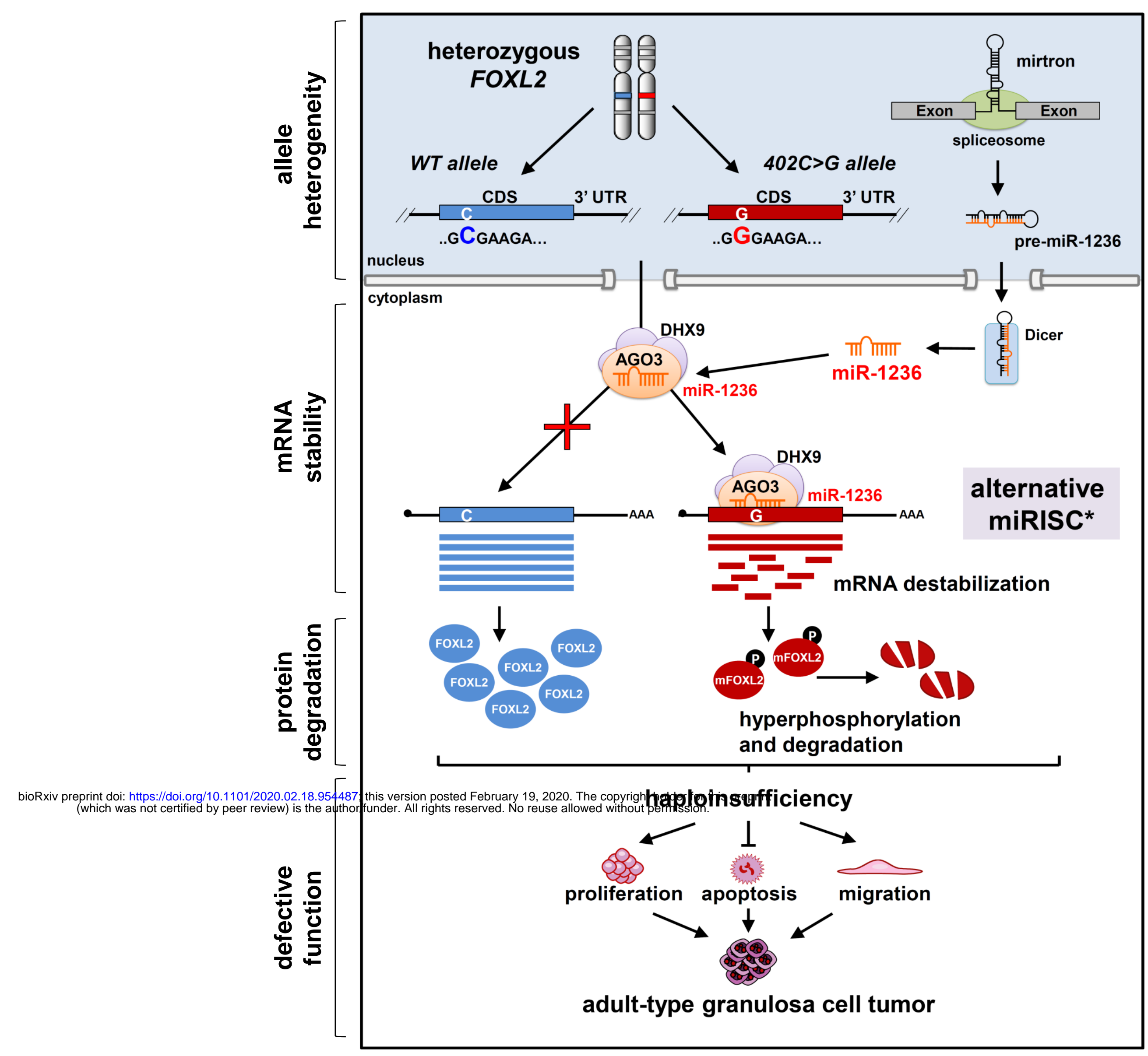

